University of Louisville

ThinkIR: The University of Louisville's Institutional Repository

Electronic Theses and Dissertations

$12-2011$

\title{
Algebra knowledge in early elementary school supporting later mathematics ability.
}

Scott A. Strother 1979-

University of Louisville

Follow this and additional works at: https://ir.library.louisville.edu/etd

\section{Recommended Citation}

Strother, Scott A. 1979-, "Algebra knowledge in early elementary school supporting later mathematics ability." (2011). Electronic Theses and Dissertations. Paper 1394.

https://doi.org/10.18297/etd/1394

This Doctoral Dissertation is brought to you for free and open access by ThinkIR: The University of Louisville's Institutional Repository. It has been accepted for inclusion in Electronic Theses and Dissertations by an authorized administrator of ThinkIR: The University of Louisville's Institutional Repository. This title appears here courtesy of the author, who has retained all other copyrights. For more information, please contact thinkir@louisville.edu. 


\title{
ALGEBRA KNOWLEDGE IN EARLY ELEMENTARY SCHOOL SUPPORTING
} LATER MATHEMATICS ABILITY

\author{
By \\ Scott A. Strother \\ B.A., Notre Dame University, 2002 \\ M.A., University of Louisville, 2004

\begin{abstract}
A Dissertation
Submitted to the Faculty of the

College of Arts and Sciences of the University of Louisville in Partial Fulfillment of the Requirements for the Degree of
\end{abstract} \\ Doctor of Philosophy \\ Department of Psychological and Brain Sciences \\ University of Louisville \\ Louisville, Kentucky
}

December 2011 


\section{ALGEBRA KNOWLEDGE IN EARLY ELEMENTARY SCHOOL SUPPORTING}

LATER MATHEMATICS ABILITY

By

Scott Strother

B.A., University of Notre Dame, 2002

M.A., University of Louisville, 2005

A Dissertation Approved on

November 14, 2011

by the following Dissertation Committee:

\begin{tabular}{c}
\hline John Pani, Dissertation Director \\
\hline Keith B. Lyle \\
\hline Patrick Shafto \\
\hline Barbara Burns \\
\hline
\end{tabular}

Elizabeth Todd Brown 


\section{ACKNOWLEDGEMENTS}

I would like to gratefully acknowledge the contributions of committee members Drs. John Pani, Elizabeth Todd Brown, Barbara Burns, Keith B. Lyle, and Patrick Shafto. I would like to thank Dr. Barbara Burns for advising me throughout graduate school and being supportive of all my decisions to this point. She truly helped launch me into my research career. I would like to thank Dr. Elizabeth Todd Brown for helping to create the idea for this project. She also spurred my interest in applying cognitive psychology to education. I would like to thank Dr. John Pani for chairing my dissertation and being supportive and encouraging throughout the entire process. I would also like to thank Keith Lyle and Patrick Shafto for agreeing to join my committee in the middle of the project and offering useful advice and encouragement.

This study was made possible with the support, trust, and partnership of the participating district. Thank you to the personnel who assisted me with project ideas, approval, and data collection.

Finally, I would like to thank my parents, Margot and Michael Strother, and my spouse, Amanda Warren, who have believed in me and encouraged me through every day of hard work on this dissertation. 


\begin{abstract}
ALGEBRA KNOWLEDGE IN EARLY ELEMENTARY SCHOOL SUPPORTING LATER MATHEMATICS ABILITY
\end{abstract}

Scott A. Strother

November 14, 2011

The current study explored the impact that algebra knowledge in $1^{\text {st }}$ and $2^{\text {nd }}$ grade can have in growth and achievement in mathematics through $5^{\text {th }}$ grade. Previous studies have shown the positive impact of teaching algebra in middle school (e.g. Smith, 1996). Other studies have shown that students can learn and apply fundamental algebra concepts even earlier, including early elementary grades (e.g. Schifter et al., 2008; Brizuela and Earnest, 2008). The current study aimed to expand upon this research by showing students' knowledge of early algebra concepts can predict positive longitudinal outcomes. This would support cognitive and education theories that students can use algebraic concepts to structure their overall mathematics knowledge.

The current study utilized an archival dataset with five years of student data from one district. District assessments measured student knowledge of algebra in $1^{\text {st }}$ and $2^{\text {nd }}$ grade. Students' standardized mathematics test scores and district assessments for mathematics were collected for $3^{\text {rd }}, 4^{\text {th }}$, and $5^{\text {th }}$ grade. Algebra knowledge in $1^{\text {st }}$ and $2^{\text {nd }}$ grade predicted students' mathematics ability on the state standardized assessment in $5^{\text {th }}$ grade. It also predicted growth in scores from $3^{\text {rd }}$ through $5^{\text {th }}$ grade. Algebra was a 
significant predictor in a model that included students' abilities in other areas of mathematics, reading ability, and race. The model also included school level socioeconomic data. Parallel models were done using the district assessments in $3^{\text {rd }}$ through $5^{\text {th }}$ grade as the outcome measure. Algebra knowledge in $1^{\text {st }}$ and $2^{\text {nd }}$ grade was a significant predictor of $5^{\text {th }}$ grade mathematics knowledge on these assessments. Algebra knowledge did not predict growth from $3^{\text {rd }}$ through $5^{\text {th }}$ grade. Overall, this study underlines the importance of including algebra in early elementary teaching, standards, and assessment. Early algebra may help students structure their mathematics knowledge from the beginning of their education. This can lead to improved longitudinal mathematics knowledge and performance. 


\section{TABLE OF CONTENTS}

PAGE

ACKNOWLEDGEMENTS ........................................................................................... ii

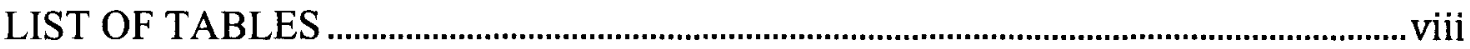

INTRODUCTION

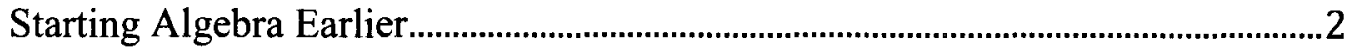

Algebra Can Help Structure Students' Mathematics Knowledge .............................5

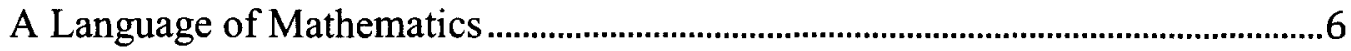

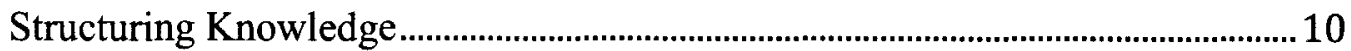

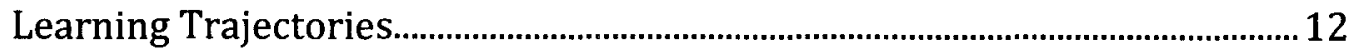

Algebra and Number Properties and Operations....................................................... 15

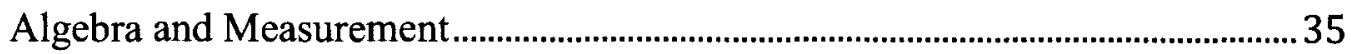

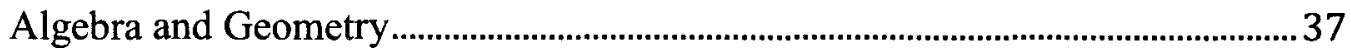

Algebra and Data Analysis and Probability ............................................................ 41

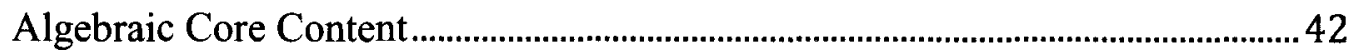

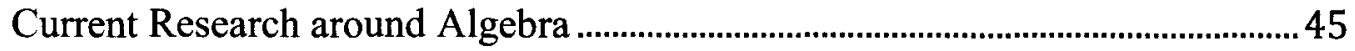

Algebra Research in Elementary Grades................................................................51

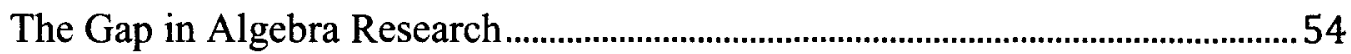

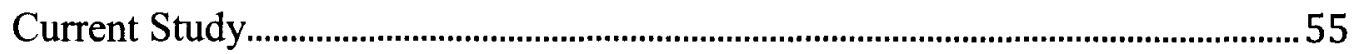




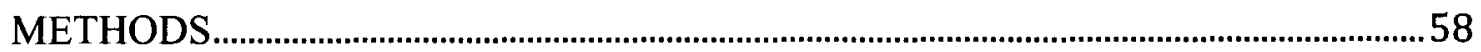

Participants ..............................................................................................................

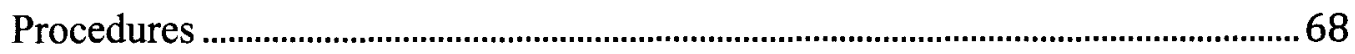

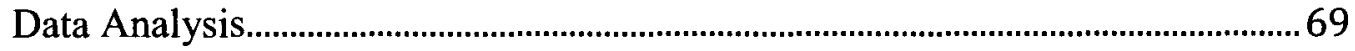

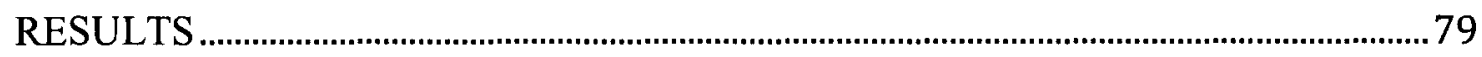

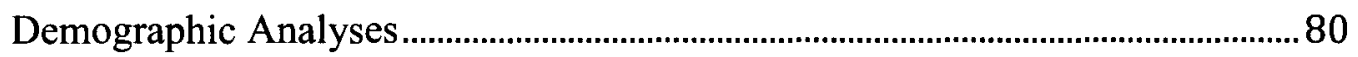

HLM Model 1 .............................................................................................................

HLM Model 2 2............................................................................................................

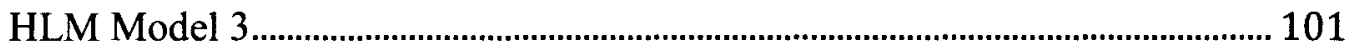

DISCUSSION

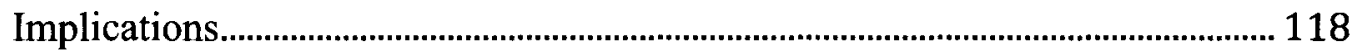

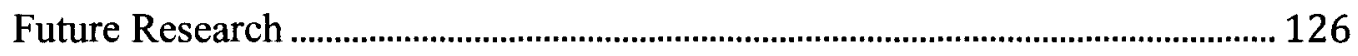

Conclusions ........................................................................................................ 129

REFERENCES

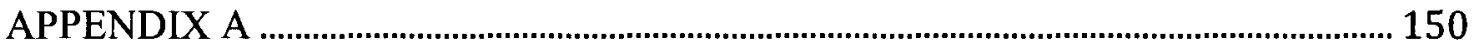

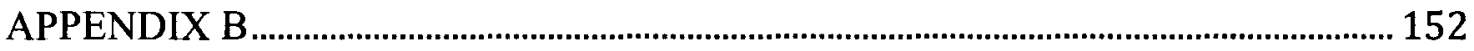

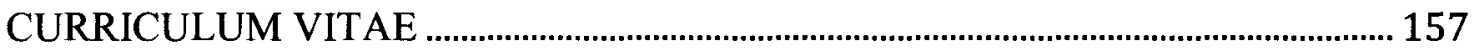




\section{LIST OF TABLES}

TABLE

PAGE

1. Core Content Areas of Mathematics in Elementary School.......................... 14

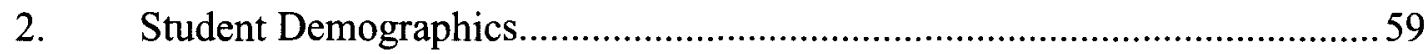

3. Percentage of Students Receiving Free and Reduced Lunch.........................59

4. Percentage of KCCT Items for Each Content Area..........................................61

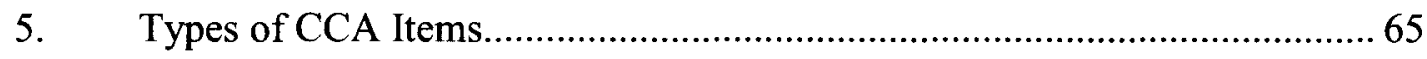

6. Percentage of CCA Mathematics Items Targeting Each

Content Area

7. Percentage of CCA Algebraic Thinking Items Targeting

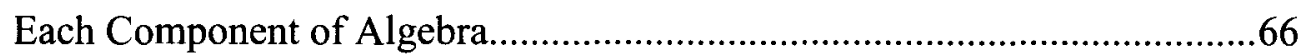

8. Students' Mean Performance across $1^{\text {st }}$ and $2^{\text {nd }}$ Grade.................................79

9. Students' Mean Performance in $3^{\text {rd }}, 4^{\text {th }}$, and $5^{\text {th }}$ Grade................................80

10. Intraclass Correlation for HLM Model 1 ..................................................... 84

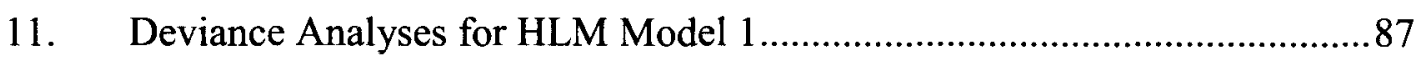

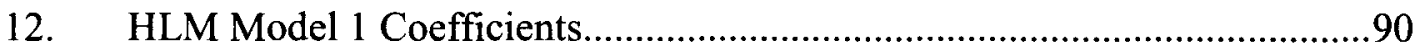

13. HLM Model 1 Coefficients with General Mathematics

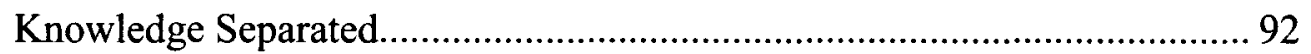

14. Intraclass Correlation for HLM Model 2 ...................................................94

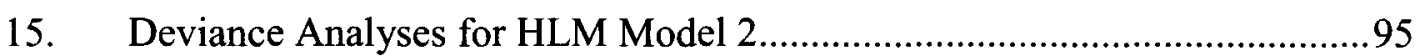




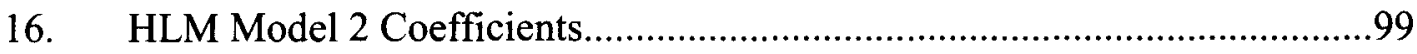

17. HLM Model 2 Coefficients with General Mathematics

Knowledge Separated............................................................................. 100

18. Intraclass Correlation for HLM Model 3 …………................................... 102

19. Deviance Analyses for HLM Model 3........................................................ 103

20. HLM Model 3 Coefficients......................................................................107

21. HLM Model 3 Coefficients with General Mathematics

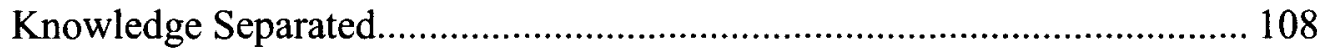

22. Percentage of CCA Number Properties and Operations

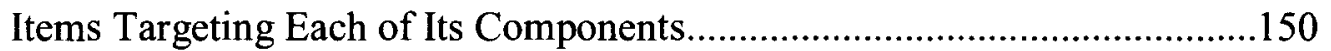

23. Percentage of CCA Data Analysis and Probability Items

Targeting Each of Its Components............................................................ 150

24. Percentage of CCA Measurement Items Targeting Each

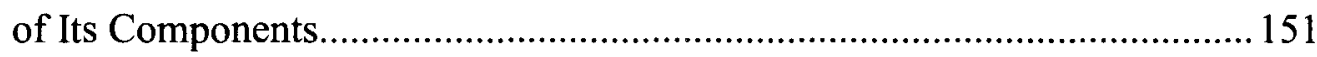

25. Percentage of CCA Geometry Items Targeting Each of

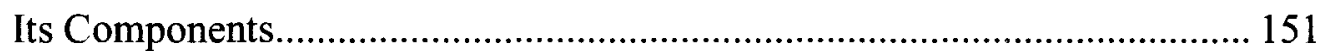

26. Student Mathematics Comparison by Gender............................................ 152

27. Student Mathematics Comparison by Race................................................... 153

28. Testing for the Achievement Gap in Student Mathematics:

Caucasian and Asian-American students (CA) compared to

African-American and Hispanic students $(\mathrm{AH})$. .155

29. Correlations of Students' Mathematics Scores to Their

Reading Scores and Schools' Percentage of Students 
Receiving Free and Reduced Lunch (FRL) ........................................ 156 


\section{INTRODUCTION}

Recently, there has been a strong push from educators and researchers to incorporate algebra into early mathematics education (e.g. NCTM, 2000; 1998; Fosnot \& Jacob, 2010; Kaput \& Blanton, 2000). Researchers feel that the fundamentals of algebra underlie and connect many basic principles in early mathematics. They have argued that algebra can support how students structure their mathematics knowledge in elementary education. This push has encouraged educators and policy makers to include algebra in

the emerging Common Core State Standards for mathematics in kindergarten through $5^{\text {th }}$ grade (CCSSI, 2010).

Students form cognitive structures of basic mathematics concepts as they learn. Students may perform better in mathematics if they form strong connections between and across fundamental concepts. Early algebra concepts may help students to structure their knowledge around each mathematics content area taught in elementary school. Having an integrated knowledge structure early in elementary school may help students learn mathematics longitudinally.

The current project will examine if knowing algebra concepts in early grades can lead to better longitudinal mathematics knowledge. The project will aim to answer the following research questions: 
1) Does students' performance on assessment items targeting algebraic thinking in $1^{\text {st }}$ and $2^{\text {nd }}$ grade predict:

a) Performance on a mathematics state standardized assessment in $5^{\text {th }}$ grade?

b) Growth in performance on a mathematics state standardized assessment in $3^{\text {rd }}$ through $5^{\text {th }}$ grade?

c) Performance on assessment items targeting algebraic thinking in $5^{\text {th }}$ grade?

d) Growth in performance on assessment items targeting algebraic thinking in $3^{\text {rd }}$ through $5^{\text {th }}$ grade?

e) Performance on assessment items targeting other areas of mathematics in $5^{\text {th }}$ grade?

f) Growth in performance on assessment items targeting other areas of mathematics in $3^{\text {rd }}$ through $5^{\text {th }}$ grade?

\section{Starting Algebra Earlier}

Incorporating algebra into early mathematics teaching in the United States may help bridge the gap between the US and top performing nations around the world. Students in the United States are above average internationally in mathematics, but lag behind many other countries. The 2003 Trends in International Mathematics and Science Study (TIMSS) reported that $4^{\text {th }}$ grade students in the United States were significantly behind eleven of the twenty-four participating countries in mathematics (Gonzalez et al., 2004). Eighth grade students were significantly behind fifteen of the forty-four participating countries.

The countries that are ahead of the United States have standards aimed at thinking and structuring knowledge. Their standards encourage using fundamental skills and 
knowledge when solving problems. This helps students make cognitive connections between fundamental and higher level concepts. For example, Singapore's Mathematics Syllabus for early grades lays out a progression from addition, subtraction, multiplication, and division, from whole numbers to fractions, which builds slowly up from the most basic concepts of the earliest grade. The Syllabus focuses largely on student thinking around open problems to ensure students understand the underlying concepts (Ginsburg, Leinwand, Anstrom, \& Pollock, 2005). In the TIMSS study, Singapore was the strongest performing country in both $4^{\text {th }}$ and $8^{\text {th }}$ grades. In fact, the top four countries in $4^{\text {th }}$ grade and the top five countries in $8^{\text {th }}$ grade were from western Asia and have similar mathematics education systems.

Educators in the United States have recently reanalyzed how standards can support students' knowledge growth. The Common Core State Standards were created to focus on core concepts and how students are thinking about and applying those concepts. In this way, the Standards align closely with the Mathematics Syllabus of Singapore (Achieve, 2010; EDinformatics, 2010). The main difference Achieve (2010) noted was the Common Core State Standards include even more details in outlining students' learning trajectory across grades.

The Common Core State Standards also aim to address issues seen in students' performance on the National Assessment of Educational Progress (NAEP). Recent NAEP reports have shown that students in the United States have a strong knowledge base in mathematics in $4^{\text {th }}$ grade, but their scores decline by $8^{\text {th }}$ grade and even more by $12^{\text {th }}$ grade. In fact, the 2008 National Report Card reported that only $32 \%$ of $8^{\text {th }}$ grade students are at or above the "proficient" level on NAEP mathematics and $23 \%$ of $12^{\text {th }}$ grade 
students reach that mark.

The National Mathematics Advisory Panel (2008a; 2008b) concluded that students' decline on the NAEP is in large part due to students' lack of conceptual knowledge and overall preparedness for algebra. The decline in scores in late middle and high school corresponds to the grades where algebra is introduced and taught in most areas in the United States. The National Mathematics Advisory Panel performed a survey of 743 randomly selected Algebra I teachers who on average reported students' background preparation in algebra as "weak". In the Panel's (2008a; 2008b) survey, teachers most often reported the reason for students' weak preparation was a lack of knowledge of the fundamental algebra concepts. The teachers reported a greater need to focus on basic algebra concepts and skills at the elementary level.

The National Mathematics Advisory Panel (2008) recommended that algebraic concepts be identified, assessed, and strengthened in elementary grades. The Panel felt that standards should include algebraic concepts and should encourage students to solve problems by reasoning with these concepts. This will allow students to build algebra based cognitive structures that will help with conceptual understanding as well as computational fluency.

These recommendations were heeded in forming the new Common Core State Standards. The Common Core State Standards discuss 'operations and algebraic thinking' in each of the elementary grades $(\mathrm{K}-5)$. The Standards underline the importance of structuring students' knowledge using algebraic principles and language. The Standards outline how algebra can be used to represent operational concepts, situations, problems, explanations, expressions, and equations (CCSSI, 2010). 
The Standards outline how students can use the basic algebraic concepts presented in early grades to connect and structure their knowledge in later grades. This emphasizes a focus on building up from the fundamentals of mathematics, as seen in Singapore's Mathematics Syllabus. This also addresses the need for teaching algebra earlier. Lastly, this approach supports researchers and educators who have stated that fundamental algebra concepts can help students build their cognitive structures for all of mathematics (e.g. Kaput, 1995; Kaput, Carraher, \& Blanton, 2008).

\section{Algebra Can Help Structure Students' Mathematics Knowledge}

Researchers have proposed that using algebra to help students structure their knowledge will foster better understanding of later mathematics (Fosnot \& Jacob, 2010; Kaput \& Blanton, 2000). How exactly does algebra underlie the concepts and operations of other mathematics areas? Can greater attention to this process actually have a longitudinal impact on students?

There are two landmark works that have helped explain exactly what algebra is in the early grades and how it supports general mathematics learning. Kaput et al. (2008) and Fosnot and Jacob (2010) present a coherent argument by defining the fundamental principles of algebra and explaining how they apply to each grade and mathematics content area. The works by these authors show that algebraic principles can be used to make sense of mathematics and provide the language, concepts, and strategies that students need to structure their learning.

This section will present a summary of their arguments and show that they complement each other in explaining how algebra can be a mechanism to learning mathematics. Both explanations begin as early as $1^{\text {st }}$ grade and build through $5^{\text {th }}$ grade. 
First, Kaput and Blanton's (2000) ideas of algebra will be explained followed by a summary of Fosnot and Jacob's ideas (2010). This section will also expand upon these arguments by discussing the supporting research.

\section{A Language of Mathematics}

Kaput $(2000 ; 1999)$ believed that algebra is a language of mathematics that has fundamental concepts through which all areas of mathematics can be perceived. Algebra can be thought of as a language system because it uses fundamental concepts and quantitative notation to emphasize relations among quantity and space (Kaput, 1999; 1995). This language allows students to form a foundation of skills that help structure mathematical knowledge. The algebraic skills Kaput et al. (2008) posit to underlie mathematics include:

- $\quad$ Creating and understanding generalizations;

- Representation and symbolization of quantities and generalizations.

Creating and understanding generalizations. Algebra deals with creating generalizations about mathematics and expressing these generalizations with symbolic notation. This is done by first understanding relationships within or between quantities. One can then use symbolic notation to represent these relationships. Reasoning with these relationships can help one form generalizations that can apply to any quantities.

These generalizations may be taught, but can also be learned via experience and reasoning with patterns and mathematical representations. For example, abstracting fundamental number properties such as the commutative property $(a+b=b+a)$ through arithmetic reasoning is considered algebraic. Schifter, Monk, Russell, and Bastable (2008) discussed an example of this in a $3^{\text {rd }}$ grade classroom. They discussed how 
students learned that a certain number of blocks can be parceled into several different groups without changing the total number of blocks (e.g. 8 blocks can become groups of 3 and 5 or 5 and 3 ). The students were able to generate the generalization that reversing two piles and adding them together will still result in the same total. From there, the teacher helped with the symbolic notation and students translated their knowledge into the commutative property.

Representation and symbolization of quantities and generalizations. Algebra includes being able to represent (through mathematical notation or symbolization) a single quantity or a relationship between two quantities. The ability to symbolize and to represent mathematics in several ways may help students learn from early elementary grades through middle school and beyond (Brizuela \& Earnest, 2008; Brenner et al., 1997; Yerushalmy, 1997; diSessa, 2004). For example, Brenner et al. (1997) showed that students who practiced representing problems in multiple ways performed better than a control group on function word problems and representation tasks, such as translating word problems into tables and graphs. Participants in this study were $1287^{\text {th }}$ and $8^{\text {th }}$ grade students from six classes in three junior high schools. Gender and socioeconomic status of the students was not reported. Seventy-two of the students participated in a unit based on representations of functions. Fifty-six students, the control group, received the standard text book lesson on functions. Three teachers participated in the study, each teaching one experimental class and one control class. Students took parallel versions of the function word problem test (FWPT) before and after the unit. This test was designed to measure students' ability to represent and solve a function-based word problem. Students also took a word problem representation test designed to test students' ability to 
translate a function-based word problem into a table, chart, or graph. In analyzing the FWPT, the experimental group scored higher than the control group on problem representation, $\mathrm{F}(1,121)=23.53, M S E=.08, p<.001$. There was also a group by teacher interaction, $\mathrm{F}(2,121)=4.54, M S E=.08, p<.05$. Two of the teachers had higher performing students in their experimental class: one teacher had an average proportion correct of .08 for control students and .53 for treatment students, $t(121)=5.61$, and another had .15 and $.39, \mathrm{t}(121)=2.25$. The experimental group also did better on problem solving with functions, with proportion correct of .42 versus .14 of the control group, $\mathrm{F}(1,121)=4.19, M S E=.57, p<.05$. These two findings were not isolated. Analysis also showed that students who could and did use a representation while solving were more likely to get a correct answer, $\mathrm{X}^{2}(1)=11.0, p<.001$. Experimental students also performed better on the word problem representation test, with proportion correct .60 compared to .39 from the control group, $\mathrm{F}(1,121)=18.35, M S E=.04, p<.001$.

Brizuela and Earnest (2008) followed up this study with a three-year longitudinal investigation that explored how students work with early algebraic fundamentals in $2^{\text {nd }}$ through $4^{\text {th }}$ grade. They observed seventy students in four classrooms in the Boston area. The students were mostly minority (75\% Latino) and qualified for free and reduced lunch status $(83 \%)$. In each semester of $2^{\text {nd }}, 3^{\text {rd }}$, and $4^{\text {th }}$ grade, these students performed six to eight algebra activities that each lasted ninety minutes. The activities focused on how students could represent problems externally using variables, functions, equations, tables, and graphs. Their goal was to show that students' understanding of relationships in mathematics problems could grow if the students are able to representing the problem in multiple ways. 
In this study, students attempted to represent a problem verbally, algebraically, tabular, and graphically (Williams, 1993; Brenner et al., 1997). The authors interviewed 8 groups of 3 students about a problem where the students had to decide which deal was better: doubling your money or tripling your money and giving back seven dollars (essentially ' $2 x$ ' versus ' $3 x-7$ '). Students had to state which deal was better with varying amounts of money and why. The interviewers asked students to represent the problem in each of the four methods and discuss their thought process. The authors found that students could successfully represent the problem in each of the four methods. They found that each method revealed new insights to students that were helpful for their overall understanding. For example, most groups were able to formulate tentative conclusions when discussing the problem, put their ideas into algebraic notation, and solidify them using a table. Each group of students successfully made a table with input amount, output amount, and which deal was better for varying dollar amounts. In other words, the students applied algebraic concepts as they discussed as they solved the problem. The students also learned they could solve a problem several ways (verbally, algebraically, tabular, and graphically) and that each strategy could be complimentary in understanding the solution.

Using algebraic reasoning, symbolization may help students as young as $1^{\text {st }}$ grade (Cobb, Gravemeijer, Yackel, McClain, \& Whitenack, 1997; Gravemeijer, Cobb, Bowers, \& Whitenack, 2000; Sfard, 2000). Students may begin to take mathematical situations such as word problems and frame them in terms of algebraic symbolization. The symbolization can make reasoning about the problem easier (Kaput, Blanton, \& Moreno, 2008). For example, Cobb et al. (1997) worked with one $1^{\text {st }}$ grade classroom that 
consisted of 11 female and 7 male students from middle to upper socioeconomic families. The teacher in this classroom consistently attempted to extract students' reasoning when thinking about mathematics. She would then symbolically represent their reasoning on a whiteboard. Students were asked to agree or disagree if the teacher had accurately depicted their thought process. At the beginning, middle, and end of the year, the authors tested the students via interviews on how well the students could represent their additive strategies. Students showed strong progress for both representing quantities and generating strategies for addition problems across the year. Following the pre-test at the beginning of the year, the authors felt students showed mathematical growth that was "atypical when compared with that of $1^{\text {st }}$ grade students who have experienced traditional instruction" (p. 176). For example, most students were able to generate and compute basic number sentences from word problems representing different types of additive strategies. However, this study did not have a comparison group or a standardized assessment. It also did not report statistical effects or the influence of demographic variables.

\section{Structuring Knowledge}

A large part of algebra is the ability to take quantities or problem situations and represent them meaningfully. In this respect, algebraic reasoning also underlies the computational processes of many mathematics areas. Students can use algebraic reasoning to create oral, written, drawn, or even modeled representations of problems using symbols or descriptions that extracts the relationships of the problem components. For example, in an arithmetic word problem stating 'Johnny has 5 apples and Megan has 7, how many more apples does Megan have?', students need to do more than just 
compute $7-5=2$. A student must first infer that Megan has more apples and that the difference is an unknown. The quantities could be represented visually using drawings or manipulatives. A student could then find a strategy after breaking down the problem components. For example, a counting strategy could be used to move from 5 up to 7 or a subtracting strategy could be used, taking away 5 units from 7 until 2 are left.

Students' ability to represent and reason about problem components may help them understand problems in all areas of mathematics. Fosnot and Jacob (2010) discuss how this algebraic process can help students structure their general mathematics knowledge. Students can approach any given problem with their basic algebraic skill set to identify the quantities and relationships in the problem. This will allow them to reason using the concepts in the problem and eventually incorporate the concepts into their cognitive framework. Eventually their algebraic born knowledge structures will grow in two dimensions: (1) horizontally, which entails parallel but more complex problems using similar operations, and (2) vertically, which entails creating structure that involve higher order concepts and problems such as the move from addition to multiplication.

Fosnot and Jacob (2010) outline how algebra can guide students' first attempts at building knowledge structures around mathematics (see Learning Trajectories). The authors describe the driving principles of algebra that help students apply knowledge towards reasoning, problem solving, and building more complex, integrated structures throughout mathematics education. They believe students can learn and perform better in mathematics if they have more densely integrated and connected knowledge structures. 
The authors believe that many algebraic concepts can drive students to create and improve their mathematics structures, including:

- Early structuring of the number system

- $\quad$ Comparing quantities and relations

- Equivalence

- Variance and variables

Early structuring of the number system begins with counting and seeing a progression of greater quantities by the factor of +1 or -1 . Students can then begin comparing quantities and relations, such as more than or less than. Eventually this will translate into addition and subtraction problems. The focus will not be on the problems themselves, but how to use problem context and models to think about the problems. This will allow students to apply their knowledge structure to the problem to discuss and eventually solve it. Then, by doing more difficult problems horizontally and vertically, their knowledge structures will grow accordingly. As their knowledge structures grow, algebraic big ideas such as equivalence and representing quantities and varying amounts with variables will emerge. The following section will discuss how this can unfold in a step by step learning progression from $1^{\text {st }}$ through $5^{\text {th }}$ grade and will also include the supporting research showing that students can understand and use fundamental algebraic concepts to scaffold this process.

\section{Learning Trajectories}

Algebra has not traditionally been emphasized in $1^{\text {st }}$ through $5^{\text {th }}$ grade. Research around the impact of learning algebra in these grades is also sparse. This section discusses how algebra can help students in these grades. This section lays out a 
theoretical framework explaining how algebra can help students progress as they structure their mathematics knowledge (also see Current Research around Algebra).

With the emerging Core Common State Standards, more research will be devoted in the upcoming years to how algebra is supporting mathematics learning in early grades. Some states and school districts have been ahead of the curve, including algebra in their standards. The district in the current study is one example. This district follows the state mathematics standards shown in Table 1 (Kentucky Department of Education, 2008a; 2009).

Districts that have algebra in their standards are ideal for research on algebra's impact. Research can examine if the algebra in the early grades provides the structural foundation to help students learn each other content area, such as those in Table 1. Table 1 is by no means comprehensive of every mathematics area and concept (that would be too comprehensive for this paper), but attempts to demonstrate the array of content areas that algebra may help support.

Algebra may scaffold students' knowledge structures of these content areas starting in $1^{\text {st }}$ grade. The remainder of this section will discuss how algebra can support student's learning in each area of mathematics shown in Table 1. The discussion is based on how students structure their knowledge using basic algebra components (Fosnot and Jacob, 2010), such as representing quantities and creating generalizations (Kaput and Blanton, 2000). 
Table 1

Core Content Areas of Mathematics in Elementary School

\begin{tabular}{|c|c|c|}
\hline Topic & Primary Grades (1-3) & Late Elementary Grades (4-5) \\
\hline $\begin{array}{l}\text { Number } \\
\text { Properties } \\
\text { and } \\
\text { Operations }\end{array}$ & $\begin{array}{l}\text { Represent quantities in multiple } \\
\text { ways. } \\
\text { Represent word problems } \\
\text { mathematically. } \\
\text { Comparisons }(<,>,=) \\
\text { Addition, subtraction. } \\
\text { Multiplication, division } \\
\text { (numbers less than } 10) .\end{array}$ & $\begin{array}{l}\text { Multiple representations of place value, } \\
\text { whole numbers, fractions, mixed fractions, } \\
\text { decimals. } \\
\text { Comparisons }(<,>,=\text { ) of the type of numbers } \\
\text { above. } \\
\text { Apply representations by performing } \\
\text { operations to solve problems relate to the } \\
\text { type numbers above. } \\
\text { Addition, subtraction, multiplication, division } \\
\text { (numbers }>10 \text { and basic mixed numbers). }\end{array}$ \\
\hline Measurement & $\begin{array}{l}\text { Identify measureable attributes } \\
\text { Taking basic measurements } \\
\text { (e.g. length, temperature). } \\
\text { Applying correct units. } \\
\text { Unit relationships and } \\
\text { conversion. }\end{array}$ & $\begin{array}{l}\text { Measuring fractions of units. } \\
\text { Continuing basic measurements (e.g. weight, } \\
\text { angles). } \\
\text { Continue unit relationships and conversion. }\end{array}$ \\
\hline Geometry & $\begin{array}{l}\text { Describe basic geometric shapes } \\
\text { and their elements. } \\
\text { Describe examples of symmetry } \\
\text { and similarity. }\end{array}$ & $\begin{array}{l}\text { Describe all basic terms (e.g. segment, } \\
\text { parallel), shapes, and types of angles. } \\
\text { Describe and provide examples of basic 3-D } \\
\text { shapes. } \\
\text { Identify and describe similar and congruent } \\
\text { figures. } \\
\text { Identify and graph ordered pairs on a positive } \\
\text { coordinate system. And apply graphing to } \\
\text { solve real world problems. } \\
\text { Identify and perform rotation, reflection, and } \\
\text { translation. }\end{array}$ \\
\hline $\begin{array}{l}\text { Data Analysis } \\
\text { and } \\
\text { Probability }\end{array}$ & $\begin{array}{l}\text { Collect, display, and make } \\
\text { inferences from data. } \\
\text { Basic probability knowledge. }\end{array}$ & $\begin{array}{l}\text { Construct data using drawings, tables, and } \\
\text { graphs. } \\
\text { Analyze and make inferences from drawings, } \\
\text { tables, and graphs. } \\
\text { Determine mean, median, mode, and range. } \\
\text { Determine likelihood of events with limited } \\
\text { outcomes }(<12) \text {. }\end{array}$ \\
\hline $\begin{array}{l}\text { Algebraic } \\
\text { Thinking }\end{array}$ & $\begin{array}{l}\text { Make and extend patterns. } \\
\text { Model math problems with } \\
\text { number sentences, unknown, } \\
\text { and symbols. } \\
\text { Describe functions. }\end{array}$ & $\begin{array}{l}\text { Extend patterns, find missing terms in a } \\
\text { pattern, and apply to real world problems. } \\
\text { Model real world situations with number } \\
\text { sentences, including blanks and variables, } \\
\text { and solve them. } \\
\text { Describe functions through pictures, tables, } \\
\text { or words to analyze real world problems. } \\
\text { Determine output of functions. }\end{array}$ \\
\hline
\end{tabular}




\section{Algebra and Number Properties and Operations}

Number properties and operations involve three areas of mathematics: number sense; number operations; and properties of numbers and operation. Fosnot and Jacob (2010) show how these areas are inter-related through the algebra that underlies each of them. The authors believe that students can begin to structure their knowledge of mathematics from the very beginning of learning number sense. This structure will grow vertically and horizontally, in size and complexity, and will eventually incorporate formal operations and properties of numbers. Fosnot \& Jacob (2010) feel that all four of their major algebraic concepts can help students learn number properties and operations. Early structuring of the number system. Number sense includes the ability to count and to understand numerical notation, order, and quantity. It precedes formal operations in mathematics and is algebraic in several ways. Understanding numbers and counting can entail knowledge of spatial relationships, patterns, and combinations that coincide with early concepts of algebra (Van de Walle, 1990). Simple counting can be thought of

in algebraic terms since numbers themselves grow proportionally as the real or abstract quantity of something increases. Focusing on number sense may help children get an accurate spatial and algebraic understanding of numbers even before they learn to manipulate them.

Fosnot and Jacob (2010) describe how children can use the counting strategies to structure their early knowledge of mathematics. Children structure each subsequent number as $a+1$ relationship. The infinite number set then has an $(\mathrm{N},<)$ ordered relationship. The one-to-one covarying relationship can be thought of as the first algebraic principle of functions children can incorporate into their mathematical 
knowledge structure. This aspect of number sense can be taught using objects to show children that as physical quantities of toys or circles on a page increase, the height of number counting directly and proportionally increases (Sfard, 2000). Children will realize that numbers must remain in order so the proportional relationship remains intact.

Kaput and Blanton (2000) feel the next step to structuring knowledge is learning how numbers link to quantities. Symbolization and representation is another important aspect of number sense (Cobb et al., 1997; Gravemeijer et al., 2000). Being able to represent quantities as numbers and eventually variables is key to students' algebraic reasoning (Goldenberg \& Shteingold, 2003). Children can relate a physical quantity, such as toy giraffes, to a numerical representation. The representation could be anything from circles to the corresponding numerical figure. Children can use these varying representations to build a sense of how numbers and quantities relate. For example, children can start to understand that 7 can be represented as

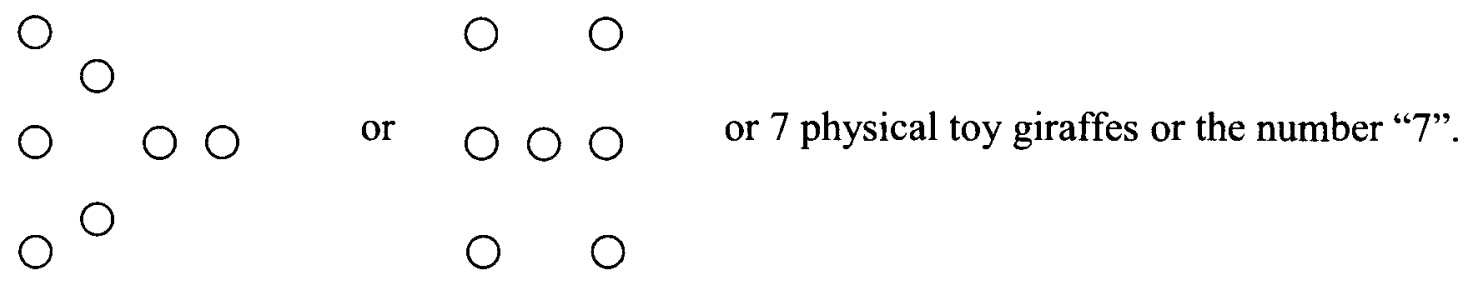

This may provide students with a base of representational thinking. Representational thinking allows students to use a referent, such as circles or the physical number 7 to represent something such as 7 toy giraffes. This can help students understand equivalence of quantities through various representations. This knowledge can build into understanding equations, and eventually unknowns.

Equivalence. Children's understanding that two quantities can be equal, even if 
represented a different way, begins to structure the idea of equivalence when comparing amounts. Children can learn that representation does not influence quantity. Children can then apply this knowledge towards understanding the equal sign. From the previous example, children's structures could be extended to understand that (at least in quantity):

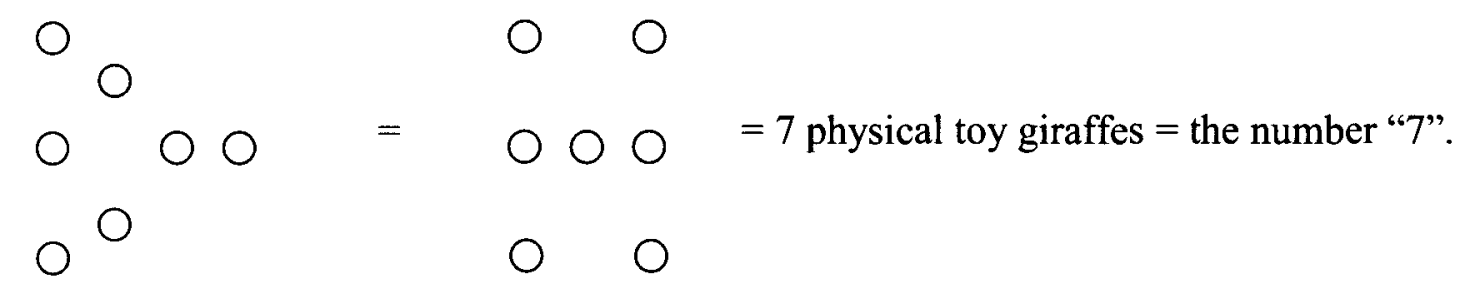

Understanding quantities in this manner can lead to pre-formal operation such as basic comparison of quantities. If a child can understanding the previous example, they could extend the algebra to discover that

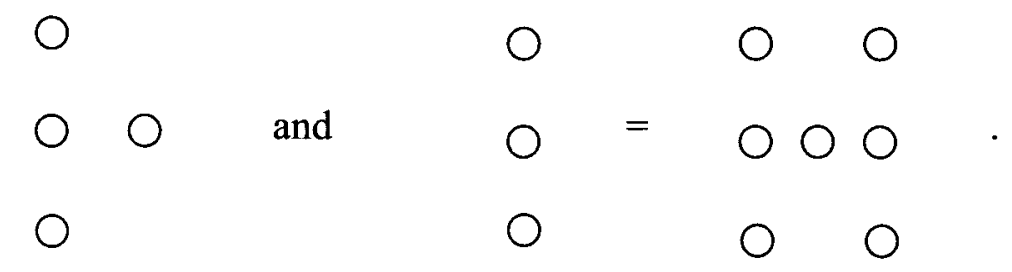

This is a prerequisite to understanding $3+4=7$.

Fosnot and Jacob (2010) emphasize taking this algebraic route to equalities because equalities are foundational to most of mathematics. They feel that this algebraic approach may help students understand that the equal sign is not an operational indicator, which can be a strong misconception with students (Seo \& Ginsburg, 2003). Students should see operational situations as a statement with the balanced quantities on each side of the equal sign. Students will realize that adding three plus four is not just an operation, but finding an equivalent amount to having three of something and four of something. Seo and Ginsburg (2003) studied a $2^{\text {nd }}$ grade classroom and showed that the students can 
learn this relational use of the equal sign if their algebraic thinking is supported with corresponding instruction. They demonstrated that students can begin discussing the equal sign to mean 'the same as', relating two equal quantities, when doing a variety of problems, instead of viewing it strictly as an operator.

Fosnot and Jacob (2010) discuss how thinking of quantities in this manner relates to students' perceptions of unknowns. The authors use an example of $x+3=8$. Students with little algebraic understanding may not be able to reason about $x+3$ as a constant quantity that is the same as 8 . Instead, they look for a procedure to solve the problem, which is more complicated and can be more confusing (Behr, 1980).

Having students identify that $x+3$ can be treated as one quantity "is a huge shift in thinking" (Fosnot \& Jacob, 2010, p 31). Students will then be less timid when looking at unknown quantities in operational situations. If they understand the underlying components of quantity based on their structured early understanding of the number system, they can use these concepts to build more advanced knowledge and problem strategies.

Comparing quantities and relations. After children have structured their knowledge of the number system and representing quantities, they can also perform comparisons of different quantities. Similar to how children learn that

00

is the same as

00

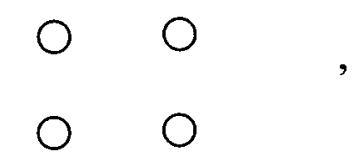

they can also learn that

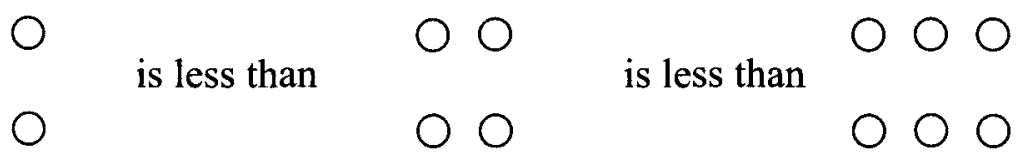


Further algebraic concepts, such as patterns and functions, can be built into children's knowledge structures within this context of number sense. Teachers can use physical quantities of objects, such as marbles, in order to get children to build and to see equality in matching two sets of marbles. They can then have children build patterns such as segregating two marbles, then four, then six, and so on and can organize them in groups of two as follows:

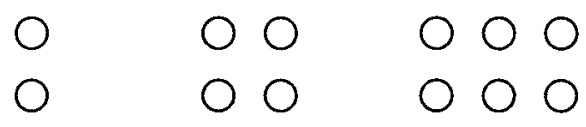

This can allow students to see relationships between quantities and how they can build into patterns. Students can begin to see patterns of odds and even or even sets of three, etc. Students can also observe where the quantities within each set fall onto the number line to build upon their early structures of number sense.

Kaput (2000) would argue that students could use their knowledge of basic patterns to look for generalizations that they can represent symbolically. When children are learning how quantities relate and compare, the equal sign (=), greater than ( $>)$ and less than $(<)$ signs can all be introduced. A quick example can be seen as follows:

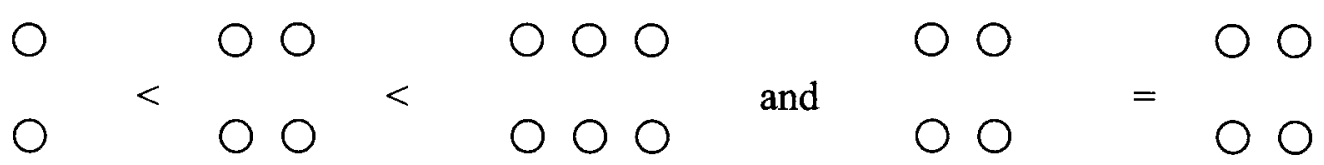

In the examples above, a student can see that each group is not just greater than the previous, but is greater by a quantity of +2 . This comparison can be related to symbolic notation in the form of $n+2$. Students can begin seeing comparison of quantities, patterns, and learn symbolism all while gaining basic number sense. 
Dougherty (2008) continues to explain that once children can represent comparisons this way, and can represent quantities symbolically, they can begin to do full numeric comparisons of groups, such as $\mathrm{A}<\mathrm{B}$. Ignoring spatial information or how objects are represented and focusing on numeric quantity may allow students to better see the relationship of two quantities.

Algebraic symbolism can be incorporated within counting and pattern construction activities, as in the above example. Symbolization can also be in the form of letters, as is typical in applied algebra. A student can learn that if two of something are added to a group, that the total objects increase by 2 . If the student can represent the original quantity abstractly as ' $n$ ', the total number of new objects in this example can be perceived as $n+2$ (Carraher, Schliemann, \& Schwartz, 2008).

Carraher et al. (2008) demonstrated some of these points in a longitudinal investigation with 70 students from $2^{\text {nd }}$ grade to $4^{\text {th }}$ grade in four classrooms (3 mainstream and 1 bilingual) in a major metropolitan area with a $75 \%$ Latino population (Brizuela, Carraher, \& Schliemann, 2000; Carraher, Schliemann, \& Brizuela, 2000; Schliemann, Carraher, \& Brizuela, 2000). In these studies, the authors implemented activities they designed with the goal of helping students build knowledge around addition, subtraction, multiplication, division, fractions, ratio, proportion, and negative numbers using an algebraic approach with an emphasis on functions. Activities lasted around 90 minutes and were implemented six to eight times per semester during each year of the study when students were in $2^{\text {nd }}, 3^{\text {rd }}$, and $4^{\text {th }}$ grade. Authors observed teachers and students and performed student interviews during activities throughout the study.

Carraher et al. (2008) showed how students in $2^{\text {nd }}$ and $3^{\text {rd }}$ grade began to represent 
unknown quantities algebraically. The students could represent changes to quantities and unknowns using algebraic representation, such as $n+2$. Schliemann et al. (2000) and Carraher et al. (2001) showed how students can even use the unknown representations to find applicable solution sets. For example, in a problem where a person gains three more pieces of candy than he or she had previously, students had to represent the new quantity of candy. Second and $3^{\text {rd }}$ grade students were both able to generate possible solution sets such as 0 and 3,6 and 9, etc. following their agreement that the amount could be represented as $n+3$.

Fosnot and Jacob (2010) even show how students can compare and operate on two unknown quantities, such as $x$ and $x+4$. This is an advanced comparison that comes after some basic operation skills are formed (see below), but the idea is embedded in basic number structure. Students can understand that two quantities can be added together or compared, even if their exact value is unknown. This principle leads into advanced algebra problems where two variables, such as $\mathrm{x}$ and $\mathrm{y}$, are unknown (see Algebra Core Content).

Addition and subtraction. Fosnot and Jacob (2010) state that "manipulation of numbers to produce an answer can seem like a magic trick to learners if they haven't constructed the implicit relations for themselves" (p. 15). Students' who build early number structures algebraically will be able to expand their structures to include more formal addition and subtraction knowledge. Students may start by 'counting on' to perform addition problems, which is a way of applying their early knowledge structure to incorporate addition. Students then begin to build their additive knowledge structures which allow them to see how pieces of quantities are related to the whole (Baroudi, 2006). 
Students need algebraic additive structures to understand the underlying relations among quantities before they perform formal operations. For example, students need to understand the concept of the numeral ' 8 ' and how it represents a quantity that they can reach through counting or adding objects together. Students can use this knowledge to build the foundation for performing operations involving the number 8 . Students with these knowledge structures will recognize that 8 circles represent a constant quantity of 8 . Students can then see how 8 can be represented in two portions of 4 and 4 . Eventually, this knowledge can be applied to addition. An example of parsing the quantity of 8 to begin showing students addition is show below:

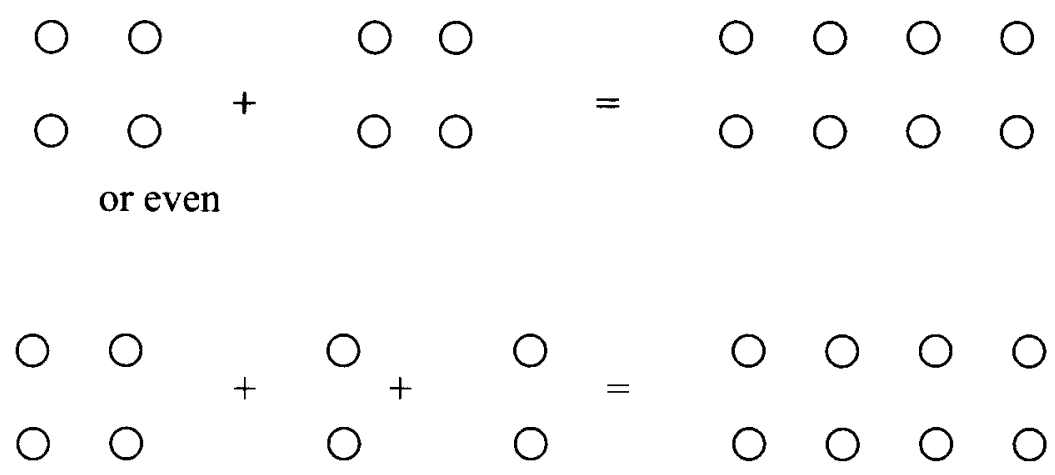

Students may not know the full underlying algebra of this problem, such as the associative property, but learning algebraically can build the foundation for children to reason abstractly (Cuoco, Goldenberg, \& Mark, 1996).

This is also the foundation for equivalence (see Algebra Core Content). Students can begin to understand that the two side of an equation are balanced, even if they do not look identical (Fosnot \& Jacob, 2010). Fosnot and Jacob use similar problems to represent this idea, such as $5+3=4+4$ or $8+2+10=12+4+4$. In these problems, both sides of the equation are broken into pieces. The pieces are not the same, but their 
sum is. Students can learn apply algebraic knowledge structures to understand equations and how they are balanced.

Dougherty (2008) further discusses how parts and wholes could be taught algebraically early in education. He feels that once students can represent amounts using symbols (such as the circles above), letters can be connected with the quantities. For example, the symbols can be broken down into parts, such as demonstrating that $\mathrm{A}$ is the same as B and B together (when B is half of A). The above example could then translate to $\mathrm{B}+\mathrm{B}=\mathrm{A}$ where

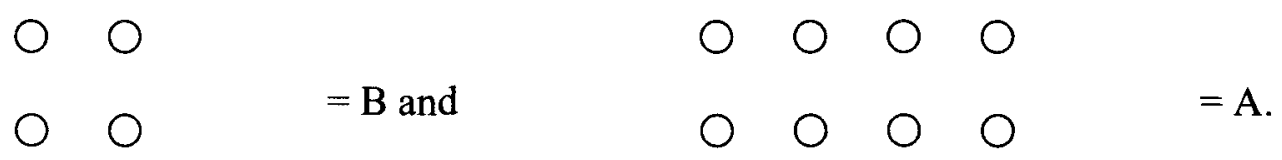

Without putting specific numbers of operations, students can focus on the relationship of A and B. Dougherty discusses how this can lead to parsing number strategies, such as round numbers strategies, in more advanced addition problems. For example, when a student is adding $9+6$, he or she may not know the answer, but may know $10+5$ is 15 . A strategy for adding $9+6$ is borrowing 1 from 6 and adding it to 9 to make it $10+5$. The algebraic notation for that strategy would be $A+B=(A+1)+(B-$ 1). Students may do this on their own, but if they can realize that it is an algebraic strategy that can be generalized to all addition problems, students can reason with that generalization to solve many other problems (Kaput et al., 2008).

Many have proposed that thinking about quantity in an algebraic way may lead to a different type of understanding of addition procedures (e.g. Carraher et al., 2008; Fujii, 2003). Using algebraic quantities allows student to focus on the situation and variables in 
a problem, initially ignoring the exact method of calculation that will take place to solve the problem (Smith \& Thompson, 2008). Students who are or are not proficient at computation can use reasoning about quantities in addition problems to start to build their knowledge of relationships. Without the process of reasoning algebraically, students will often read addition and subtraction statements as instructions to compute and will attempt to solve the problem accordingly (Baroudi, 2006; Kieran, 1981). Algebraic reasoning allows students to form generalizations and representations of problem situations that can help them when solving (Carraher et al., 2008).

Carraher et al. (2008) discuss examples where $3^{\text {rd }}$ grade students could represent unknown quantities using algebraic notation in the context of addition and subtraction. The students could also discuss changes in an unknown amount using addition and subtraction. For example, in solving a word problem, students were able to track several changes in an unknown amount of money to discover the end amount of money (e.g. $n+$ $3+1-2$ ). Students were able to represent the changing unknown amount using multiple representations, such as a number line and charts. Carraher et al. (2008) reported that students generally progressed from using iconic drawings and random number assignment to more algebraic, abstract representation of problems situations as they became more comfortable with this type of reasoning. For example, rather than making up a starting value of 10 , then adding 5 and subtracting 2 , students began noting that the change was +5 and -2 , so the shift in quantity could be represented as $n+3$.

The previous example also connects subtraction to additive cognitive structures (Fosnot \& Jacob, 2010). Students may understand subtraction better if they represent it as part of their basic number structure. Subtraction can represented as moving down the 
number line, as addition is moving up. In Schifter's larger research project, Lester (1996) reported an example of $2^{\text {nd }}$ grade students discovering the inverse relationship between addition and subtraction using missing addend problems. An example provided was 'when driving somewhere 54 miles away, how far away are you after 27 miles'. Some students in the class attempted an addition strategy, while others tried a subtraction strategy. A conversation ensued where students began to algebraically identify that addition and subtraction could both be used because of their inter-relation.

Students' knowledge of algebraic representation of basic addition and subtraction problems may help them solve more advanced problems, such as open number sentences. With an algebraic view of number sense and operation, the problems $5+_{-}=8$ or $8-_{-}=$ 5 may feel much less daunting. Students can visualize the quantity of eight being separated into two pieces of 5 and 3 . They can reason algebraically for products or missing values, such as $4+4=$, as well as $4+_{-}=8$.

Multiplication and Division. Students can use their knowledge structures from addition and subtraction to incorporate multiplicative structures. Multiplication and division are not independent mathematics topics, but stem from the same algebraic principles that can scaffold students when learning addition and subtraction.

Fosnot and Jacob (2010) discuss how looking at patterns and groups of quantities provides the opportunities for students to structure their number sense in a new way that will build towards multiplicative understanding. As students see relationships of sets, such as three, six, and nine, they can recognize number patterns within their previous knowledge of number sense. The algebraic concepts that help students understand $n+3$ can allow them to expand their structured knowledge to $\mathrm{n} x 3$. When analyzing patterns 
within number sets, instead of adding three, example quantities could be multiplied by three. Students may then represent the patterns as $\mathrm{n} \times 3$.

This algebraic knowledge can be extended to operation problems, such as $13 \times 3$. Student can use their algebraic structure of multiplication to realize this problem can be represented as $(10 \times 3)+(3 \times 3)$. Students can even use this knowledge to understand basic functions (Kalchman, \& Koedinger, 2005). For example, students can generate a 3x function by reasoning that any number multiplied by 3 is equivalent to adding three sets of that number.

Fosnot and Jacob (2010) discuss another example of using cognitive structures of addition to help students learn multiplication. An example problem they use involves pairs of people holding hands. They use this visual to help students see a pattern of adding by two. Students can see patterns of even numbers which will lay the groundwork for multiplying by two and thinking about factors of even numbers. The authors also discuss more complex problems, such as using egg cartons or chocolate boxes with various numbers of rows, columns, and layers to help students think about relationships among sets of quantities. As students begin to think of the sets as one quantity or unit, they are beginning to structure their knowledge for multiplication.

When it comes to formal operation of multiplication or division, students can use their knowledge structures to reason about the problems algebraically (Fosnot \& Jacob, 2010). When approaching multiplication, instead of adding pennies or other symbolic objects, students may begin thinking about sets of pennies or about series of blocks in a matrix. Students could explore patterns of 7 to see that $3 \times 7$ is similar to adding three objects, where the 'objects' are blocks of 7 . Similarly, they could add 7 'objects' that 
consist of 3 blocks. Students would not be memorizing the answer to $3 \times 7$, but using their algebraic language to discover multiplicative relationships that will help them reason about problems.

Students can use algebraic knowledge to explore more advanced number sense concepts as well, such as square numbers. Schifter (1996) discusses an example from a $4^{\text {th }}$ grade classroom where students were graphing square numbers and looking for relations between them. A group of students was able to explore square relationship to deduce and articulate that they could calculate $(n+1)^{2}$ from $n^{2}$ : simply add $n$ and $(n+1)$. One student began to notice this trend early when graphing overlapping square numbers and other students helped to extract the rule. Although they did not have the algebraic experience to articulate the rule using symbolic notation, they could reason algebraically to form a number property generalization from multiplication problems.

Schifter (1996) even found that $2^{\text {nd }}$ grade students could extract generalizations about square numbers. In one lesson where students were exploring square numbers using blocks, students were able to generate nine accurate conclusions about square numbers including several that were based on algebraic generalizations. For example, students extracted that square numbers alternated between odd and even.

Carraher et al. (2000) showed that $3^{\text {rd }}$ grade students were able to represent multiplication problems and concepts algebraically. For example, students were able to reason about functions using multiplication tables. To understand $3 x$, students did not simply make a $3 \mathrm{x}$ multiplication table. Instead, students reasoned about multiplication through problems, such as how much do 'n' boxes of cookies cost if they each cost three dollars. Students filled in partially complete tables to see how price rises in increment of 
3 dollars per box. These activities got students doing number operations with multiplication as well as learning about functions. The authors reported that students were able to extract functions from such tables, such as 'price $=\mathrm{n} \times 3$ '. Students were able to fill in tables for more complex functions such as $2 x+1$ and discover these functions from number sets. The students were able to focus on the relationships between quantities instead of computational solutions. This study did not research the longitudinal impact that thinking algebraically had on the students' mathematics knowledge.

Number Properties. Algebraic reasoning with number sense and operations may lead to discovering informal and formal properties of numbers and operations (Schifter et al., 2008). Kaput et al. (2008) discuss that students can create generalizations if they can reason using symbolic representations. This is not something students do naturally (Kieran, 2008). If students are supported in learning these skills, they can learn to lift generalizations from problems and representations of patterns. Students can then use algebraic reasoning to discover more advanced mathematics principles, such as the associative property in addition or multiplication. For example, students could deduce the commutative property using the reasoning skills discussed above. Students could think about two children, Johnny and Megan, who have 5 pennies total. They could reason that if Johnny has 3 pennies and Megan has 2, their total is 5. Students could then count Megan's pennies first, then add Johnny's, and see the total is still 5. After seeing several such problems, students could see that when two quantities are added together in either order, their total is the same. When the quantities are then expressed using symbolic representation, students will be able to understand or even derive the commutative property and its symbolic notation. 
When helping to form a curriculum that incorporated algebraic thinking, Schifter et al. (2008) found several examples of students discovering rules such as the commutative property in early elementary grades. The authors held monthly meetings with a group of $\mathrm{K}-5$ teachers across an ethnically diverse region to discuss how algebraic ideas naturally emerged in their mathematics classrooms. One $1^{\text {st }}$ grade teacher said the algebraic idea of the commutative property arose when they were discussing how many ways you could add to get 10 . When students realized you could add $6+4$ and $4+6$, as well as $7+3$ and $3+7$, etc. they naturally began asking if the number 'turn around' always worked. They explored the property using larger numbers, blocks, and charts until the students were convinced that the property always held constant. Schifter et al. (2008) gave another example in $3^{\text {rd }}$ grade classrooms where students attempted to translate the commutative property to subtraction, but found it only worked with addition.

Schifter, Bastable, and Russell (1997) gave an example of $3^{\text {rd }}$ grade students generating the commutative property using multiplication and realizing it does not work with division. Schifter et al. (2008) also discuss a $3^{\text {rd }}$ grade classroom where students discover associative properties when learning about factors. In this classroom, students worked with sets of blocks and began breaking them apart in different ways. For example, students were able to understand that 8 blocks could be broken into eight sets of 1 , four sets of 2 , or two sets of 4 , or any combination thereof would add to the same total amount. They reasoned that how a sum was added together did not change the final sum.

Algebraic reasoning about the properties of arithmetic can build towards multiplicative reasoning. Goldenberg and Shteingold (2008) discuss how algebraic language underlies the distributive property. They feel that long before children can 
compute $100 \times(2+5)$ they can answer 'how many is 2 pennies plus 5 pennies'. Often children can answer the parallel problem 'how many is 2 hundred plus 5 hundred' or even 'how many is 2 eighths plus 5 eighths'. Cognitively, children can listen to the language of the problem and reason the answer by representing the operators in their mind as abstract quantities.

Understanding the distributive property of addition in algebraic terms can lead to understanding the distributive property of multiplication (which can be represented as $\left.A(B+C)=A^{*} B+A^{*} C\right)$. Just as 8 was preserved when separating it into 4 and 4 in addition, the product derived from multiplying 8 by another number is preserved when multiplying the pieces of 8 ( 4 and 4$)$ by that same number. For example, Schifter et al. (2008) discussed a $3^{\text {rd }}$ grade classroom where this reasoning occurred. The teacher asked students how they could break up $12 \times 6$ to make it as easier problem. Students initially posed doing 2 groups of 12 then adding it to two more groups and two more groups, prompting the teacher to notate $12 \times 6=(12 \times 2)+(12 \times 2)+(12 \times 2)$, which the class agreed was correct. The students never named the rule, but began to reason about distribution by learning new ways to represent problems.

The research performed by Schifter (1996), Brown (1996) provided an example of $3^{\text {rd }}$ grade students discovering the commutative property of multiplication using algebraic reasoning. In a problem where Brown's students had to add the total pencils in 3 boxes of 12 pencils, students first attempted the addition procedure $12+12+12$. Brown guided them to see the connection of $12+12+12$ and $12 \times 3$. One student then unexpectedly stated that the boxes could be broken in half and summed by adding $6+6+6+6+6+$ 6 , or multiplying $6 \times 6$. Another student then stated you could break the 6's in half and 
add twelve 3's. Then another student announced that multiplying twelve 3's was the reverse of the original problem, which multiplied three 12 's. Students continued this process and discovered they could also add 9 sets of 4 , which was the same as 4 sets of 9 . For homework, they pondered if this commutative property was always true. The next day, they were able to use arrays to demonstrate how the total number of blocks always stayed consistent if a multiplication problem was reversed.

The abilities seen in Schifter's (1996) research corresponds to Fosnot and Jacob's (2010) idea of using additives structures to learn and explore multiplicative structures and principles. Fosnot and Jacob (2010) also propose using similar tasks to get students to think exhaustively about combinations of addition and multiplication in a real life context. For example, students can compute the possibilities of postage using three and six cents stamps. By analyzing the patterns and relationships of addition, they can build $\times 3$ and $\times 6$ multiplication knowledge and the foundation for more advance concepts. The authors even discuss how $4^{\text {th }}$ grade students are able to generate ideas that relate to the commutative, distributive, and associative properties of multiplication.

The above theories and research show how students are able to discover and discuss, in a classroom context, generalizations when performing certain number operations. These algebraic abilities also translate into more advanced number properties and operations.

Advanced learning. The algebraic knowledge structures students build when learning basic topics will easily connect to learning more advanced topics covered in elementary school, such as fractions. Students have to understand quantity and how it can be parceled to understand division and fractions. Algebraic reasoning allows students to see fractions 
as a comparison of quantity. For example, $\mathrm{A} / \mathrm{B}=2$ can be used an example of a generalization to display any two numbers where one is twice as large as the other. Conversely, showing $B / A=1 / 2$ shows more traditional approach to fractions while still allowing the students to generalize meaning. Fractions can also be represented as dividing a whole quantity into pieces, such as cutting a pizza in half. Students can learn that the fraction $1 / 2$ simply means one half of any object one breaks apart. Dougherty (2008) goes one step further and discusses how using algebraic notations early may further help understand fractions. She discusses how a total quantity can be represented as a letter and its pieces as another letter. For example, how many H's are in E. Being able to use letters first to abstractly understand breaking things into fractions may help the transition to using real numbers in operations (Dougherty, 2008).

Fractions can be one of the most difficult areas for children to understand (Behr, Lesh, Post, \& Silver, 1983). Using algebraic reasoning may help students see generalizations using fractions (Mason, 2008) as well how to perform operations with fractions. For example, Moynahan (1996) showed how students in $6^{\text {th }}$ grade could revisit generalizations from basic multiplication and division problems to apply them to problems involving fractions. Moynahan's students were able to use the fact the multiplication is the inverse of division to reason about multiplying and dividing with fractions. For example, Moynahan had students think about $15 \ldots 1 / 3=5$, where students had to figure which operator should be inserted in the blank. After discussion, students came to understand that multiplication was correct since $15 / 3=5$ and $1 / 3$ is the inverse of 3 .

This type of algebraic reasoning may help with the diverse properties of fraction 
knowledge and manipulation (Behr et al., 1983; Carpenter, Fennema, Franke, Levi, \& Empson, 2000; 1999). For example, early research by the Rational Number Project indicated that higher performing students were able to understand and apply certain concepts about fractions when solving problems (Behr, Wachsmuth, \& Post 1985). The Rational Number Project worked with teachers to incorporate expansive use of manipulatives and physical models of the world that could give children a realistic perspective of the concepts of fractions and how they were applied (Cramer, Behr, Post, \& Lesh, 1997; Behr et al., 1983; Post, 1979). In Behr and colleagues' (1985) study, sixteen $4^{\text {th }}$ and $5^{\text {th }}$ grade students, who had recently been taught about adding fractions, were asked to solve one problem and explain their reasoning. They had to use the digits $3,4,5,6,7$, and 11 to complete the equation $\mathrm{X} / \mathrm{X}+\mathrm{X} / \mathrm{X}=1$ (or as close to 1 as possible). No digit could be used twice. High performing students were able reason algebraically by using the rational number order and fraction equivalence concepts they had learned to solve this unique problem. Lower performing students applied concepts in a manner that was constrained by basic procedural learning. They did not generalize as well using underlying concepts of the problem (e.g. finding numbers that were close to the $1 / 2$ proportion). Lower performing students also showed less accurate problem representations within their strategies.

Algebraic reasoning may also help students when adding or multiplying fractions. Taking $3 / 8$ and realizing it is simply three objects where the object is $1 / 8$ may make adding or multiplying the fraction easier. For example, Moss and Case (1999) studied a teacher who implemented the RNP curriculum with sixteen $4^{\text {th }}$ grade students. When compared to a control classroom, the students receiving the experimental curriculum had 
larger gains on the Rational Numbers Test. They also referenced proportional concepts more when justifying answers and had larger gains on each sub-group of items within the test: decimals, fractions, and percents.

Cramer et al. (2002) followed up this study on a larger scale, implementing a 30day instructional program using their materials and curriculum to replace the commercial curriculum in 33 randomly assigned $4^{\text {th }}$ and $5^{\text {th }}$ grade classes (out of 66 participating classrooms) in one school district (Cramer, Post, \& delMas, 2002). The RNP students outperformed the control group on a 34-item post-test, designed by the authors, which assessed knowledge in six areas: fraction concepts, fraction equivalence, fraction order, concept of unit ideas, operations and estimation, and transfer. Treatment students also performed better in four of the six strands on a retention test administered four weeks later. Additionally, interviews with the experimental students showed they took a more conceptual approach in finding problem strategies, where the control students more often used rote procedures.

Fosnot and Jacob (2010) further discuss how students' basic multiplicative knowledge structures will help them in more advanced topics such as factoring and multiples. If students have a strong algebraic structure of knowledge, they can represent quantities and relationships in any higher-level multiplication problems. Students who use algebraic multiplicative structures will be able to reason algebraically and not just attempt to compute a formulaic answer (Smith \& Thompson, 2008). Smith and Thompson (2008) provide the example of a classic rate vs. time vs. distance problem where elementary students must calculate how far two people will walk before they eventually meet. There is a formulaic answer to such problems (using distant $=$ rate * 
time), but students at this level may not have learned the exact formula. Instead, the students will need to apply algebraic reasoning using the relationships in the problem to deduce the formula.

Students can reason about the quantities, properties, and relationships in any given problem. They can then understand how and why they are using certain equations or comparisons. This allows students to decide and justify what calculations are needed, which results in better problem solving (Sowder, 1988). Sowder (1988) demonstrates this idea when interviewing $6^{\text {th }}$ and $8^{\text {th }}$ grade students while they attempted to solve word problems, but did not research younger students. Sowder discovered four levels of sophistication in the students' problem solving. Students who could understand and relate quantities showed signs of a more pre-algebraic approach to finding a solution. The more sophisticated strategies attended to the quantities and relationships among variables in the problem. For example, some students discussed the concepts of the problem and used them to create a generalized problem representation that identified unknowns as well as operands. This guided them in identifying the operators and procedures required to find a solution. The less sophisticated strategies searched directly for operations among the stated numbers. This study showed the importance of understanding quantities and relationships in problems before formerly taking algebra, but it was only performed with $6^{\text {th }}$ and $8^{\text {th }}$ grades students. This study did not extend to students in elementary school.

\section{Algebra and Measurement}

Algebra can help students incorporate the principles of measurement into the knowledge structure. Many researchers feel that children come into education with a basic view of quantities that is based around measurement by comparison (Davydov, 
1975; Dougherty, 2008). This idea can be nurtured as students learn basic number structure and learn how to apply units to quantity. Education lessons can then guide students to more formal approaches of which quantity is more or less using comparative symbols, such as $=,<$, and $>$ and labeling the quantities with units.

The ability to understand measurement requires some algebraic reasoning using generalizations and representation. Students need to understand that there are properties, such as length, that are attributable to many objects and shapes. Students need to realize that these can be represented using standardized units, and that the number of units equates to one measure, not a series of objects or measurements. Reasoning algebraically can reduce confusion by helping students represent amounts abstractly through units. Dougherty (2008) discusses an example where a $1^{\text {st }}$ grade student stated during an interview that the number 3 or 8 could be larger when making a measurement, depending on what the units are. The student stated that 3 larger units could be larger than 8 smaller units.

Elementary standards often address students' need to master units and formulas for measurement. Once students understand the idea behind units, as the $1^{\text {st }}$ grade student above, they can begin to add labels, or representation to units. Algebraic symbols can help students understand the concept of a unit and how multiple units can be equated with a property such as length or weight. For instance, knowing that 1 inch equals approximately $3 \mathrm{~cm}$ can help students understand that one length can be represented in two ways that are comparable by $3 x$. Students may better understand these relationships between units, such as Fahrenheit and Celsius, if they understand patterns and relations of units. For example, students can apply real world problems and see the relationship 
between Fahrenheit and Celsius and eventually deduce the actual algebraic equation ${ }^{\circ} \mathrm{F}=$ $9 / 5^{* \circ} \mathrm{C}+32$. This could be done through formula tables as seen in Carraher et al. (2000).

Algebraic reasoning can also help link measurement to number operations for comparison of attributes such as volume (Dougherty, 2008). Students can learn that adding or multiplying to a quantity can increase the physical attribute as well as the number of units, which allows students to see the comparison of an object and its quantitative representations.

\section{Algebra and Geometry}

Students who have algebraic knowledge structures may better learn principles of geometry. For example, Boester and Lehrer (2008) studied how algebra related to representational competence in the context of geometry. Their study was performed over two years, using twenty $6^{\text {th }}$ grade students ( 11 female and 9 males) in the first year and 14 in the second ( 2 female and 12 male). Students had diverse socioeconomic backgrounds. The authors designed a series of lessons where students used physical shapes, such as cut-out rectangles, to identify patterns within and across shapes and to discover multiple ways to represent those patterns. One goal was to have students use the physical shapes to create and understand verbal descriptions of the shapes, such as the long side is twice as long as the short side. They also wanted students to translate those descriptions into algebraic representations, such as LS $=2 \times$ SS. The authors also wanted students to look

for patterns across numerous shapes as well. The goal was then to get students to display all relationships through tables, graphing, and linear equations.

Boester and Lehrer (2008) interviewed all students at the end of the series of lessons to identify which aspects of the activities they mastered. The interview task was 
parallel to the classroom activities they had performed, but used cut out cylinders. The first part of the task was to indentify patterns within the physical cylinders. All students were able to classify several of the cylinders that had a 1 to 1 height to width ratio and several noted those that were 2 to 1 . Most students used a graphing strategy to ensure and represent the relationships among the shapes. All but two students were also able to generate the corresponding equation to represent both relationships. Most students were also able to identify more complex relationship, such as 5 to 1 ( $85 \%$ of students) and 2 to $3(90 \%)$. Eight-five percent of students were able to discuss that there were theoretically infinite shapes that fit into the graph and equations they created.

Boester and Lehrer (2008) showed that students can use algebraic reasoning to fluidly discuss varying representations of geometric relationships. Students could see spatial and geometric relationships as algebraic. They learned to describe this relationship using a variety of symbolic methods, such as graphing and the Cartesian line. This study, however, was performed on $6^{\text {th }}$ grade students, and did not test younger students to examine if algebraic learning could support geometry in $1^{\text {st }}$ through $5^{\text {th }}$ grade. This study was also not experimental and does not provide empirical evidence for long term impact of using algebra to gain geometry knowledge.

A similar study has been performed with $3^{\text {rd }}$ grade students showing parallel results (Lehrer, Strom, \& Confrey, 2002). Lehrer et al. (2002) studied $223^{\text {rd }}$ grade students with one teacher in a Midwestern town. Three children were labeled as special needs and 4 qualified for free and reduced lunch. These students learned to classify shapes, including similarity, as a method of classification. Students were able to sort a group of rectangles into smaller similar piles. Students were then able to create algebraic 
expressions to compare the length of one side to the adjacent within each smaller pile of shapes. Similar to Boester and Lehrer (2008), the students represented these similarities using Cartesian coordinates. Three dimensional cylinders were even used for an activity. Students were again able to compare and represent relationships (in this case height to circumference) in algebraic notation using graphs and charts. Students worked in groups and were heard offering conjectures and justifications without direct prompting.

Other studies have shown that elementary students can use algebraic reasoning when performing early geometry tasks. For example, Lehrer et al. (1999) showed how $2^{\text {nd }}$ grade students can use geometry to represent their world (Lehrer, Jacobson, Kemeny, \& Strom, 1999). The authors showed how students in one classroom learned about classifying real world objects into shapes using geometric principles and relationships. The students were able to reason about the relationships of shapes to real world objects in space. They applied this reason to learn about the structure and principles of shapes.

Algebra connects to geometry in several other ways. For example, relationships between variables can be displayed by coordinate graphs, which are symbolic and representational. Shapes are classified by patterns and generalizations, which are algebraic. For example, students have to understand that rectangles have four right angles, which lead to two parallel sides of equal length. Understanding more complex relationships, such as area $=$ base $\mathrm{x}$ height, also requires algebraic symbolization and reasoning.

Fosnot and Jacob (2010) discuss how relationships such as $\mathrm{A}=\pi \mathrm{r}^{2}$ (the formula for the area of a circle) can help students learn about algebra. The authors discuss how these relationships are not meant to simply be memorized. Students should explore these 
relationships with real examples and understand how and why the relationships exist. This will deepen the meaning of the geometry as well as give students time to explore algebraic relations and provide proofs for known relationships.

Students can also apply measurement to geometry to help with their representations. Before students can learn what constitutes congruency, etc., they need to be able to measure and compare relationships of lines and angles within and between shapes (Goldenberg, Cuoco, \& Mark, 1998). Students can use quantitative comparisons to see what is required for shapes to be congruent or similar. They can also use representations to understand what occurs to shapes during reflection, rotation, and translation. The corresponding geometry principles can be thought of as patterns (Smith, 2008). For example, when a shape is rotated 180 degrees, the same thing will happen to each and every shape that has that action performed to it. Understanding a shape's properties and the algebraic relation of its sides and angles may help students with comparison to other shapes and when mentally performing movement on that shape. Relating how 2-D shapes relate to 3-D shapes also applies the algebraic concepts of patterns and equations.

Students can use measurement along with algebra to calculate and compare more advanced properties of shapes, such as area and perimeter. Goldenberg et al. (1998) discuss how students can work with and manipulate properties of shapes using algebra. For example, they can see that if a side of a square doubles in length, the area quadruples and the perimeter doubles. Another example is putting shapes, 2-D or 3-D, side by side. By putting more and more blocks in a row, students can count how the total number of faces, sides, etc. changes as a function of the number of units. 
Students in $1^{\text {st }}$ through $5^{\text {th }}$ grade can even use algebra to learn coordinate geometry. Coordinate geometry uses symbols and begins to build students' understanding of formulas. A student who has a base knowledge of these concepts from the earliest grades in elementary school may better understand higher level areas of geometry and other areas of mathematics in advanced courses (Goldenberg et al., 1998).

\section{Algebra and Data Analysis and Probability}

Students who understand algebraic principles may be better able to structure knowledge of data analysis and probability. Data analysis and probability, much like algebra, involves representing quantities and relationships while looking for patterns within numbers. The early standards around data analysis involve collecting data and representing it in multiple ways. Students need to take numbers and represent them with tables, charts, and graphs in ways that are meaningful to them. Students can represent singular quantities or how two quantities relate.

Understanding how two quantities interrelate leads to equalities and functions which are algebraic by nature. Functions can help students use data to predict an outcome. For example, if students have been graphing how a plant grows over time, they could discover a function associated with its height at any given time. Once students are proficient at gathering and interpreting data, they can learn ways to mathematically represent the data, such as using the mean, median, mode, and range. All of these are standards from Table 1 and correspond to the algebraic ideas of representation and generalization. How students can connect algebra to these concepts has been evidenced by many of the studies discussed above. 


\section{Algebraic Core Content}

Although algebra is intertwined with the other subject areas, it is generally considered its own content area. As seen in the state mathematics standards in Table 1, algebraic thinking can have its own standards even in elementary school. The core content areas within algebra from these state standards include: patterns, relations, and functions; variables, expressions, and operations; and equations and inequalities. The above discussion focused on how algebra relates to other subject areas through structuring knowledge and creating generalizations and representations. The discussion will now turn to the conceptual areas of algebra often used in standards and how they build upon each other.

Students who begin to structure their mathematics knowledge algebraically from the earliest concepts of number sense, quantities, and basic operations will have an advantage when algebra is tested explicitly. These students will be better able to understand the explicit, as well as implicit, concepts of algebra. Building early fundamental knowledge of algebra may help with growth in each of the three algebraic content areas mentioned above.

Patterns, relations and functions. Patterns are represented all over our world in colors, sizes, shapes, words, object relations, and other areas including numerical patterns (Greenes, Cavanagh, Dacey, Findell, \& Small, 2001; Cramer, 2001; Cuevas \& Yeatts, 2001). Students can see patterns when they are comparing quantities, as discussed above. These comparisons can help students to structure knowledge about the number system. This knowledge relates to operations, such as addition and multiplication, as well as external areas such as geometry (e.g. Lehrer et al., 2002). 
Seeing patterns requires the ability to perceive relations between quantities. One can then discover how and if the quantities fit into a continuous relationship. Once someone has this skill, he or she can begin to add to a pattern, fill in missing pieces, or construct a new pattern. Students as early as kindergarten have been shown to create, manipulate, and understand patterns (Moyer, Niezgoda, \& Stanley, 2005). Moyer et al. (2005) demonstrated that kindergarten students could use physical and virtual representations of quantities to create numerous patterns of varying complexity. Kindergarteners simply need the support and opportunity to use creativity in exploring and learning about quantitative relationships.

Algebraic reasoning with patterns can lead to knowledge of relations and functions (Greenes et al., 2001; Cuevas \& Yeatts, 2001; Dreyfus \& Eisenberg, 1984), which are difficult for students (Clement, 2001). Relations are simply how one object compares to other objects of its kind or to another group of objects. For example, a relation of fathers' ages to daughters' ages is that of greater magnitude $(a<b)$. This relationship will always hold true even though the exact age differences will vary. A function extends the relation principle to incorporate situations in which one member of a set is exactly predicted by another member. For example, a function could be created for predicting one daughter's age from her father's age. If the father were 20 years older than the daughter, the function would exist where the daughter's age (a) could be exactly determined from her father's age (b) by subtracting 20 years $(a-20=b)$.

Students' ability to understand and represent patterns, relationships, and functions can help them understand and solve problems, as discussed above. Learning these skills early is important since students often have misconceptions about functions and their 
purpose (Clement, 2001). Using prior knowledge of algebraic concepts to learn what functions are could help students with these misconceptions. Students who use prior algebraic knowledge to build knowledge structures of advanced topics, such as functions, will have an easier time integrating the topics into their cognitive structures of mathematics (Kalchman \& Koedinger, 2005).

Variables, expressions, and operations. Representing patterns and relationships is a large part of algebra (Kaput et al., 2008). Being able to symbolically represent quantities is often considered formal algebra but this can be introduced much earlier. Students can learn to algebraically express the mathematics concepts they are using in their thought process from the earliest of formal operations.

Symbols represent a given quantity in a problem situation, expression, or operation. Variables can be taught as symbols that represent relationships between quantities. Using variables and symbols is a form of representation that students can practice when thinking about concepts or problems (Greenes et al., 2001; Cuevas \& Yeatts, 2001). Substituting a variable into a mathematical situation may also help students make generalizations, as discussed above (e.g. Schifter et al., 2008). Once students understand that symbols and variables can represent quantities and relationships, students can expand variable use into more complex algebraic problems, such as formulas and graphs.

Equations and inequalities. Another component of algebra is understanding equations and inequalities. Equations are a subset of relationships and functions where two sides are equal. They are a backbone to many basic operation problems as well as understanding relationships among amounts, as discussed above. To review briefly, students' 
understanding of equations or equalities may start out as basic quantity knowledge, such as three dots and four dots are the same as seven dots. This can build into knowledge about addition and eventually multiplication and beyond. The main idea is that quantities can appear differently and algebraic reasoning leads to an understanding that the underlying quantities are still the same (Fosnot \& Jacob, 2010).

Equalities are directly relevant to basic operations and number concepts and are foundational for more advanced, traditional algebra. Fosnot and Jacob (2010) discuss how basic knowledge structures of equality help students when they face more advanced algebra problems such as $4 x-5=2 x+3$. Understanding that the expressions represent an equal amount makes solving this type of problem much easier. When performing a step such as adding 5 to each side, students who grasp the concept of equivalence will have a much easier time seeing why this maintain equality while simplifying the expression. Other students may only attempt to memorize and apply correct procedural steps.

The algebraic core concepts above have been discussed throughout this section because they relate to how students can structure and apply their mathematics knowledge from the beginning of formal education. These concepts may give a window into students' ability to reason algebraically and build their knowledge structures. If students understand the algebraic principles that underlie each mathematics content area discussed, they may be able to better learn and apply the concepts within each content area. Thus, early algebraic knowledge may predict how students will perform in later algebra as well as overall mathematics.

\section{Current Research around Algebra}

Researchers and educators have long proposed that beginning algebra earlier than 
high school would be beneficial for students (Kaput, 1995; NCTM, 1989; Phillips \& Lappan, 1998; Fey, 1989; Dossey, 1998; Briggs, Demana, \& Osborne, 1986). These works attempted to disprove the traditional but inaccurate view that algebra is a complex compilation of procedures and higher order concepts that should not be learned until at least $8^{\text {th }}$ grade or later (Kaput, 2000; 1995). Many have heeded this call and implemented algebra programs that have helped students learn algebra concepts before taking the traditional Algebra I course.

The majority of the programs and research around early algebra has occurred in the middle school grades. Educators, programs, and curricula have attempted to bring the fundamental concepts of algebra into these grades so students can construct a framework for algebra before entering Algebra I (e.g. Carpenter and Levi, 2000; Bastable and Schifter, 2008; Kaput and Blanton, 2001; Dietiker, Kysh, Hoey, \& Salley, 2006). The research has included both independent studies and large scale programs (e.g. Fernandez $\&$ Anhalt, 2001; Moses \& Cobb, 2001). Researchers have had success showing a positive impact from teaching algebra concepts and reasoning in middle school (e.g. Carpenter and Levi, 2000; Fernandez \& Anhalt, 2001; Bastable \& Schifter, 2008; Driscoll, 1999; Moses \& Cobb, 2001).

Before the impact on students is discussed, it is important to note that studies have shown that teachers can adjust their practices to integrate algebra earlier. For example, Transition toward Algebra $\left(\mathrm{T}^{2} \mathrm{~A}\right)$ was created to give teachers the tools to teach algebra in middle school. The goal of the program was to have teachers create a base of algebra knowledge they could apply to all areas of mathematics (Fernandez \& Anhalt, 2001). In this program, teachers took part in professional development that promoted teaching 
strategies that interweave the basic concepts of algebra into other content areas. For example, teachers were taught how to show students that basic concepts in measurement can be algebraic, such as functional relationships and comparing units. Then, teachers were taught how to help students think algebraically when solving problems. To study the impact of the program, Fernandez and Anhalt (2001) researched forty teachers from $5^{\text {th }}$ through $9^{\text {th }}$ grade over two years. In the first year, twenty teachers completed a month long summer institute. Afterwards, project staff orchestrated monthly meetings, classroom collaborations, site visits and videotaping to provide feedback. The twenty teachers then helped lead the program in the second year for twenty additional teachers. The study found that initially $85 \%$ of the teachers defined algebra in a limited way, such as "algebra is solving equations with unknowns" (p. 237). After taking part in the program, teachers were able to give more complete definitions of algebra. Most described how algebra consists of looking for patterns and relationships among concepts that will help in problem solving. The authors reported that the teachers were also able to give better examples of problems that conceptually represented algebra that would engage their students.

Driscoll and colleagues $(1999 ; 2001)$ created an entire toolkit as part of their work for the National Science Foundation. It was created to help teachers in $6^{\text {th }}$ through $10^{\text {th }}$ grade ease the transitions into algebra. It utilized hands on approaches to building students' algebraic thinking. The toolkit encouraged using problems, data collection, and discussion to have students connect algebra to the previously learned concepts. The toolkit helped teachers identify where they could promote algebraic concepts in students' reasoning. The toolkit framework was reported to be successful in helping teachers 
promote algebraic reasoning. Longitudinal experimental studies were not performed around this framework and could add further information about its impact.

There are also student-based programs that target curricula reform in middle school grades. Many of these have also shown success. For example, the Algebra Project is a constructivist program implemented to better prepare middle school students for high school algebra (Silva \& Moses, 1990; Moses \& Cobb, 2001). The program targeted students as far back as $6^{\text {th }}$ grade. The goal was to provide an opportunity for all students to learn the concepts of algebra, especially urban and minority children, before they entered Algebra 1 .

The Algebra Project provided a solid conceptual transition from addition and multiplication to algebra. It also used a wide variety of familiar physical examples and experiences to help guide conceptual discussion and knowledge building. The curriculum for this project used models and drawings to represent physical objects and observations. The authors helped teachers use the representations to speak conceptually to the students to build students' algebra knowledge and reasoning. Once students understood changing physical occurrences, such as a tree growing taller over time, they translated the concepts into algebraic language through symbolization. Only after this did they attempt problems, procedures, and analysis.

The Algebra Project demonstrated that starting a few years earlier can greatly enhance algebraic knowledge and performance (Smith, 1996; Driscoll, 1999). Children who graduated from this program were more knowledgeable in algebra than their counterparts and were more likely to enroll in higher level mathematics courses in high school and beyond (Smith, 1996; Silva \& Moses, 1990; Moses \& Cobb, 2001). Smith 
(1996) also investigated the students who were able to take an algebra course before entering high school. Her research demonstrated that these students had increased algebra knowledge, were more likely to take advanced courses, and had increased overall achievement in high school.

A line of research that aims to use computerized cognitive tutors to help students learn the concepts of mathematics has also been applied to algebra (Anderson, Corbett, Koedinger, \& Pelletier, 1995; Koedinger \& MacLaren, 2002). Corbett and colleagues (2001) built a cognitive tutor, called the Algebra I Cognitive Tutor, to be used with students in high school or upper middle school. Koedinger and colleagues also built an algebra tutor for the Pittsburgh Urban Mathematics Project (PUMP), called PAT (Corbett, Koedinger, \& Hadley, 2001; Koedinger, Anderson, Hadley, \& Mark, 1997). These tutors use the same interactive, concept-based problem solving environment to help students to reason using algebra. The programs used familiar concepts to learn new concepts and problem solving strategies in algebra. For example, the programs helped students use their existing knowledge in arithmetic to make generalizations using algebraic patterns and symbols.

Koedinger and Anderson (1998) demonstrated the effectiveness of the Algebra I Cognitive Tutor during a summer tutoring program for high school students who had recently taken an algebra course. The cognitive tutor was used for three or four days for two hours a day. Thirty students participated in the study and were randomly assigned to one of three conditions. Each condition used the tutor, but the tutor ran the problems in different orders. The textbook condition presented concepts in the same order as the textbook. The traditional conditional presented the concepts corresponding to traditional 
algebra. The inductive condition had the problems in order so their concepts started from the most fundamental and built upwards. Each student took a 30-minute test consisting of eight items before using the tutor and again after their experience with the tutor. All students had significant gains in learning within a short period of time. Their post-tests were significantly higher, $F(1,29)=9.7, p<.005$. The inductive group had the largest gains in performance $F(1,17)=4.4, p<.05$. On the eight item algebra test with a scoring metric that yielded the highest possible score at 26 , the inductive group on average gained 3.4 points from pre- to post-course compared to 2.4 and 0.6 from the traditional and textbook conditions, respectively.

Koedinger and colleagues (1997) demonstrated the effectiveness of PAT in a year-long study in Pittsburgh Public High Schools. PAT focused on real world problems to which algebra is critical. PAT was similar to the Algebra I Cognitive Tutor (Koedinger \& Anderson, 1998), but was designed specifically to coincide with the PUMP curriculum. The PUMP curriculum was designed to help students learn graphing, modeling, and functioning. It emphasized group work and creating charts and graphs. The PUMP curriculum also had students complete reports and share results via presentation to the class. PAT was aligned to this program by supporting group work and creating graphs. PAT's designers also used teachers' input to help make its problem solving tasks culturally and personally relevant to students. Teachers of 20 PUMP classes with a total of 470 students across three schools used the PAT. These students were compared to 120 students from five traditional classes within the same schools. The students with the PUMP curriculum combined with the tutor scored significantly higher on the Iowa Algebra Aptitude test, $F(2,398)=17.0, p<.0001$, and on two author created 
tests: the Problem Situation Test, designed to measure verbally presented situation problems with algebraic content, $\mathrm{F}(2,186)=5.3, \mathrm{p}<.01$, and the Representations Test, designed to test students' ability to translate various forms of algebraic representation, $\mathrm{F}(2,183)=13.4, \mathrm{p}<.0001$. The two author-created tests were made to assess NCTM recommended algebra skills and concepts (Koedinger et al., 1997). Students in the control condition averaged $52 \%(S D=19 \%)$ on the Iowa Algebra Aptitude test, $39 \%$ $(S D=33 \%)$ on the Problem Situation test, and $37 \%(S D=32 \%)$ on the Representations Test, compared to the control group's $46 \%(S D=17 \%), 22 \%(S D=22 \%)$, and $15 \%$ $(S D=18 \%)$, respectively.

\section{Algebra Research in Elementary Grades}

The algebra programs in middle school have shown positive effects, but were never fully expanded to investigate students' algebra knowledge before $6^{\text {th }}$ grade. Few research projects or programs have attempted to teach algebra in grades earlier that $6^{\text {th }}$. There is less evidence demonstrating the impact of students' learning algebra in elementary grades. Studies that have been performed around elementary algebra were discussed above (see Algebra Can Help Structure Students' Mathematics Knowledge). Most of those studies were performed in one class or a handful of classes. Many only provided qualitative evidence of findings. Most of the studies focused on evidence of student's learning and using algebra in elementary grades. They did not fully explore the impact that knowing algebra in these grades can have on later learning.

For example, Suh and Moyer (2007) showed that students in elementary school can learn and improve on formal algebraic problems using representational thinking. Their study included two groups of $3^{\text {rd }}$ grade students. The students performed a one 
week unit around representing relational thinking using algebra. Some students performed the unit using physical manipulatives and some performed the unit with a virtual program. Students explored how to create algebraic models of problems to informally represent how they were thinking about the problems. For example, students would place a random amount of cubes on two sides of a balance and use an 'unknown' pawn piece to represent the amount that was needed to balance the equation. Students could then use manipulatives to reason how many blocks the pawn represented. They would also translate the physical amounts into a numeric representation and attempt to solve the problems with equations. Additionally, they would attempt to verbally state the concepts and problem strategies. The problems also included multiplication and required complex balancing with different sized weights. An example problem with multiplication was ${ }^{\circ} 4 \mathrm{x}+5=\mathrm{x}+8$ '.

After completing the unit, students showed significant gains on an algebraic assessment. The assessment contained eighteen items including pictorial, symbolic, and word problems. Both the physical manipulatives and virtual groups demonstrated significant gains. Students also showed gains in representational fluency using manipulatives and symbols. Both groups demonstrated problem solving strategies that included pictorial representations to illustrate the problem. Both groups were also able to translate these representations into algebraic notation when solving problems. This study demonstrated that students as early as $3^{\text {rd }}$ grade can learn to represent quantities and solve for unknowns using algebraic representation and relational thinking. It also demonstrates that these students can use this knowledge to improve performance on formal algebraic problems. It is also of note that the improvement occurred in only one week. 
Further research around algebra in elementary grades has support from many educators, policy makers, and researchers alike, but researchers such as Mason (2008) have cautioned that showing an overall impact of early algebra may be difficult. Mason (2008) discusses how the difficulty in garnering evidence around the impact of algebra has to do with the nature of algebra itself. He states that "the difficulty with demanding evidence is that expressing generalities is not a strategy to be used and tested, but a holistic approach to mathematics" (p. 86). Nonetheless some studies have attempted to show how early algebra can impact students mathematics performance.

One study that demonstrated the impact of early algebra knowledge was performed by Kaput and Blanton (2001). Kaput and Blanton (2001) performed a threeyear study in one district that was taking steps toward integrating algebra earlier in education. The district was underachieving and had a large percentage of students with low socioeconomic status (SES) (Kaput, 1999). In their 2001 study, they analyzed the impact of a professional development program, led by the authors, which focused on integrating their ideas about algebraic reasoning into the classroom. The authors worked with teachers in the district to help them understand how algebra was embedded in their curriculum and how they could get students thinking algebraically. Over the course of the year, the authors found that one of the three trained teachers was truly supporting algebraic thinking and her students showed evidence of creating generalizations (Blanton \& Kaput, 2003).

Kaput and Blanton (2001) tested fourteen students from this $3^{\text {rd }}$ grade teacher's class. Her students were tested on sixteen items selected from the previous year's $4^{\text {th }}$ grade state standardized mathematics tests, the Massachusetts Comprehensive 
Assessment System. The items tested a variety of standards and concepts with seven items being algebraic in nature. The experimental group of students performed better than a control classroom of sixteen students on eleven of the sixteen items with four reaching significance (at alpha $=.05$ ). They also outperformed the previous year's $4^{\text {th }}$ grade students from the same district and performed equivalently to the statewide population of $4^{\text {th }}$ grade students.

\section{The Gap in Algebra Research}

Large scale mathematics programs have often focused on how students' mastery of algebra concepts benefits middle school students. These programs have shown success, but they have not extended their research into elementary grades. For example, the Algebra Project and $\mathrm{T}^{2} \mathrm{~A}$ have shown short and long term success helping teachers and students recognize and apply algebra concepts in $6^{\text {th }}$ grade and higher. Student impact has been found in these grades, but only for students transitioning to high school or advanced algebra courses.

No large scale studies have been done to demonstrate the longitudinal impact of learning fundamental algebraic concepts in early elementary education. Despite the strong research that has been done around demonstrating that algebra can be used in the elementary classroom, there is a dearth of research about the long term effects of knowing or learning algebra in $1^{\text {st }}$ through $5^{\text {th }}$ grade.

The Common Core State Standards in mathematics have been adopted by over 40 of the 50 states. Thus at least 40 states will be aiming to have students in $1^{\text {st }}$ grade begin learning and applying algebra. These students should theoretically have a stronger mathematics trajectory (Fosnot \& Jacob, 2010; RAND Mathematics Study Panel, 2003), 
but no research has explored this trajectory on a large scale. To generate motivation for teaching early algebra, research is needed around the long term impact of early algebra knowledge. Research demonstrating that students who know early algebra concepts have better learning trajectories, for algebra and overall mathematics, could garner further support and excitement for the new Standards around algebra.

Research on the long term results of the Common Core State Standards themselves will have to wait years. Is there a way to better understand how early algebra helps students now? How can researchers examine if students who understand the basics of algebra in early elementary school in fact have better mathematics trajectories?

To answer these questions now, we need to use longitudinal archival data from an area where early algebra has already been included and assessed in all elementary grades. Instead of attempting to implement an expensive and time consuming reform program or waiting to research the impact of the new Standards, researchers can use pre-existing data to better understand if early algebra knowledge predicts long term mathematics performance.

\section{Current Study}

The goal of the current study is to use a large scale, longitudinal set of data to explore the impact of algebra knowledge in early elementary school on later mathematics knowledge. The study is taking place in one district that has included and assessed algebra content in elementary grades for the last five years. The district is within the state of Kentucky, which has had standards that address algebra concepts beginning in $1^{\text {st }}$ grade, as discussed above (see Table 1). The current study utilizes archival longitudinal data collected from this district that follows students from $1^{\text {st }}$ through $5^{\text {th }}$ grade. 
The district has collected mathematics assessments that contain algebraic items during each of the previous five years. They also have archived standardized test scores in mathematics and reading for students in $3^{\text {rd }}$ through $5^{\text {th }}$ grade. This study utilizes the archival data for longitudinal analysis. Using this archival data has some limitations, such as a lack of data around teaching practices that students experienced. Only student and school level data are archived. For example, students' scores and potential moderating demographic information are explored; however, teaching practices and fidelity of curriculum implementation are not used in analyses.

The study explores the level of algebra knowledge students have in $1^{\text {st }}$ through $5^{\text {th }}$ grade. It also explores if their early algebra knowledge predicts later algebra and overall mathematics knowledge. Analysis will determine if students who have higher knowledge of early algebra concepts have higher scores on algebra and overall mathematics assessments in later grades, including state standardized mathematics test scores and district created formative assessments. Analysis will also determine if students with higher algebra knowledge in early grades have higher rates of growth across three years of these assessments. 
Thus this study is guided by the following research questions:

1) Does students' performance on assessment items targeting algebraic thinking in $1^{\text {st }}$ and $2^{\text {nd }}$ grade predict:

a) Performance on a mathematics state standardized assessment in $5^{\text {th }}$ grade?

b) Growth in performance on a mathematics state standardized assessment in $3^{\text {rd }}$ through $5^{\text {th }}$ grade?

c) Performance on district assessment items targeting algebraic thinking in $5^{\text {th }}$ grade?

d) Growth in performance on district assessment items targeting algebraic thinking in $3^{\text {rd }}$ through $5^{\text {th }}$ grade?

e) Performance on district assessment items targeting other areas of mathematics in $5^{\text {th }}$ grade?

f) Growth in performance on district assessment items targeting other areas of mathematics in $3^{\text {rd }}$ through $5^{\text {th }}$ grade? 


\section{METHODS}

\section{Participants}

This study occurred within one large urban Kentucky school district. Participants were students who have completed $1^{\text {st }}$ through $5^{\text {th }}$ grade in these schools. Students were in $1^{\text {st }}$ grade during the $2005-2006$ academic year and completed $5^{\text {th }}$ grade during the 2009-2010 academic year. Students must have attended one school within the district for all five years of the study. Students who moved out or entered in the middle of the study were not included. The exclusion was made to increase the validity of the sample and to eliminate issues with missing data and attrition.

The district has had standards that address early algebra concepts beginning in the $1^{\text {st }}$ grade (see Table 1). The district has assessed algebraic thinking and each other mathematics content areas in every year of the study. The district was able to provide all relevant test scores and demographic information (discussed below) for 1,385 students from 68 schools.

The student demographic variables that were collected are gender and race (see

Table 2). Schools' free and reduced lunch information and curriculum use were also collected (see Table 3).

Gender. Gender was provided for each student as 'male' or 'female' which was dummy coded as ' 0 ' and ' 1 ' respectively.

Race. Race was provided for each student as 'Asian-American/Pacific Islander', 
'African-American', 'Caucasian', 'Hispanic', 'Native American/Alaskan Native', or 'Other/Unknown' (see Table 2).

Table 2

Student Demographics

\begin{tabular}{lcc}
\hline Demographic & Number of Students & Percentage \\
\hline & & \\
Male & 683 & $49.3 \%$ \\
Female & 702 & $50.7 \%$ \\
& & \\
Asian-American/Pacific Islander & 29 & $2.1 \%$ \\
African-American & 466 & $33.6 \%$ \\
Caucasian & 701 & $50.6 \%$ \\
Hispanic & 75 & $5.4 \%$ \\
Native American/Alaskan Native & 1 & $0.1 \%$ \\
Other/Unknown & 113 & $8.2 \%$ \\
\hline
\end{tabular}

Free and reduced lunch (FRL) status. The National School Lunch Program provides free and reduced cost lunches to eligible students (United States Department of Agriculture, 2009). Since eligibility is determined by family income, free and reduced lunch information is often used as a measure for students' or schools' socioeconomic status. This data was not available at the student level due to district confidentiality reasons, so publicly available school level data was used (United States Department of Agriculture, 2011). The percent of students in each school that received free and reduced lunch was used as a school level variable.

Table 3

Percentage of Students Receiving Free and Reduced Lunch

\begin{tabular}{ccccc}
\hline Schools & Mean & S.D. & Minimum & Maximum \\
\hline 68 & $58.6 \%$ & $25.2 \%$ & $12.0 \%$ & $95.0 \%$ \\
\hline
\end{tabular}

Curriculum use. This study considered the impact of curriculum on student outcomes. 
The majority of the 68 schools used the Investigations in Numbers, Data, and Space ${ }^{\circledR}$ curriculum $(n=37)$ exclusively over the last five years. This information was confirmed by the district and by the principal or head of the math department in each school. Investigations in Numbers, Data, and Space is a "complete K-5 mathematics curriculum, developed at TERC in Cambridge, Massachusetts. It is designed to help all children understand fundamental ideas of number and operations, geometry, data, measurement and early algebra" (TERC, 2007). The concepts and content area progressions are parallel to the state standards followed by the district. Using this curriculum may have an additional benefit for students when learning or applying early algebra.

The other 31 school used one of the following: Investigations blended with another curriculum; one other curriculum only; or a blend of other curricula. Other curricula used were: Everyday Mathematics; Math Trailblazers; Harcourt; Houghton Mifflin; Scott Foresman; and McGraw Hill. Thus a dummy variable was created to compare schools who used the Investigations curriculum only, coded as ' 1 ', compared to schools who used other, multiple, or varied curricula, coded as ' 0 '.

Exclusion criteria. This study did not include schools that primarily serve students who are classified as ELL or have an IEP. Ideally, this study would include all students, but being exploratory in nature, the range of participants was limited. These variables could allow for an interesting follow-up study that would be specific to ELL and IEP populations. Twenty-three schools were also excluded because they did not collect and report to the district all measures used in the study.

\section{Measures}

Kentucky Core Content Test. The Kentucky Core Content Test (KCCT) is the largest 
portion of Kentucky's Commonwealth Accountability Testing System (CATS). KCCT assesses student mastery of the state's core content, as well as higher order thinking and communication skills. The KCCT consists of open response items and multiple choice questions. This assessment is given in April to all students in $3^{\text {rd }}$ through $8^{\text {th }}$ grade and $10^{\text {th }}$ and $11^{\text {th }}$ grade. The assessment has separate sections for reading, mathematics, science, social studies, arts and humanities and practical living/vocational studies. Each section is administered independently to students.

The KCCT results are reported as an overall score as well as a performance level for students in the following order: novice low; novice medium; novice high; apprentice low; apprentice medium; apprentice high; proficient; and distinguished (Kentucky Department of Education, 2004). The mathematics section of KCCT is designed to reflect the mathematical content areas in the current Core Content for Assessment guide, which is based around the same five core principles as the CCA: number properties and operations, measurement, geometry, data analysis and probability, and algebraic thinking (Kentucky Department of Education, 2008a; 2008b; 2009). The percentage of items that focus on each of these five domains varies slightly across grade levels and is shown in Table 4 (Kentucky Department of Education, 2010).

Table 4

Percentage of KCCT Items for Each Content Area

\begin{tabular}{lccc}
\hline Content Area & \multicolumn{3}{c}{ Grade Level } \\
\hline & $3^{\text {rd }}$ & $4^{\text {th }}$ & $5^{\text {th }}$ \\
\hline Number Properties and Operations & $40 \%$ & $40 \%$ & $40 \%$ \\
Measurement & $10 \%$ & $10 \%$ & $10 \%$ \\
Geometry & $25 \%$ & $20 \%$ & $20 \%$ \\
Data Analysis and Probability & $10 \%$ & $15 \%$ & $15 \%$ \\
Algebraic Thinking & $15 \%$ & $15 \%$ & $15 \%$ \\
\hline
\end{tabular}


Due to state level archiving procedures, only overall scores for this assessment are available and not item or content level scores. Variables created from this assessment include:

KCCT mathematics ability. This is a measure of students' knowledge of early mathematics across all five content areas using the overall score on the KCCT. This variable was created for each student for $3^{\text {rd }}, 4^{\text {th }}$, and $5^{\text {th }}$ grade.

KCCT reading ability. This is a measure of students' reading ability using the overall reading score on the KCCT. The reading section of KCCT is designed to reflect the reading standards in the current Core Content for Assessment guide, which is based around five core principles areas: forming a foundation for reading, developing an initial understanding, interpreting text, reflecting and responding to text, and demonstrating a critical stance (Kentucky Department of Education, 2006). This variable was created for each student for $3^{\text {rd }}, 4^{\text {th }}$, and $5^{\text {th }}$ grade.

The scores reported out to students on these assessments are only categorical and range from 'novice' to 'distinguished'. These KCCT categories are based on a nationally normed continuous scale that ranges from 325 to 800 . From the nationally normed data, a scale is created called the "Kentucky metric" that transform Kentucky students' data into a scale ranging from 0 to 80 (see Sinclair, Bynum, Thacker, \& Hoffman, 2008). The Kentucky Department of Education uses the Kentucky metric to create cutoff scores for its eight categories into which students can fall. For the current study, the district was able to provide to Kentucky metric score for each student on each assessment (descriptive statistics are shown in Table 9).

Core Content Assessments. Core Content Assessments (CCA) are a tool used by the 
district to monitor schools' progress in keeping students' learning trajectories in line with the state standards. The CCA are formative assessments used to help schools and teachers track students' progress throughout the year. They were created when the state recommended that districts track student performance in the same areas tested by KCCT. Instead of assessing students once a year starting in $3^{\text {rd }}$ grade, these assessments start in $1^{\text {st }}$ grade and occur several times throughout each year. They were created as part of a school improvement plan where principles have to set goals and show student progress on standards. Schools are not mandated to implement the CCA, but can find other ways to demonstrate and report on student's progress; however, the CCAs are encouraged by the superintendent and the majority of the schools have used CCA regularly since they were created.

For mathematics testing, the district supports schools and teachers choosing to implement the CCA by creating and providing full assessments and an open bank of items that can be used by teachers. Teachers can use the premade assessments, the item bank, work with district specialists, or create items on their own to assess students' progress on the standards. During the first two years of the study when the CCA were newer, teachers used predominantly the district premade assessments. During the first year, $85.5 \%$ of the items used came from district premade assessments, and $90.9 \%$ during the second year. During the $3^{\text {rd }}, 4^{\text {th }}$, and $5^{\text {th }}$ year of the study, teachers implemented a similar amount of district premade assessments, but also administered many additional assessments. Thus the percent of items from district premade assessments was lower in these grades $(73.3 \%, 39.6 \%$, and $55.0 \%$, respectively).

In the current study, district premade assessments and teacher created assessments 
were included. District premade assessments were included since the majority of students received these assessments and they were created by district specialists to target the standards on which the students were supposed to be progressing. The teacher created assessments were also included since these may have been an even better gauge of students' knowledge around the concepts they were currently learning. Researchers such as Stiggins and Marzano have thoroughly explained how teacher created informal assessments can be accurately used to gauge students' current knowledge around specific topics (Stiggins, Arter, Chappuis, \& Chappuis, 2009; Stiggins, 2005; Marzano, 2006). These assessments are more likely to match the exact content that students have been learning since all classrooms and students do not progress at the same pace. Teachers can also use these assessments for instant feedback on their teaching to identify on which concepts the students need more work (see Stiggins et al., 2009). Thus both forms of CCA were used to have the most inclusive and accurate data on each student.

Core Content Assessments for mathematics consist of a blend of multiple choice and open response questions. The open ended questions are composed of multiple components and designed so students can score up to 4 points. Thus students' scores range from 0 to 4 on these items. Multiple choice items are worth 1 point for a correct response and 0 for an incorrect response. Thus the open ended responses are weighted more heavily, but the majority of items given to students are multiple choice (see Table $5)$. 
Table 5

Types of CCA Items

\begin{tabular}{lcc}
\hline Grade & Multiple Choice Items & Open Ended Items \\
\hline $1^{\text {st }}$ & $79.6 \%$ & $20.4 \%$ \\
$2^{\text {nd }}$ & $81.1 \%$ & $18.9 \%$ \\
$3^{\text {rd }}$ & $82.3 \%$ & $17.7 \%$ \\
$4^{\text {th }}$ & $84.6 \%$ & $15.4 \%$ \\
$5^{\text {th }}$ & $84.7 \%$ & $15.3 \%$ \\
\hline
\end{tabular}

Each question is designed to target specific standards. When the item and answer are reported, teachers must select the exact standard that the item was created to assess. The targeted standard for each item is reported along with each student's answer. With this reporting system, the mathematics CCAs can specifically reflect progress on the mathematical concepts in the state's Core Content for Assessment Guide for each grade (Kentucky Department of Education, 2008b; 2009). For example, the tests in $1^{\text {st }}$ through $5^{\text {th }}$ grade are comprised of questions from the five core principles, or big ideas, found in the mathematics Core Content for Assessment Guide for primary grades: number properties and operations, measurement, geometry, analysis and probability, and algebraic thinking. The percentages of total items given to students that targeted standards in each mathematics content area are shown in Table 6. 
Table 6

Percentage of CCA Mathematics Items Targeting Each Content Area

\begin{tabular}{lccccccc}
\hline & \multicolumn{3}{c}{$\begin{array}{c}\text { Average } \\
\text { Items } \\
\text { per }\end{array}$} & $\begin{array}{c}\text { Number } \\
\text { Properties } \\
\text { and }\end{array}$ & $\begin{array}{c}\text { Measure- } \\
\text { ment }\end{array}$ & Geometry & $\begin{array}{c}\text { Data } \\
\text { Analysis } \\
\text { and }\end{array}$ \\
Prade & Items & Student & Algebraility & Thinking \\
\hline $1^{\text {st }}$ & 25,412 & 18.3 & $48.5 \%$ & $11.6 \%$ & $25.5 \%$ & $9.8 \%$ & $4.6 \%$ \\
$2^{\text {nd }}$ & 52,465 & 37.9 & $51.4 \%$ & $13.5 \%$ & $12.7 \%$ & $12.1 \%$ & $10.4 \%$ \\
$3^{\text {rd }}$ & 49,764 & 35.9 & $57.6 \%$ & $8.2 \%$ & $13.5 \%$ & $6.1 \%$ & $14.6 \%$ \\
$4^{\text {th }}$ & 50,430 & 36.4 & $54.4 \%$ & $11.7 \%$ & $13.4 \%$ & $14.3 \%$ & $6.3 \%$ \\
$5^{\text {th }}$ & 42,131 & 30.4 & $63.9 \%$ & $9.8 \%$ & $17.4 \%$ & $5.5 \%$ & $3.4 \%$ \\
\hline
\end{tabular}

Items also receive more specific labels of components within each content area.

These components, including those within algebraic thinking, also reflect the state's Core

Content for Assessment guide (Kentucky Department of Education, 2008b; 2009). There

are three components of algebra thinking: patterns, relations and functions; variables,

expressions and operations; and equations and inequalities. Table 7 shows the percentage

of algebraic thinking items that teachers used that correspond to each component.

Appendix A also shows the breakdown into components of the other mathematics content areas.

Table 7

Percentage of CCA Algebraic Thinking Items Targeting Each Component of Algebra

\begin{tabular}{lccc}
\hline Grade & $\begin{array}{c}\text { Patterns, Relations } \\
\text { and Functions }\end{array}$ & $\begin{array}{c}\text { Variables, Expressions } \\
\text { and Operations }\end{array}$ & $\begin{array}{c}\text { Equations and } \\
\text { Inequalities }\end{array}$ \\
\hline $1^{\text {st }}$ & $97.1 \%$ & $0.0 \%$ & $2.9 \%$ \\
$2^{\text {nd }}$ & $79.1 \%$ & $0.0 \%$ & $20.9 \%$ \\
$3^{\text {rd }}$ & $77.6 \%$ & $0.1 \%$ & $22.4 \%$ \\
$4^{\text {th }}$ & $80.5 \%$ & $2.0 \%$ & $17.5 \%$ \\
$5^{\text {th }}$ & $61.7 \%$ & $21.8 \%$ & $16.5 \%$ \\
\hline
\end{tabular}

Scores for the CCAs are available on an item level. Thus overall scores for each 
assessment were computed, as well as scores for each of the big ideas, or content areas, being targeted, including algebraic thinking. Students' scores in each area were computed using the total points earned divided by the total possible points. This provided a percent correct for each assessment and content area. These scores were calculated separately for each grade. The exception was $1^{\text {st }}$ and $2^{\text {nd }}$ grade, which were combined for practical and statistical reason described in Data Selection and Compilation below. Thus each knowledge score for CCAs will range between $0 \%$ and $100 \%$. Descriptive statistics are provided in Table 8 and Table 9.

Thus the variables produced from the CCA were:

CCA algebraic thinking knowledge. This is a measure of students' knowledge of early algebra created by using the items that target algebra standards on the CCA.

CCA general mathematics knowledge. This is a measure of students' knowledge of early mathematics outside the algebra content area created by using the rest of the items on the CCA. This composite score was also broken into its components:

CCA number properties and operations knowledge. Knowledge of this content area created by using the items that target the corresponding standards on the CCA.

CCA data analysis and probability knowledge. Knowledge of this content area created by using the items that target corresponding standards on the CCA. CCA measurement knowledge. Knowledge of this content area created by using the items that target corresponding standards on the CCA. CCA geometry knowledge. Knowledge of this content area created by using the items that target corresponding standards on the CCA. 


\section{Procedures}

Data selection and compilation. The participating district had previously collected all data used in the study. The researcher worked with the district to identify what pieces of data were needed for the study and to determine what was available and accessible to use. The district was able to provide the overall KCCT scores, student demographic and school information, and item level data for the CCA. The district initially emailed the data to the researcher in the form of excel files using coded student and school ID numbers for confidentiality. One file contained all the KCCT data for all students, $3^{\text {rd }}$ through $5^{\text {th }}$ grade. For the CCA, one excel file was sent for each grade that contained one line for every CCA item that was administered. Each line identified the student, the school, the student's grade level, the student's gender, the student's race, they type of question (multiple choice or open ended), the targeted standard, and the student's score on the item.

The researcher was responsible for cleaning and compiling all data into one cohesive dataset. Once datasets were built that contained all of the data for each student as it was provided by the district, the researcher had to compile item level CCA information and scores into grade level information and scores. For example, to compute students' CCA algebraic thinking knowledge for a grade, the researcher computed points earned across all algebraic thinking items that year and divided it by total points possible on those items. The researcher performed these calculations for each content area in each grade and calculated the CCA general mathematics knowledge score, as described above. The researcher also compiled summative information on how many items in each grade level were given to each student. The researcher then checked frequencies and 
distributions on the data to ensure there were no outliers or significant skewing and kurtosis. Appropriate data cleaning was then performed.

After preliminary analysis, data from $1^{\text {st }}$ and $2^{\text {nd }}$ grade were merged to form knowledge variables for these early grades. Data in $1^{\text {st }}$ grade was much more limited in amount and variation among standards. For example, in the $1^{\text {st }}$ grade, the CCA algebraic thinking knowledge items consist of almost entirely patterns, relations, and functions (>97\%; see Table 7). Students in $1^{\text {st }}$ grade only had, on average, half as many items administered compared to the other grades (see Table 6). These differences were in part due to the newness of the CCA during that year. If the CCAs are being used in slightly different manners in these grades, looking at growth from $1^{\text {st }}$ to $2^{\text {nd }}$ grade would not be as meaningful as overall knowledge of the standards being assessed across the two grades. Another reason $1^{\text {st }}$ and $2^{\text {nd }}$ grade scores were combined is that the KCCT are given in $3^{\text {rd }}$, $4^{\text {th }}$, and $5^{\text {th }}$ grade. This may have contributed to spike in teacher created assessments during these years. It also means that teachers may view the purpose of the CCA assessments differently these years. They may have seen them as preparation for the KCCT. This led to the decision that $1^{\text {st }}$ and $2^{\text {nd }}$ grade should be treated separately from the other grades as a predictor of growth within those grades $\left(3^{\text {rd }}\right.$ through $5^{\text {th }}$ grade).

\section{Data Analysis}

Five years of student data were analyzed. Students were in the $1^{\text {st }}$ grade during the first year of the study and had data collected through the $5^{\text {th }}$ grade. Descriptive analyses were performed to determine the means and standard deviations of each student variable in the study. These analyses revealed baseline data on how well students performed on algebra and other sections of each assessment in each grade and the variation within their 
performance. Analyses were also performed around demographic and other student level variables to reveal contextual trends across the mathematics scores within the district. Students' mathematics scores were compared against their race and gender using analyses of variance. Their mathematics scores were also compared to their KCCT reading ability and schools' percentage of free and reduced lunch status using correlation analyses to see if the variables were related.

The subsequent analyses were geared directly towards answering the research questions, as stated above:

1) Does students' performance on assessment items targeting algebraic thinking in $1^{\text {st }}$ and $2^{\text {nd }}$ grade predict:

a) Performance on a mathematics state standardized assessment in $5^{\text {th }}$ grade?

b) Growth in performance on a mathematics state standardized assessment in $3^{\text {rd }}$ through $5^{\text {th }}$ grade?

c) Performance on district assessment items targeting algebraic thinking in $5^{\text {th }}$ grade?

d) Growth in performance on district assessment items targeting algebraic thinking in $3^{\text {rd }}$ through $5^{\text {th }}$ grade?

e) Performance on district assessment items targeting other areas of mathematics in $5^{\text {th }}$ grade?

f) Growth in performance on district assessment items targeting other areas of mathematics in $3^{\text {rd }}$ through $5^{\text {th }}$ grade?

Hierarchical linear modeling (HLM). Hierarchical linear modeling (HLM) was chosen as the primary means for analysis to answer the above research questions. HLM was 
created to test models with nested data. In the current study, students were nested within school. This means that average students' scores and trajectories were expected to vary across the range of schools due to school factors such as leadership, emphasized teaching styles and practices, and characteristics associated with socioeconomic status, such as resources and community factors in which the school is located (Sameroff, Bartko, Baldwin, \& Seifer, 1998; Caldas \& Bankston, 1997; Greenwald \& Hedges; 1996). Hierarchical linear modeling can also have advantages for addressing missing data in longitudinal analyses. HLM uses an estimation-maximization algorithm (Little \& Rubin, 2002; Raudenbush \& Bryk, 2002) to estimate missing data points on the outcome level in longitudinal analysis to create the best fitting points and slope considering the within and between subject variance around missing data (Snijders, 1996).

Hierarchical linear modeling can be used to perform longitudinal modeling, which was necessary for the current study. Hierarchical linear modeling was performed to analyze the relationship of students' CCA algebraic thinking knowledge in $1^{\text {st }}$ and $2^{\text {nd }}$ grade to their KCCT mathematics ability, CCA algebraic thinking knowledge, and CCA general mathematics knowledge in $5^{\text {th }}$ grade and their growth from $3^{\text {rd }}$ through $5^{\text {th }}$ grade. In longitudinal models such as those in the current study, hierarchical linear modeling provides coefficients that reveal which predictors are significantly related to students performance at one point in time (intercept of the model) and which are significantly related to students rate of learning over time (slope of the model). The current study will determine if students algebra knowledge in $1^{\text {st }}$ and $2^{\text {nd }}$ grade significantly predicts both students performance in $5^{\text {th }}$ grade (intercept) as well as growth in learning from $3^{\text {rd }}$ through $5^{\text {th }}$ grade (slope). 
HLM model 1. The first hierarchical linear model analyzed how students' CCA algebraic thinking knowledge in $1^{\text {st }}$ and $2^{\text {nd }}$ grade predicted students' KCCT mathematics ability in $5^{\text {th }}$ grade (intercept) and growth in KCCT mathematics ability across $3^{\text {rd }}$ through $5^{\text {th }}$ grade (slope). The HLM was longitudinal and included three levels.

Level 1 of the HLM model was longitudinal including students' KCCT mathematics ability scores in $3^{\text {rd }}$ through $5^{\text {th }}$ grade as the outcome measure. To analyze changes in these scores over time, a 'time' variable was created that marked whether each student's score was from $3^{\text {rd }}, 4^{\text {th }}$, or $5^{\text {th }}$ grade. This time variable was also formatted so the prediction line had an intercept that represented students' $5^{\text {th }}$ grade score. The time variable labeled $3^{\text {rd }}$ grade scores as ' -2 ', $4^{\text {th }}$ grade scores as ' -1 ', and $5^{\text {th }}$ grade scores as ' 0 '. Thus the intercept was students' predicted score at time ' 0 ', or in the $5^{\text {th }}$ grade. The slope, or change over time, predicted students' change in mathematics knowledge from $3^{\text {rd }}$ through $5^{\text {th }}$ grade.

Level 2 of the HLM model included student-level information. This level included students' gender, race, KCCT $3^{\text {rd }}$ grade reading ability, and all CCA knowledge scores from $1^{\text {st }}$ and $2^{\text {nd }}$ grade. Students' CCA knowledge scores included their score for algebraic thinking and general mathematics knowledge. Students' knowledge scores for each content area within general mathematics knowledge (number properties and operations, data analysis and probability, measurement, and geometry) were also included for post-hoc analysis.

Level 3 of the HLM model accounted for students' being nested within school. This level included which school students attended to account for school level variance. It also included the schools' percentage of students receiving free and reduced lunch (FRL), 
to control for schools' differences due to their populations' socioeconomic status. Level 3 also included the schools' curriculum information, as discussed above, to check for potential differences in student performance for schools that used Investigations in Number, Data, and Space. The effect the school level variables were explored on the outcome variables in level 1 . The impact of level 2 variables were not predicted to be dependent on school context. Thus the included school level variables were only included in predicting students' outcome, on both their trajectory and intercept ( $5^{\text {th }}$ grade scores), and were not used for interaction effects.

The strongest predictors for both the slope and the intercept of the model were predicted to be students' CCA general mathematics knowledge and KCCT reading ability. Students with initial strong mathematics knowledge were predicted to stay strong and to grow across each grade. Students who showed higher academic ability through their reading score should have strong mathematics knowledge and growth. Student gender and school level curriculum were predicted to have little to no effect, but were explored against the slope and intercept of the model. School level SES (FRL) was predicted to have a negative effect. Schools with a higher percentage of free and reduced lunch students were predicted to be lower performing and have lower trajectories in KCCT mathematics ability.

Students' CCA algebraic thinking knowledge was predicted to be a positive predictor for both intercept and slope in this model. Even after controlling for CCA general mathematics knowledge and KCCT reading ability, students' early CCA algebraic thinking knowledge was hypothesized to predict students' growth in KCCT mathematic ability across $3^{\text {rd }}$ through $5^{\text {th }}$ grade and to predict higher scores in $5^{\text {th }}$ grade. 
HLM model 2. The second HLM model analyzed how students' CCA algebraic thinking knowledge in $1^{\text {st }}$ and $2^{\text {nd }}$ grade predicted students' CCA algebraic thinking knowledge in $5^{\text {th }}$ grade (intercept) and growth in CCA algebraic thinking knowledge across $3^{\text {rd }}$ through $5^{\text {th }}$ grade (slope).

The hierarchical linear model was again longitudinal and included three levels. With one exception, all variables were identical to $H L M$ model 1 . The only difference was the outcome variable. Instead of students' KCCT mathematics ability in $3^{\text {rd }}$ through $5^{\text {th }}$ grade, CCA algebraic thinking knowledge was used.

Students' CCA general mathematics knowledge and their KCCT reading ability were hypothesized to be significant predictors for both the slope and the intercept of the model. Students with initial strong CCA algebraic thinking knowledge and CCA general mathematics knowledge were predicted to stay strong and to grow across each grade. Students who showed higher academic ability through their KCCT reading ability should also have strong CCA algebraic thinking knowledge and growth. Student gender and school level curriculum were predicted to have little to no effect, but were explored against the slope and intercept of the model. School level SES was predicted to have a negative effect. Schools with a higher percentage of free and reduced lunch students were predicted to be lower performing and have lower trajectories in CCA algebraic thinking knowledge.

Students' CCA algebraic thinking knowledge was hypothesized to be a positive predictor for both intercept and slope in this model. Even after controlling for CCA general mathematics knowledge and KCCT reading ability, students' early CCA algebraic thinking knowledge was predicted to help students learn higher level algebra 
concepts across $3^{\text {rd }}$ through $5^{\text {th }}$ grade.

HLM model 3. The last HLM model analyzed how students' CCA algebraic thinking knowledge in $1^{\text {st }}$ and $2^{\text {nd }}$ grade predicted students' CCA general mathematics knowledge in $5^{\text {th }}$ grade (intercept) and growth in CCA general mathematics knowledge across $3^{\text {rd }}$ through $5^{\text {th }}$ grade (slope).

The hierarchical linear model was again longitudinal and included three levels. With one exception, all variables were identical to HLM model 1 . The only difference was the outcome variable. Instead of students' KCCT mathematics ability scores in $3^{\text {rd }}$ through $5^{\text {th }}$ grade, students' CCA general knowledge scores were used.

When analyzing students' later CCA general mathematics knowledge, the strongest predictors for both the slope and the intercept of the model were predicted to be students' early CCA general mathematics knowledge and their KCCT reading ability. Students with initial strong mathematics knowledge were predicted to stay strong and to grow across each grade. Students who showed higher academic ability through their reading scores should also have strong mathematics knowledge and growth. Student gender and school level curriculum were predicted to have little to no effect, but were explored against the slope and intercept of the model. School level FRL was predicted to have a negative effect. Schools with a higher percentage of free and reduced lunch students were predicted to be lower performing and have lower trajectories in CCA general mathematics knowledge.

Students' CCA algebraic thinking knowledge was predicted to be a positive predictor for both intercept and slope in this model. Even after controlling for CCA general mathematics knowledge and KCCT reading ability, students' CCA algebraic 
thinking knowledge was predicted to boost students' growth in CCA general mathematics knowledge across $3^{\text {rd }}$ through $5^{\text {th }}$ grade and to predict higher scores in $5^{\text {th }}$ grade. HLM analysis. The first step to analyzing these models was to determine the intraclass correlation of the null model, or unconditional model. The null model was a model that only includes the outcome, or level 1, variables and the student- and school level identifiers. The intraclass correlation "is the proportion of variation that is between groups" (Scientific Software International, 2010b, p. 1). In this analysis, the null model showed the proportion of variation in the outcome variables that was accounted for by the level of nesting, in this case the school level. This intraclass correlation was calculated after retrieving the sigma squared and the tau coefficient from the null model. In the null model, sigma squared $\left(\sigma^{2}\right)$ was the total variance in outcomes within schools that can be explained by the level 1 variables while tau $\left(\tau_{00}\right)$ was the total explainable variation at the school level. Intraclass correlation was then calculated using the equation $\tau_{00} /\left(\tau_{00}+\sigma^{2}\right)$. If the school level variability was greater than 5\%, then HLM analysis was warranted (Scientific Software International, 2010a).

If HLM was warranted, the next step was to determine which variables removed deviance from the null model. The deviance "can be regarded as a measure of lack of fit between model and data. In general, the larger the deviance, the poorer the fit to the data." (Scientific Software International, 2010b, p. 1). In order to have the most robust and accurate model to explain your outcome, variables that do not alleviate deviance in the model can be considered superfluous and can be excluded from the final model (Scientific Software International, 2010b; McCoach \& Black, 2008). Once level 2 and level 3 variables were checked for eliminating deviance, the final models were 
determined, run, and interpreted. Each model contained an intercept and a slope. Analysis of the intercept demonstrated which variables significant predicted students' scores on the included outcome measure in $5^{\text {th }}$ grade. Analysis of the slope demonstrated which variables significant predicted students' rate of growth on the included outcome measure in $5^{\text {th }}$ grade. Both analyses were of interest to determine if algebra could support students' longitudinal performance and well as their rate of growth across time.

Attrition. Due to the archival nature of the study, attrition was controlled by only including students who have attended one school within the district for all five years of the study. Students who moved out or entered the district in the middle years of the study were not included. This was to increase the validity of the sample and to eliminate issues normally associated with missing data and attrition.

Missing data. The problems created by missing data were accounted for in two ways in this study. First, CCA scores were aggregated for each overall year, and early grades $\left(1^{\text {st }}\right.$ and $2^{\text {nd }}$ ) were aggregated together. This allows for students who had not completed the same amount of CCA to still have a valid average using the assessments they have taken. However, students needed to have all level 2 data, which included CCA assessments that consisted of items on each of the five mathematics content areas across $1^{\text {st }}$ and $2^{\text {nd }}$ grade. Second, hierarchical linear modeling (HLM) also helped to account for missing outcome level data, as described above.

Power analysis. The study had 68 schools participate with an average student sample of 20 students. The power analysis on this population used a clustered (by school) and longitudinal design. To estimate power, Optimal Design was used to calculate the minimal detectable effect size based on our model and population. Under the clustered 
repeated measures setting of Optimal Design, the parameters were set to the minimum detectable effect size (MDES) assuming a two-tailed test $($ alpha $=.05)$ and power at 0.80 .

The MDES estimates ranged from 0.22 when the ICC $=0.05$ to 0.26 when the estimated ICC is increased to 0.10 (see Figure 1). Using Cohen's (1988) commonly applied criteria, these numbers suggested that the study was powered to detect small to medium effects while being calculated conservatively. A two-tailed alpha was used when predictions indicate an increase in student performance. These power calculations suggested that the study was sufficiently powered for its intended purpose.

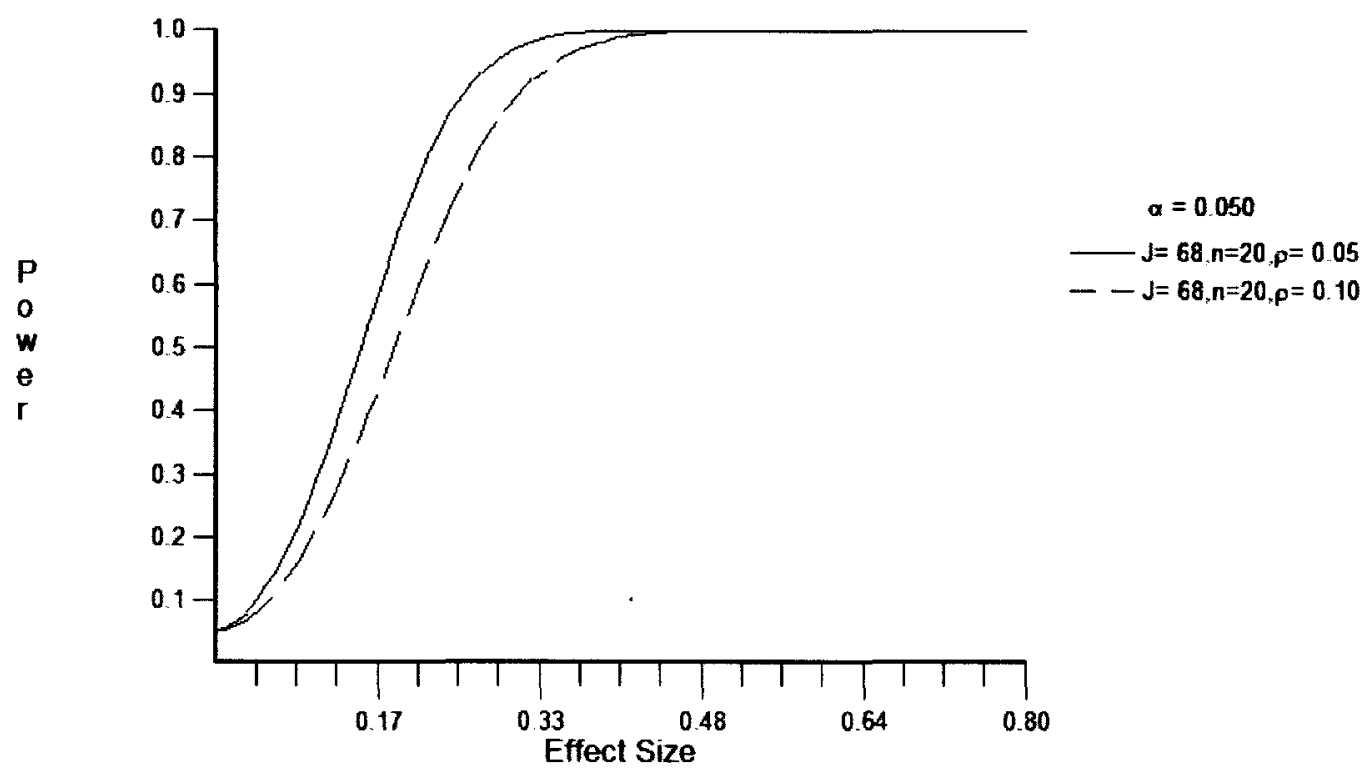

Figure 1. Estimating MDES through a power versus effect size analysis. 


\section{RESULTS}

Before addressing the main research questions, descriptive analyses were completed to show how students performed on each measure. Students showed a wide range of knowledge and ability in each mathematics content area from $1^{\text {st }}$ through $5^{\text {th }}$ grade (see Tables 8 and 9).

Table 8

Students' Mean Performance across $I^{\text {st }}$ and $2^{\text {nd }}$ Grade

\begin{tabular}{lcc}
\hline \multicolumn{3}{c}{ Core Content Assessments } \\
\hline \multirow{3}{*}{ Algebraic Thinking } & Mean & S.D. \\
& $77.93 \%$ & $25.72 \%$ \\
General Mathematics & & \\
Number Properties and Operations & $76.45 \%$ & $16.33 \%$ \\
Measurement & $71.80 \%$ & $18.40 \%$ \\
Geometry & $73.14 \%$ & $26.07 \%$ \\
Data Analysis and Probability & $85.57 \%$ & $16.61 \%$ \\
\hline
\end{tabular}


Table 9

Students' Mean Performance in $3^{\text {rd }}, 4^{\text {th }}$, and $5^{\text {th }}$ Grade

\begin{tabular}{lcccccc}
\hline & \multicolumn{3}{c}{$3^{\text {rd }}$ Grade } & $4^{\text {th }}$ Grade & \multicolumn{2}{c}{$5^{\text {th }}$ Grade } \\
\cline { 2 - 7 } & Mean & S.D. & Mean & S.D. & Mean & S.D. \\
Mathematics & 54.65 & 21.85 & 52.21 & 22.11 & 48.29 & 22.66 \\
Reading & 51.73 & 19.55 & 50.36 & 19.78 & 50.06 & 19.31 \\
& \multicolumn{5}{c}{ Core Content Assessments } \\
& Mean & S.D. & Mean & S.D. & Mean & S.D. \\
& $71.83 \%$ & $24.11 \%$ & $74.82 \%$ & $28.17 \%$ & $66.92 \%$ & $38.02 \%$ \\
Algebraic Thinking & & & & & & \\
& $73.93 \%$ & $17.50 \%$ & $64.01 \%$ & $20.97 \%$ & $68.46 \%$ & $19.53 \%$ \\
General Mathematics & $72.37 \%$ & $18.17 \%$ & $67.09 \%$ & $19.70 \%$ & $71.29 \%$ & $18.57 \%$ \\
Number Properties and & $81.22 \%$ & $25.12 \%$ & $61.34 \%$ & $28.03 \%$ & $68.78 \%$ & $26.56 \%$ \\
Operations & $77.31 \%$ & $22.24 \%$ & $64.62 \%$ & $33.38 \%$ & $65.96 \%$ & $29.23 \%$ \\
Measurement & $66.16 \%$ & $26.05 \%$ & $62.29 \%$ & $24.37 \%$ & $70.37 \%$ & $34.04 \%$ \\
Geometry & & & & &
\end{tabular}

\section{Demographic Analyses}

Before addressing the main research questions, analyses were performed around the demographic variables that the district was able to provide. These demographic analyses added important contextual information about the mathematics scores within the district.

Gender. Multivariate analysis of variance demonstrated that there was not an overall significant difference in mathematics knowledge between males and females in this study at $p<.05$. Multivariate analyses were performed using outcomes measures from each grade (CCA algebra knowledge; CCA general mathematics knowledge; KCCT mathematics ability). Even though no overall differences were found, exploratory univariate analyses were performed and also found no differences among gender on any outcome measure in any grade (see Appendix B). Other gender differences, such as males 
having wider variances in score by being clustered towards the top and bottom, may still exist; however, for the current study only differences in means were analyzed. Since the means were comparable on all measures, gender was not expected to have an effect in the larger HLM models.

Race. Multivariate analysis of variance demonstrated significant differences between races in mathematics scores, Hotelling's Trace $(11,159)=125.48, \mathrm{p}<.001$. The mean scores for Caucasian and Asian-American students were higher on nearly every assessment (see Appendix B). This was consistent with previous research (e.g. Thernstrom \& Thernstrom, 2004; Lee, 2002; Stiefel, Schwartz, \& Ellen, 2006). For example, Thernstrom and Thernstrom (2004) carefully outlined the achievement gap that is seen when comparing Caucasian and Asian-American students to their AfricanAmerican and Hispanic counterparts on standardized test data, such as the National Assessment of Educational Progress (NAEP).

Follow-up univariate analyses of variance showed that the gap discussed by Thernstrom and Thernstrom existed in the current sample of students. Univariate analyses of variance showed that the four races differed on every outcome measure except CCA algebraic thinking knowledge in $5^{\text {th }}$ grade (see Appendix B). The other/unknown race category was not included in these analyses due to its ambiguity and the Native American/Alaskan Native group was not included due its sample size of 1.

Additionally, t-tests were performed that compared the two groups representing the achievement gap (Caucasian and Asian-American students compared to Hispanic and African-American students) to verify that this gap was attributing to the variation due to race. These two groups showed differences on every outcome measure except CCA 
algebraic thinking knowledge in $5^{\text {th }}$ grade (see Appendix B). This racial gap was then predicted to have an effect in the larger HLM models. Thus the HLM models described below included a race variable to account for the effect of being a race other than Caucasian or Asian-American.

Reading. KCCT reading ability was correlated to student's mathematics scores. With the exception of students' CCA algebraic thinking knowledge in $5^{\text {th }}$ grade, students' KCCT reading ability in each grade was significantly correlated to every mathematics outcome measure (see Appendix B). Students' scores in each grade were also found to be highly intercorrelated, with correlations ranging from .70 to $.76(\mathrm{p}<.001)$.

Overall, these analyses provided validity to using reading as a control for intelligence or overall academic ability, since no other such measures was available from the district. This analysis indicated that KCCT reading ability should act a significant positive predictor in the larger HLM models. The high level of intercorrelation also indicated that reading could be inserted as a single measure in level 2 . Thus $3^{\text {rd }}$ grade ability was selected. Using only $3^{\text {rd }}$ grade ability also alleviated any potential problems with power since additional level 1 repeated measures variables creates more complex models.

Free and Reduced Lunch Status. Schools' percentage of students receiving free and reduced lunch (FRL) had a strong negative correlation to students' mathematics ability. With the exception of students' CCA algebraic thinking knowledge in $5^{\text {th }}$ grade, FRL was significantly correlated to every mathematics outcome measure (see Appendix B). This analysis provided validity to using school level controls for demographic data when student level information was not available. This analysis also indicated that FRL should 
act a significant negative predictor in the larger HLM models.

\section{HLM Model 1}

The first HLM model analyzed how students' CCA algebraic thinking knowledge in $1^{\text {st }}$ and $2^{\text {nd }}$ grade predicted students' KCCT mathematics ability in $5^{\text {th }}$ grade and growth in KCCT mathematics ability across $3^{\text {rd }}$ through $5^{\text {th }}$ grade.

This analysis aimed to answer a) and b) of the research questions:

1) Does students' performance on assessment items targeting algebraic thinking in $1^{\text {st }}$ and $2^{\text {nd }}$ grade predict:

a) Performance on a mathematics state standardized assessment in $5^{\text {th }}$ grade?

b) Growth in performance on a mathematics state standardized assessment in $3^{\text {rd }}$ through $5^{\text {th }}$ grade?

Effect of Nesting. The first step to analyzing these questions was to determine if there was sufficient nesting to warrant hierarchical linear modeling. To determine this, intraclass correlations were calculated, using the null model. The intraclass correlation showed the proportion of variance within the level of nesting, in this case the school level. The null model, shown below, was comprised of only the outcome variables along with student and school identifiers. The predicted intercept was represented as $\pi_{0}$. The time variable, or $\pi_{l}$, was also included which represented the predicted slope of students' growth in mathematics knowledge. The superscripts in the model indicated which grade levels were included in the variable. 


\section{HLM model 1: Null model}

Level 1:

KCCT mathematics knowledge $\mathrm{e}^{345}=\pi_{0}+\pi_{l}($ time $)+e$

Level 2:

$$
\begin{aligned}
& \pi_{0}=\beta_{00}+r_{0} \\
& \pi_{l}=\beta_{10}+r_{l}
\end{aligned}
$$

Level 3:

$$
\begin{aligned}
& \beta_{00}=\gamma_{000}+u_{00} \\
& \beta_{10}=\gamma_{100}+u_{10}
\end{aligned}
$$

In this model, intraclass correlations (ICC) were calculated for both Level 1 and Level 2. The intraclass correlations for each level were calculated as shown in Table 10.

Table 10

Intraclass Correlations for HLM Model 1, Level 1

\begin{tabular}{lccc}
\hline & $\tau_{00}$ & $\sigma^{2}$ & ICC \\
\hline Intercept $\left(\pi_{0}\right)$ & 337.21 & 94.44 & 0.7812 \\
Slope $\left(\pi_{l}\right)$ & 19.83 & 94.44 & 0.1735 \\
\hline
\end{tabular}

Intraclass Correlations for HLM Model 1, Level 2

\begin{tabular}{lccc}
\hline & $\tau_{00}$ & $\sigma^{2}$ & ICC \\
\hline Intercept $\left(\beta_{00}\right)$ & 91.97 & 94.44 & 0.4934 \\
Slope $\left(\beta_{10}\right)$ & 7.68 & 94.44 & 0.0752 \\
\hline
\end{tabular}

This analysis demonstrated that the proportion of school level variance was sufficient to necessitate hierarchical linear modeling at both levels. Level 1 showed nesting for predicting students' KCCT mathematics ability in $5^{\text {th }}$ grade $\left(\pi_{0}, 78.12 \%\right)$ and for student trajectories $\left(\pi_{l}, 17.35 \%\right)$. This indicated that the school in which students 
attended had a significant influence on their predicted $5^{\text {th }}$ grade score and trajectories from $3^{\text {rd }}$ through $5^{\text {th }}$ grade. HLM should be used to account for this nesting. Level 2 also showed nesting. School level nesting accounted for $49.34 \%$ of the amount of student to student variation in the intercept $\left(\beta_{00}\right)$ and $7.52 \%$ of the variation in slope $\left(\beta_{10}\right)$.

Building the model. The next analyses determined which variables were appropriate to be included in the final HLM model. This was done by inserting one variable into the null model to determine if it significantly lowered the deviance. For example, gender was inserted into the null model (shown below). Running this model produced a deviance score, similar to a 'goodness of fit' score, for the model. This deviance was then compared to deviance of the null model. The deviance score from the model that included gender was not significantly lower than the deviance score for the null model (see Table11). This demonstrated that gender did not improve the fit of the model and was therefore superfluous and should not be included in further analyses. If the deviance score had been significantly lower than the null model, it would have indicated that gender improved model fit and should be included in further analyses. This was repeated for each variable shown in Table 11. 


\section{HLM model 1: Null model + gender}

Level 1:

KCCT mathematics knowledge $\mathrm{e}^{345}=\pi_{0}+\pi_{l}($ time $)+e$

Level 2:

$$
\begin{aligned}
& \pi_{0}=\beta_{00}+\beta_{0 I}(\text { gender })+r_{0} \\
& \pi_{l}=\beta_{I 0}+\beta_{I l}(\text { gender })+r_{I}
\end{aligned}
$$

Level 3:

$$
\begin{aligned}
& \beta_{00}=\gamma_{000}+\mathrm{u}_{00} \\
& \beta_{01}=\gamma_{010} \\
& \beta_{10}=\gamma_{100}+\mathrm{u}_{10} \\
& \beta_{11}=\gamma_{110}
\end{aligned}
$$

Deviance analysis, measured using $\mathrm{X}^{2}$ statistics, demonstrated that both gender and curriculum use did not improve the fit of the model which indicates that these variables were superfluous to the model (see Table 11). The deviance analysis indicated that students' race, $\mathrm{KCCT}$ reading ability, CCA algebraic thinking knowledge, CCA general mathematics knowledge scores, and school level free and reduced lunch information should be included in the final model. These variables significantly reduced the deviance of the null model, or improved the model fit, and were therefore appropriate to include in the final model (shown below). 
Table 11

Deviance Analyses for HLM Model 1

\begin{tabular}{lccccccc}
\hline \multicolumn{1}{c}{ Variable } & \multicolumn{2}{c}{ Conditional Model } & \multicolumn{2}{c}{ Null Model } & & & \\
\cline { 2 - 5 } \multicolumn{1}{c}{ Added } & Deviance & Parameters & Deviance & Parameters & $\mathrm{X}^{2}$ & df & $\mathrm{p}$ \\
\hline Gender & 33119.85 & 11 & 33121.54 & 9 & 1.69 & 2 & $\mathrm{~ns}$ \\
Race & 33033.33 & 11 & 33121.54 & 9 & 88.21 & 2 & $<.001$ \\
Reading & 32039.33 & 11 & 33121.54 & 9 & 1082.21 & 2 & $<.001$ \\
Algebraic & 32880.95 & 11 & 33121.54 & 9 & 240.59 & 2 & $<.001$ \\
Thinking & & & & & & & \\
General & 32270.52 & 11 & 33121.54 & 9 & 851.02 & 2 & $<.001$ \\
Mathematics & & & & & & & \\
FRL & 33070.98 & 2 & 33121.54 & 9 & 50.56 & 2 & $<.001$ \\
Curriculum & 33120.00 & 2 & 33121.54 & 9 & 1.54 & 2 & ns \\
\hline
\end{tabular}

The variables that lowered the deviance of the null model were used to create the final model to analyze the role that early CCA algebraic thinking knowledge played in KCCT mathematics ability knowledge and growth. The final model is shown below. Student level variables (level 2$)$ were used to predict students intercept $\left(\pi_{0}\right)$ and slope $\left(\pi_{l}\right)$. For example, race could be a significant predictor for students' intercept at $5^{\text {th }}$ grade $\left(\beta_{03}\right)$ and students' growth, or slope, from $3^{\text {rd }}$ to $5^{\text {th }}$ grade $\left(\beta_{13}\right)$. At the school level (level $3)$, FRL was the only predictor. It was included in predicting the intercept $\left(\gamma_{001}\right)$ and the slope $\left(\gamma_{010}\right)$. The effect of the level 2 variables $(\beta)$ was not predicted to vary based on school level FRL, thus FRL was not included in predicting the other level 2 coefficients.

Superscripts in the model again indicate which grade levels were included in the variable. Asterisks indicate that a continuous variable had been centered for statistical purposes. 


\section{HLM model 1: Final model}

Level 1:

KCCT mathematics knowledge $\mathrm{B}^{345}=\pi_{0}+\pi_{l}($ time $)+e$

Level 2:

$$
\begin{aligned}
& \pi_{0}=\beta_{00}+\beta_{01}\left(\mathrm{CCA} \text { general mathematics knowledge }{ }^{12} *\right)+\beta_{02}(\mathrm{KCCT} \\
& \text { reading ability } \left.{ }^{3 *}\right)+\beta_{03}(\text { race })+\beta_{04}\left(\text { CCA algebra knowledge }{ }^{12}\right)+r_{0} \\
& \pi_{1}=\beta_{10}+\beta_{11}\left(\mathrm{CCA} \text { general mathematics knowledge }{ }^{12} *\right)+\beta_{12}(\mathrm{KCCT} \\
& \text { reading ability } \left.{ }^{3 *}\right)+\beta_{13}(\text { race })+\beta_{14}\left(\text { CCA algebra knowledge }{ }^{12 *}\right)+r_{1}
\end{aligned}
$$

Level 3:

$$
\begin{aligned}
& \beta_{00}=\gamma_{000}+\gamma_{001}\left(\mathrm{FRL}^{*}\right)+\mathrm{u}_{00} \\
& \beta_{01}=\gamma_{010} \\
& \beta_{02}=\gamma_{020} \\
& \beta_{03}=\gamma_{030} \\
& \beta_{04}=\gamma_{040} \\
& \beta_{10}=\gamma_{100}+\gamma_{010}\left(\mathrm{FRL}^{*}\right)+\mathrm{u}_{10} \\
& \beta_{11}=\gamma_{110} \\
& \beta_{12}=\gamma_{120} \\
& \beta_{13}=\gamma_{130} \\
& \beta_{14}=\gamma_{140}
\end{aligned}
$$


Model 1 results. The results of HLM model 1 showed that the baseline predicted intercept, or students' KCCT mathematics ability in $5^{\text {th }}$ grade, was 48.42 (see Table 12 ). The results showed that the predicted slope, or rate of growth in students' KCCT mathematics ability from $3^{\text {rd }}$ through $5^{\text {th }}$ grade, is -3.36 . The negative slope was consistent with the means seen in Table 9. The negative slope indicated that compared to national norms, the students' scores have lowered slightly across those years, which was consistent with the means in Table 9.

Students' CCA general mathematics knowledge in $1^{\text {st }}$ and $2^{\text {nd }}$ grade was a significant predictor of students' $5^{\text {th }}$ grade KCCT mathematics ability. Students with stronger CCA general mathematics knowledge were predicted to have higher $5^{\text {th }}$ grade KCCT mathematics ability. Students' CCA general mathematics knowledge in $1^{\text {st }}$ and $2^{\text {nd }}$ grade did not predict their growth on the KCCT from $3^{\text {rd }}$ through $5^{\text {th }}$ grade.

Students' KCCT reading ability was a significant predictor of both KCCT mathematics ability in $5^{\text {th }}$ grade and growth in ability from $3^{\text {rd }}$ through $5^{\text {th }}$ grade. Higher KCCT reading ability predicted higher KCCT mathematics ability in $5^{\text {th }}$ grade, but unexpectedly predicted a slightly lower trajectory from $3^{\text {rd }}$ through $5^{\text {th }}$ grade.

Students who were Caucasian or Asian-American were predicted to have a slightly higher score in KCCT mathematics ability in $5^{\text {th }}$ grade, but did not have different trajectories from $3^{\text {rd }}$ through $5^{\text {th }}$ grade from the students of another race.

Schools with more students receiving free and reduced lunch were predicted to have students with lower $5^{\text {th }}$ grade KCCT mathematics ability as well as lower trajectories from $3^{\text {rd }}$ through $5^{\text {th }}$ grade.

Students' CCA algebraic thinking knowledge in $1^{\text {st }}$ and $2^{\text {nd }}$ grade was a significant 
predictor of students' $5^{\text {th }}$ grade KCCT mathematics ability. Students with stronger CCA algebraic thinking knowledge were predicted to have higher $5^{\text {th }}$ grade KCCT mathematics ability. Their CCA algebraic thinking knowledge in $1^{\text {st }}$ and $2^{\text {nd }}$ grade also predicted positive growth on the KCCT from $3^{\text {rd }}$ through $5^{\text {th }}$ grade. Even when including students' CCA general mathematics knowledge, KCCT reading ability, and demographics in the model, students' CCA algebraic thinking knowledge predicted both growth in KCCT mathematics ability across $3^{\text {rd }}$ through $5^{\text {th }}$ grade and higher scores in $5^{\text {th }}$ grade.

Table 12

HLM Model 1 Coefficients

\begin{tabular}{lccccc}
\hline & \multicolumn{5}{c}{ Intercept: KCCT 5 ${ }^{\text {th }}$ Grade Mathematics Score } \\
\cline { 2 - 6 } Fixed Effect & Coefficient & S.E. & T-ratio & df & $\mathrm{p}$ \\
\hline Intercept & 48.42 & 0.91 & 52.96 & 66 & $<.001$ \\
General Mathematics & 46.77 & 3.44 & 13.59 & 1380 & $<.001$ \\
Algebraic Thinking & 8.27 & 1.97 & 4.20 & 1380 & $<.001$ \\
Reading & 0.47 & 0.026 & 17.71 & 1380 & $<.001$ \\
Race & -2.27 & 0.91 & -2.49 & 1380 & $<.02$ \\
FRL & -8.56 & 3.42 & -2.50 & 66 & $<.02$ \\
\cline { 2 - 6 } & \multicolumn{2}{c}{ Slope: Trajectory from $3^{\text {rd }}$ through $5^{\text {th }}$} & Grade \\
\cline { 2 - 6 } Intercept & -3.36 & 0.38 & -8.74 & 66 & $<.001$ \\
General Mathematics & -0.66 & 1.79 & -0.37 & 1380 & ns \\
Algebraic Thinking & 2.40 & 1.00 & 2.41 & 1380 & $<.02$ \\
Reading & -0.056 & 0.013 & -4.07 & 1380 & $<.001$ \\
Race & -0.62 & 0.47 & -1.32 & 1380 & ns \\
FRL & -4.45 & 1.28 & -3.47 & 66 & $<.01$ \\
\hline
\end{tabular}

Follow-up analysis explored if students' CCA knowledge in $1^{\text {st }}$ and $2^{\text {nd }}$ grade in any other mathematics content area predicted their KCCT mathematics ability in $5^{\text {th }}$ grade or growth in ability from $3^{\text {rd }}$ through $5^{\text {th }}$ grade. In an expanded model, the level 2 variable for CCA general mathematics knowledge was disaggregated into the four content areas used to create it (number properties and operations, measurement, geometry, and data analysis and probability). Students' knowledge on each content areas 
was included as an independent predictor in level 2 along with algebraic thinking knowledge.

In this expanded model, students' CCA knowledge of each of the five mathematics content areas was a positive predictor of students' KCCT mathematics ability in $5^{\text {th }}$ grade (see Table 13). Only the coefficient for CCA geometry knowledge did not reach significance. Students KCCT reading ability was still a positive predictor of $5^{\text {th }}$ grade ability. Race was still a negative predictor. Schools with a higher percentage of FRL students were still predicted to have lower knowledge scores.

When analyzing students' growth in KCCT mathematics ability, algebraic thinking knowledge was the only content area that predicted positive growth. Students with stronger CCA algebraic thinking knowledge were predicted to have higher growth in KCCT mathematics ability from $3^{\text {rd }}$ through $5^{\text {th }}$ grade. The other four areas did not significantly predict student trajectories. Students' with higher KCCT reading ability were still predicted to have slightly lower trajectories. Schools with more students receiving free and reduced lunch were still predicted to have students with lower trajectories. 
Table 13

HLM Model 1 Coefficients with General Mathematics Knowledge Separated

\begin{tabular}{lccccc}
\hline & \multicolumn{5}{c}{ Intercept: KCCT $5^{\text {th }}$ Grade Mathematics Score } \\
\cline { 2 - 6 } Fixed Effect & Coefficient & S.E. & T-ratio & df & $\mathrm{p}$ \\
\hline Intercept & 48.30 & 0.97 & 50.00 & 66 & $<.001$ \\
Properties/ & 33.13 & 3.48 & 9.51 & 1377 & $<.001$ \\
Operation & 6.48 & 1.91 & 3.39 & 1377 & $<.01$ \\
Measurement & 3.64 & 2.98 & 1.22 & 1377 & $\mathrm{~ns}$ \\
Geometry & 7.37 & 2.43 & 3.03 & 1377 & $<.01$ \\
Data/Probability & 6.38 & 1.99 & 3.20 & 1377 & $<.002$ \\
Algebraic Thinking & 0.45 & 0.026 & 17.08 & 1377 & $<.001$ \\
Reading & -2.20 & 0.90 & -2.45 & 1377 & $<.02$ \\
Race & -8.81 & 3.72 & -2.37 & 66 & $<.05$ \\
FRL & Slope: Trajectory from $3^{\text {rd }}$ through $5^{\text {th }}$ & Grade \\
\cline { 2 - 6 } & -3.37 & 0.38 & -8.78 & 66 & $<.001$ \\
Intercept & & & & & \\
Properties/ & 0.59 & 1.84 & 0.32 & 1377 & $\mathrm{~ns}$ \\
Operation & -0.49 & 1.01 & -0.48 & 1377 & $\mathrm{~ns}$ \\
Measurement & -0.063 & 1.57 & -0.040 & 1377 & $\mathrm{~ns}$ \\
Geometry & 0.0010 & 1.28 & 0.001 & 1377 & $\mathrm{~ns}$ \\
Data/Probability & 2.28 & 1.02 & 2.23 & 1377 & $<.05$ \\
Algebraic Thinking & -0.058 & 0.014 & -4.26 & 1377 & $<.001$ \\
Reading & -0.61 & 0.47 & -1.31 & 1377 & $\mathrm{~ns}$ \\
Race & -4.38 & 1.28 & -3.43 & 66 & $<.01$ \\
FRL & & & & & \\
\hline
\end{tabular}




\section{HLM Model 2}

The second HLM model analyzed how students' CCA algebraic thinking knowledge in $1^{\text {st }}$ and $2^{\text {nd }}$ grade predicted students' CCA algebraic thinking knowledge in $5^{\text {th }}$ grade and growth in CCA algebraic thinking knowledge in $3^{\text {rd }}$ through $5^{\text {th }}$ grade.

This analysis aimed to answer c) and d) of the research questions:

1) Does students' performance on assessment items targeting algebraic thinking in $1^{\text {st }}$ and $2^{\text {nd }}$ grade predict:

c) Performance on district assessment items targeting algebraic thinking in $5^{\text {th }}$ grade?

d) Growth in performance on district assessment items targeting algebraic thinking in $3^{\text {rd }}$ through $5^{\text {th }}$ grade?

Effect of Nesting. The first step to analyzing these questions was again to determine if there was sufficient nesting to warrant hierarchical linear modeling. To determine this, intraclass correlations were calculated, using the null model. The null model for HLM model 2 was constructed in the same manner as the null model from HLM model 1 , except the outcome variable in HLM model 2 was students' CCA algebraic thinking knowledge in $3^{\text {rd }}, 4^{\text {th }}$, and $5^{\text {th }}$ grade. The null model is shown below. 


\section{HLM model 2: Null model}

Level 1:

$$
\text { CCA algebra knowledge } \mathrm{e}^{345}=\pi_{0}+\pi_{l}(\text { time })+e
$$

Level 2:

$$
\begin{aligned}
& \pi_{0}=\beta_{00}+r_{0} \\
& \pi_{I}=\beta_{I 0}+r_{I}
\end{aligned}
$$

Level 3:

$$
\begin{aligned}
& \beta_{00}=\gamma_{000}+u_{00} \\
& \beta_{10}=\gamma_{100}+u_{10}
\end{aligned}
$$

In this model, the intraclass correlations were calculated for both Level 1 and Level 2.

The intraclass correlations for each level were calculated as shown in Table 14.

Table 14

Intraclass Correlations for HLM Model 2, Level 1

\begin{tabular}{lccc}
\hline & $\tau_{00}$ & $\sigma^{2}$ & ICC \\
\hline Intercept $\left(\pi_{0}\right)$ & 0.05518 & 0.05273 & 0.5114 \\
Slope $\left(\pi_{l}\right)$ & 0.02234 & 0.05273 & 0.2976 \\
\hline
\end{tabular}

Intraclass Correlations for HLM Model 2, Level 2

\begin{tabular}{lccc}
\hline & $\tau_{00}$ & $\sigma^{2}$ & ICC \\
\hline Intercept $\left(\beta_{00}\right)$ & 0.01447 & 0.05273 & 0.2153 \\
Slope $\left(\beta_{10}\right)$ & 0.00670 & 0.05273 & 0.1127 \\
\hline
\end{tabular}

This analysis demonstrated that the proportion of school level variance was sufficient to necessitate hierarchical linear modeling at both levels. Level 1 showed nesting for predicting students' CCA algebra knowledge in $5^{\text {th }}$ grade $\left(\pi_{0}, 51.14 \%\right)$ and for student trajectories $\left(\pi_{l}, 29.76 \%\right)$. This indicated that the school in which students 
attended had a significant influence on their predicted $5^{\text {th }}$ grade score and trajectories from $3^{\text {rd }}$ through $5^{\text {th }}$ grade. HLM should be used to account for this nesting. Level 2 also showed nesting. School level nesting accounted for $21.53 \%$ of the amount of student to student variation in the intercept $\left(\beta_{00}\right)$ and $11.27 \%$ of the variation in slope $\left(\beta_{10}\right)$.

Building the model. As done with HLM model 1, the next analyses determined which variables were appropriate to be included in the firal HLM model. This was done by inserting one variable into the null model to determine if it significantly lowered the deviance. This was repeated for each variable shown in Table 15.

These deviance analyses again demonstrated that both gender and curriculum did not improve the fit of the model and were therefore superfluous (see Table 15). The deviance analysis indicated that students' race, $\mathrm{KCCT}$ reading ability, $\mathrm{CCA}$ algebraic thinking knowledge, CCA general mathematics knowledge, and school level free and reduced lunch information should be included in the model. These variables significantly reduced the deviance of the null model, or improved the model fit, and were therefore appropriate to include in the final model (shown below).

Table 15

Deviance Analyses for HLM Model 2

\begin{tabular}{lcccccccc}
\hline \multicolumn{1}{c}{ Variable } & \multicolumn{2}{c}{ Conditional Model } & \multicolumn{2}{c}{ Null Model } & & & \\
\cline { 2 - 7 } \multicolumn{1}{c}{ Added } & Deviance & Parameters & Deviance & Parameters & $X^{2}$ & df & $\mathrm{p}$ \\
\hline Gender & -2681.21 & 11 & -2687.33 & 9 & 2.8843 & 2 & $\mathrm{~ns}$ \\
Race & -2771.47 & 11 & -2687.33 & 9 & 93.14192 & 2 & $<.001$ \\
Reading & -3333.97 & 11 & -2687.33 & 9 & 646.6428 & 2 & $<.001$ \\
Algebraic & -2911.61 & 11 & -2687.33 & 9 & 224.2798 & 2 & $<.001$ \\
Thinking & & & & & & & \\
General & -3374.48 & 11 & -2687.33 & 9 & 687.1478 & 2 & $<.001$ \\
Mathematics & -2708.22 & 2 & -2687.33 & 9 & 20.89232 & 2 & $<.001$ \\
FRL & -2686.08 & 2 & -2687.33 & 9 & 1.2508 & 2 & ns \\
Curriculum & -26 & & & & & & \\
\hline
\end{tabular}


The variables that lowered the deviance of the null model were used to create the final model to analyze the role that early CCA algebraic thinking knowledge played in later CCA algebraic thinking knowledge and growth. The final model is shown below. Student level variables (level 2 ) were again used to predict students intercept $\left(\pi_{0}\right)$ and slope $\left(\pi_{l}\right)$. At the school level (level 3), FRL was the only predictor. It was included in predicting the intercept $\left(\gamma_{001}\right)$ and the slope $\left(\gamma_{010}\right)$. The effect of the level 2 variables $(\beta)$ was not predicted to vary based on school level FRL, thus FRL was not included in predicting the other level 2 coefficients.

Superscripts in the model again indicate which grade levels were included in the variable. Asterisks indicate that a continuous variable had been centered for statistical purposes. 


\section{HLM model 2: Final model}

Level 1:

$$
\text { CCA algebra knowledge }{ }^{345}=\pi_{0}+\pi_{l}(\text { time })+e
$$

Level 2:

$$
\begin{aligned}
& \pi_{0}=\beta_{00}+\beta_{01}\left(\mathrm{CCA}_{\text {general mathematics knowledge }}{ }^{12} *\right)+\beta_{02}(\mathrm{KCCT} \\
& \text { reading ability } \left.{ }^{3 *}\right)+\beta_{03}(\text { race })+\beta_{04}\left(\text { CCA algebra knowledge }{ }^{12 *}\right)+r_{0} \\
& \pi_{l}=\beta_{10}+\beta_{l l}\left(\mathrm{CCA} \text { general mathematics knowledge }{ }^{12} *\right)+\beta_{l 2}(\mathrm{KCCT} \\
& \text { reading ability } \left.{ }^{3 *}\right)+\beta_{13}(\text { race })+\beta_{14}\left(\text { CCA algebra knowledge }{ }^{12} *\right)+r_{I}
\end{aligned}
$$

Level 3:

$$
\begin{aligned}
& \beta_{00}=\gamma_{000}+\gamma_{001}\left(\mathrm{FRL}^{*}\right)+\mathrm{u}_{00} \\
& \beta_{01}=\gamma_{010} \\
& \beta_{02}=\gamma_{020} \\
& \beta_{03}=\gamma_{030} \\
& \beta_{04}=\gamma_{040} \\
& \beta_{10}=\gamma_{100}+\gamma_{001}\left(\mathrm{FRL}^{*}\right)+\mathrm{u}_{10} \\
& \beta_{11}=\gamma_{110} \\
& \beta_{12}=\gamma_{120} \\
& \beta_{13}=\gamma_{130} \\
& \beta_{14}=\gamma_{140}
\end{aligned}
$$


Model 2 results. The results of HLM model 2 showed that the baseline predicted intercept, or students' CCA algebraic thinking knowledge in $5^{\text {th }}$ grade, was 0.71 , or $71 \%$ (see Table 16). The results showed that the predicted slope, or rate of growth in students' algebraic thinking knowledge from $3^{\text {rd }}$ through $5^{\text {th }}$ grade is -0.0065 , or $-0.65 \%$. The negative slope reflected that fact that students were performing slightly lower in $5^{\text {th }}$ grade which was consistent with the means in Table 9.

Students' CCA general mathematics knowledge in $1^{\text {st }}$ and $2^{\text {nd }}$ grade was a significant predictor of students' $5^{\text {th }}$ grade CCA algebraic thinking knowledge. Students with stronger CCA general mathematics knowledge were predicted to have higher CCA algebraic thinking knowledge in $5^{\text {th }}$ grade. Students' CCA general mathematics knowledge in $1^{\text {st }}$ and $2^{\text {nd }}$ grade did not predict their growth in CCA algebraic thinking knowledge from $3^{\text {rd }}$ through $5^{\text {th }}$ grade.

Students' KCCT reading ability was a marginally significant predictor of CCA algebraic thinking knowledge in $5^{\text {th }}$ grade, but did not predict growth in algebraic thinking knowledge. There was no effect for being Caucasian or Asian-American in this model. There was no effect at the school level for percent of students receiving free and reduced lunch.

Students' CCA algebraic thinking knowledge in $1^{\text {st }}$ and $2^{\text {nd }}$ grade was not a significant predictor of students' $5^{\text {th }}$ grade CCA algebraic thinking knowledge, but had a positive coefficient of $0.12, p=0.1$. Students' $C C A$ algebraic thinking knowledge in $1^{\text {st }}$ and $2^{\text {nd }}$ grade did not predict growth in CCA algebraic thinking knowledge as it did with overall KCCT mathematics ability. It did have a positive coefficient of 0.049 , but it was not significant, $\mathrm{p}=0.2$. 
Table 16

HLM Model 2 Coefficients

\begin{tabular}{lccccc}
\hline & \multicolumn{5}{c}{ Intercept: CCA $5^{\text {th }}$ Grade Algebra Score } \\
\cline { 2 - 6 } Fixed Effect & Coefficient & S.E. & T-ratio & df & $\mathrm{p}$ \\
\hline Intercept & 0.71 & 0.034 & 21.15 & 66 & $<.001$ \\
General Mathematics & .34 & 0.13 & 2.70 & 1380 & $<.01$ \\
Algebraic Thinking & .12 & 0.072 & 1.63 & 1380 & $=.1$ \\
Reading & 0.0017 & 0.00095 & 1.75 & 1380 & $<.08$ \\
Race & -0.0050 & 0.033 & -0.15 & 1380 & ns \\
FRL & .036 & 0.12 & 0.31 & 66 & ns \\
\cline { 2 - 6 } & \multicolumn{2}{c}{ Slope: Trajectory from $3^{\text {rd }}$ through 5 } & Grade \\
\cline { 2 - 6 } Intercept & -0.0065 & 0.018 & -0.36 & 66 & ns \\
General Mathematics & -0.062 & 0.072 & -0.87 & 1380 & ns \\
Algebraic Thinking & 0.049 & 0.041 & 1.21 & 1380 & $\mathrm{~ns}$ \\
Reading & -0.00079 & 0.00054 & -1.45 & 1380 & $\mathrm{~ns}$ \\
Race & 0.0085 & 0.018 & 0.46 & 1380 & $\mathrm{~ns}$ \\
FRL & 0.044 & 0.064 & 0.69 & 66 & $\mathrm{~ns}$ \\
\hline
\end{tabular}

Follow-up analysis explored if students CCA knowledge in $1^{\text {st }}$ and $2^{\text {nd }}$ grade in any other mathematics content area predicted their CCA algebraic thinking knowledge in $5^{\text {th }}$ grade or growth in knowledge from $3^{\text {rd }}$ through $5^{\text {th }}$ grade. In an expanded model, the level 2 variable for CCA general mathematics knowledge was disaggregated into the four content areas used to create it (number properties and operations, measurement, geometry, and data analysis and probability). Students' knowledge on each content areas was included as an independent predictor in level 2 along with algebraic thinking knowledge.

None of the predictors in this expanded model reached significance in predicting the intercept or the slope (see Table 17). The trends were comparable to the model including CCA general mathematics knowledge, but with the additional predictors, the coefficients did not reach significance. CCA algebraic thinking knowledge in $1^{\text {st }}$ and $2^{\text {nd }}$ grade again had positive coefficients for both $5^{\text {th }}$ grade CCA algebraic thinking 
knowledge and growth from $3^{\text {rd }}$ through $5^{\text {th }}$ grade, but were not significant.

Table 17

HLM Model 2 Coefficients with General Mathematics Knowledge Separated

\begin{tabular}{|c|c|c|c|c|c|}
\hline \multirow[b]{2}{*}{ Fixed Effect } & \multicolumn{5}{|c|}{ Intercept: CCA $5^{\text {th }}$ Grade Algebra Score } \\
\hline & Coefficient & S.E. & T-ratio & $\mathrm{df}$ & $\mathrm{p}$ \\
\hline Intercept & 0.71 & 0.034 & 20.96 & 66 & $<.001$ \\
\hline $\begin{array}{l}\text { Properties/ } \\
\text { Operation }\end{array}$ & 0.15 & 0.13 & 1.18 & 1377 & ns \\
\hline Measurement & 0.091 & 0.071 & 1.28 & 1377 & ns \\
\hline Geometry & 0.11 & 0.11 & 1.03 & 1377 & ns \\
\hline Data/Probability & 0.084 & 0.087 & 0.96 & 1377 & $\mathrm{~ns}$ \\
\hline Algebraic Thinking & 0.10 & 0.074 & 1.37 & 1377 & ns \\
\hline Reading & 0.0014 & 0.00095 & 1.47 & 1377 & ns \\
\hline Race & -0.0026 & 0.033 & -0.078 & 1377 & ns \\
\hline \multirow[t]{2}{*}{ FRL } & 0.031 & 0.12 & 0.25 & 66 & ns \\
\hline & \multicolumn{5}{|c|}{ Slope: Trajectory from $3^{\text {rd }}$ through $5^{\text {th }}$ Grade } \\
\hline Intercept & -0.0067 & 0.018 & -0.37 & 66 & ns \\
\hline $\begin{array}{l}\text { Properties/ } \\
\text { Operation }\end{array}$ & -0.061 & 0.074 & -0.82 & 1377 & ns \\
\hline Measurement & 0.035 & 0.040 & 0.87 & 1377 & $\mathrm{~ns}$ \\
\hline Geometry & 0.030 & 0.061 & 0.49 & 1377 & ns \\
\hline Data/Probability & -0.028 & 0.050 & -0.56 & 1377 & ns \\
\hline Algebraic Thinking & 0.049 & 0.042 & 1.18 & 1377 & $\mathrm{~ns}$ \\
\hline Reading & -0.00086 & 0.00054 & -1.59 & 1377 & $\mathrm{~ns}$ \\
\hline Race & 0.0084 & 0.019 & 0.45 & 1377 & ns \\
\hline FRL & 0.049 & 0.064 & 0.76 & 66 & ns \\
\hline
\end{tabular}




\section{HLM Model 3}

The last HLM model analyzed how students' CCA algebraic thinking knowledge in $1^{\text {st }}$ and $2^{\text {nd }}$ grade predicted students' CCA general mathematics knowledge in $5^{\text {th }}$ grade and growth in CCA general mathematics knowledge in $3^{\text {rd }}$ through $5^{\text {th }}$ grade.

This analysis aimed to answer e) and f) of the research questions:

1) Does students' performance on assessment items targeting algebraic thinking in $1^{\text {st }}$ and $2^{\text {nd }}$ grade predict:

e) Performance on district assessment items targeting other areas of mathematics in $5^{\text {th }}$ grade?

f) Growth in performance on district assessment items targeting other areas of mathematics in $3^{\text {rd }}$ through $5^{\text {th }}$ grade?

Effect of Nesting. The first step to analyzing these questions was again to determine if there was sufficient nesting to warrant hierarchical linear modeling. To determine this, intraclass correlations were calculated, using the null model. The null model for HLM model 3 was constructed in the same manner as the null models from HLM model 1 and 2, except the outcome variable in HLM model 3 was students' CCA general mathematics knowledge in $3^{\text {rd }}, 4^{\text {th }}$, and $5^{\text {th }}$ grade. The null model is shown below. 


\section{HLM model 3: Null model}

Level 1:

CCA general mathematics knowledge $\mathrm{e}^{345}=\pi_{0}+\pi_{l}($ time $)+e$

Level 2:

$$
\begin{aligned}
& \pi_{0}=\beta_{00}+r_{0} \\
& \pi_{l}=\beta_{10}+r_{l}
\end{aligned}
$$

Level 3:

$$
\begin{aligned}
& \beta_{00}=\gamma_{000}+u_{00} \\
& \beta_{10}=\gamma_{100}+u_{10}
\end{aligned}
$$

In this model, the intraclass correlations were calculated for both Level 1 and Level 2.

The intraclass correlations for each level were calculated as shown in Table 18.

Table 18

Intraclass Correlations for HLM Model 3, Level 1

\begin{tabular}{lccc}
\hline & $\tau_{00}$ & $\sigma^{2}$ & ICC \\
\hline Intercept $\left(\pi_{0}\right)$ & 0.01592 & 0.01829 & 0.4654 \\
Slope $\left(\pi_{l}\right)$ & 0.00102 & 0.01829 & 0.0528 \\
\hline
\end{tabular}

Intraclass Correlations for HLM Model 3, Level 2

\begin{tabular}{lccc}
\hline & $\tau_{00}$ & $\sigma^{2}$ & ICC \\
\hline Intercept $\left(\beta_{00}\right)$ & 0.00749 & 0.01829 & 0.2905 \\
Slope $\left(\beta_{10}\right)$ & 0.00121 & 0.01829 & 0.0621 \\
\hline
\end{tabular}

This analysis demonstrated that the proportion of school level variance was sufficient to necessitate hierarchical linear modeling at both levels. Level 1 showed nesting for predicting students' CCA general mathematics knowledge in $5^{\text {th }}$ grade $\left(\pi_{0}\right.$, $46.54 \%)$ and for student trajectories $\left(\pi_{1}, 5.28 \%\right)$. This indicated that the school in which 
students attended had a significant influence on their predicted $5^{\text {th }}$ grade score and trajectories from $3^{\text {rd }}$ through $5^{\text {th }}$ grade. HLM should be used to account for this nesting.

Level 2 also showed nesting. School level nesting accounted for $29.05 \%$ of the amount of student to student variation in the intercept $\left(\beta_{00}\right)$ and $6.21 \%$ of the variation in slope $\left(\beta_{10}\right)$.

Building the model. As done with HLM model 1 and 2, the next analyses determined which variables were appropriate to be included in the final model. This was done by inserting one variable into the null model to determine if it significantly lowered the deviance. This was repeated for each variable shown in Table 19.

These deviance analyses again demonstrated that both gender and curriculum did not improve the fit of the model and were therefore superfluous (see Table 19). The deviance analysis indicated that students' race, $\mathrm{KCCT}$ reading ability, $\mathrm{CCA}$ algebraic thinking knowledge, CCA general mathematics knowledge, and school level free and reduced lunch information should be included in the model. These variables significantly reduced the deviance of the null model, or improved the model fit, and were therefore appropriate to include in the final model (shown below).

Table 19

Deviance Analyses for HLM Model 3

\begin{tabular}{lcccccccc}
\hline \multirow{2}{*}{\begin{tabular}{l} 
Variable \\
\multicolumn{1}{c}{ Added }
\end{tabular}} & \multicolumn{2}{c}{ Conditional Model } & \multicolumn{2}{c}{ Null Model } & & & \\
\cline { 2 - 6 } & Deviance & Parameters & Deviance & Parameters & $X^{2}$ & df & $\mathrm{p}$ \\
\hline Gender & 367.4699 & 11 & 367.9224 & 9 & 0.469854 & 2 & $\mathrm{~ns}$ \\
Race & 329.2086 & 11 & 367.9224 & 9 & 38.71375 & 2 & $<.001$ \\
Reading & 103.9693 & 11 & 367.9224 & 9 & 263.9531 & 2 & $<.001$ \\
Algebraic & 279.7647 & 11 & 367.9224 & 9 & 88.15769 & 2 & $<.001$ \\
Thinking & & & & & & & \\
General & 59.36885 & 11 & 367.9224 & 9 & 308.5535 & 2 & $<.001$ \\
Mathematics & & 2 & 367.9224 & 9 & 20.92353 & 2 & $<.001$ \\
FRL & 346.9988 & 2 & 367.9224 & 9 & 0.33857 & 2 & $\mathrm{~ns}$ \\
Curriculum & 367.5838 & 2 & & & &
\end{tabular}


The variables that lowered the deviance of the null model were used to create the final model to analyze the role that early CCA algebraic thinking knowledge played in later CCA general mathematics knowledge and growth. The final model is shown below. Student level variables (level 2) were again used to predict students intercept $\left(\pi_{0}\right)$ and slope $\left(\pi_{l}\right)$. At the school level (level 3), FRL was the only predictor. It was included in predicting the intercept $\left(\gamma_{001}\right)$ and the slope $\left(\gamma_{010}\right)$. The effect of the level 2 variables $(\beta)$ was not predicted to vary based on school level FRL, thus FRL was not included in predicting the other level 2 coefficients.

Superscripts in the model again indicate which grade levels were included in the variable. Asterisks indicate that a continuous variable had been centered for statistical purposes. 


\section{HLM model 3: Final model}

Level 1:

CCA general mathematics knowledge ${ }^{345}=\pi_{0}+\pi_{l}($ time $)+e$

Level 2:

$$
\begin{aligned}
& \pi_{0}=\beta_{00}+\beta_{01}\left(\mathrm{CCA} \text { general mathematics knowledge }{ }^{12} *\right)+\beta_{02}(\mathrm{KCCT} \\
& \text { reading ability } \left.{ }^{3}\right)+\beta_{03}(\text { race })+\beta_{04}\left(\text { CCA algebra knowledge }{ }^{12} *\right)+r_{0} \\
& \pi_{1}=\beta_{10}+\beta_{11}\left(\mathrm{CCA} \text { general mathematics knowledge }{ }^{12} *\right)+\beta_{12}(\mathrm{KCCT} \\
& \text { reading ability } \left.{ }^{3}\right)+\beta_{13}(\text { race })+\beta_{14}\left(\text { CCA algebra knowledge }{ }^{12} *\right)+r_{I}
\end{aligned}
$$

Level 3:

$$
\begin{aligned}
& \beta_{00}=\gamma_{000}+\gamma_{001}\left(\mathrm{FRL}^{*}\right)+\mathrm{u}_{00} \\
& \beta_{01}=\gamma_{010} \\
& \beta_{02}=\gamma_{020} \\
& \beta_{03}=\gamma_{030} \\
& \beta_{04}=\gamma_{040} \\
& \beta_{10}=\gamma_{100}+\gamma_{001}\left(\mathrm{FRL}^{*}\right)+\mathrm{u}_{10} \\
& \beta_{11}=\gamma_{110} \\
& \beta_{12}=\gamma_{120} \\
& \beta_{13}=\gamma_{130} \\
& \beta_{14}=\gamma_{140}
\end{aligned}
$$


Model 3 results. The results of HLM model 3 showed that the baseline predicted intercept, or students' CCA general mathematics knowledge in $5^{\text {th }}$ grade, is 0.66 , or $66 \%$ (see Table 20). The results showed that the predicted slope, or rate of growth in students' CCA general mathematics knowledge from $3^{\text {rd }}$ through $5^{\text {th }}$ grade, is -0.034 , or $-3.4 \%$. The negative slope reflected that fact that students were performing slightly lower in $4^{\text {th }}$ and $5^{\text {th }}$ grade compared to $3^{\text {rd }}$ grade which was consistent with the means in Table 9.

Students' CCA general mathematics knowledge in $1^{\text {st }}$ and $2^{\text {nd }}$ grade was a significant predictor of students' $5^{\text {th }}$ grade CCA general mathematics knowledge. Students with stronger CCA general mathematics knowledge were predicted to have higher CCA general mathematics knowledge in $5^{\text {th }}$ grade. Students' CCA general mathematics knowledge in $1^{\text {st }}$ and $2^{\text {nd }}$ grade did not predict their growth in CCA general mathematics knowledge from $3^{\text {rd }}$ through $5^{\text {th }}$ grade.

Students' KCCT reading ability was a significant predictor of CCA general mathematics knowledge in $5^{\text {th }}$ grade, but did not predict growth in knowledge from $3^{\text {rd }}$ through $5^{\text {th }}$ grade. Students who were Caucasian or Asian-American were predicted to have slightly higher scores on CCA general mathematics knowledge in $5^{\text {th }}$ grade, but were not predicted to have different trajectories. There was no effect at the school level for percent of students receiving free and reduced lunch.

Students' CCA algebraic thinking knowledge in $1^{\text {st }}$ and $2^{\text {nd }}$ grade was a significant predictor of students' $5^{\text {th }}$ grade CCA general mathematics knowledge. Students with stronger CCA algebraic thinking knowledge were predicted to have higher knowledge in other mathematics areas in $5^{\text {th }}$ grade. Even when including students' CCA general mathematics knowledge, KCCT reading ability, and demographics in the model, 
students' CCA algebraic thinking knowledge predicted higher CCA general mathematics knowledge in $5^{\text {th }}$ grade. Students' CCA algebraic thinking knowledge in $1^{\text {st }}$ and $2^{\text {nd }}$ grade did not predict growth in CCA general mathematics knowledge from $3^{\text {rd }}$ through $5^{\text {th }}$ grade, as it did with overall KCCT mathematics ability.

Table 20

HLM Model 3 Coefficients

\begin{tabular}{lccccc}
\hline & \multicolumn{5}{c}{ Intercept: CCA $5^{\text {th }}$ Grade General Mathematics Score } \\
\cline { 2 - 6 } \multicolumn{1}{c}{ Fixed Effect } & Coefficient & S.E. & T-ratio & df & p \\
\hline Intercept & 0.66 & 0.010 & 63.18 & 66 & $<.001$ \\
General & 0.35 & 0.038 & 9.22 & 1380 & $<.001$ \\
Algebraic Thinking & 0.056 & 0.022 & 2.58 & 1380 & $<.01$ \\
Reading & 0.0030 & 0.00029 & 10.50 & 1380 & $<.001$ \\
Race & -0.022 & 0.010 & -2.25 & 1380 & $<.05$ \\
FRL & -0.068 & 0.039 & -1.75 & 66 & ns \\
\cline { 2 - 6 } & \multicolumn{2}{c}{ Slope: Trajectory from $3^{\text {rd }}$ through $5^{\text {th }}$ Grade } \\
\cline { 2 - 6 } Intercept & -0.034 & 0.0057 & -5.96 & 66 & $<.001$ \\
General & -0.016 & 0.023 & -0.68 & 1380 & ns \\
Algebraic Thinking & -0.0089 & 0.014 & -0.66 & 1380 & ns \\
Reading & -0.000041 & 0.00018 & -0.22 & 1380 & ns \\
Race & -0.0016 & 0.0063 & -0.25 & 1380 & ns \\
FRL & -0.028 & 0.020 & -1.38 & 66 & ns \\
\hline
\end{tabular}

Follow-up analysis explored if students' CCA knowledge in $1^{\text {st }}$ and $2^{\text {nd }}$ grade in any other mathematics content area predicted their CCA general mathematics knowledge in $5^{\text {th }}$ grade or growth in knowledge from $3^{\text {rd }}$ through $5^{\text {th }}$ grade. In an expanded model, the level 2 variable for CCA general mathematics knowledge was disaggregated into the four content areas used to create it (number properties and operations, measurement, geometry, and data analysis and probability). Students' knowledge on each content areas was included as an independent predictor in level 2 along with algebraic thinking knowledge.

Students' CCA knowledge of every mathematics content area was a positive 
predictor of CCA general mathematics knowledge in $5^{\text {th }}$ grade (see Table 21). Students KCCT reading ability was still a positive predictor of $5^{\text {th }}$ grade CCA general mathematics knowledge. Race was still a negative predictor of $5^{\text {th }}$ grade knowledge. Schools with more FRL students were still predicted to have students with lower knowledge scores, with the coefficient being marginally significant.

When analyzing students' growth in CCA general mathematics knowledge, there are no positive predictors in this model. Early CCA geometry knowledge has a small but significant coefficient that predicts less growth in CCA general mathematics knowledge.

Table 21

HLM Model 3 Coefficients with General Mathematics Knowledge Separated

\begin{tabular}{|c|c|c|c|c|c|}
\hline \multirow[b]{2}{*}{ Fixed Effect } & \multicolumn{5}{|c|}{ Intercept: CCA $5^{\text {th }}$ Grade General Mathematics Score } \\
\hline & Coefficient & S.E. & T-ratio & $\mathrm{df}$ & $\mathrm{p}$ \\
\hline Intercept & 0.65 & 0.011 & 61.75 & 66 & $<.001$ \\
\hline $\begin{array}{l}\text { Properties/ } \\
\text { Operation }\end{array}$ & 0.15 & 0.039 & 3.75 & 1377 & $<.001$ \\
\hline Measurement & 0.048 & 0.021 & 2.29 & 1377 & $<.05$ \\
\hline Geometry & 0.13 & 0.033 & 3.99 & 1377 & $<.001$ \\
\hline Data/Probability & 0.064 & 0.026 & 2.44 & 1377 & $<.02$ \\
\hline Algebraic Thinking & 0.051 & 0.022 & 2.32 & 1377 & $<.02$ \\
\hline Reading & 0.0030 & 0.00029 & 10.28 & 1377 & $<.001$ \\
\hline Race & -0.022 & 0.010 & -2.22 & 1377 & $<.05$ \\
\hline \multirow[t]{2}{*}{ FRL } & -0.075 & 0.040 & -1.85 & 66 & $<.07$ \\
\hline & \multicolumn{5}{|c|}{ Slope: Trajectory from $3^{\text {rd }}$ through $5^{\text {th }}$ Grade } \\
\hline Intercept & -0.034 & 0.0058 & -5.92 & 66 & $<.001$ \\
\hline $\begin{array}{l}\text { Properties/ } \\
\text { Operation }\end{array}$ & -0.041 & 0.025 & -1.65 & 1377 & ns \\
\hline Measurement & -0.0060 & 0.013 & -0.46 & 1377 & ns \\
\hline Geometry & -0.049 & 0.021 & 2.38 & 1377 & $<.02$ \\
\hline Data/Probability & -0.0096 & 0.017 & -0.57 & 1377 & ns \\
\hline Algebraic Thinking & -0.0039 & 0.014 & -0.28 & 1377 & ns \\
\hline Reading & -0.000016 & 0.00018 & -0.088 & 1377 & ns \\
\hline Race & -0.0019 & 0.0063 & -0.31 & 1377 & ns \\
\hline FRL & -0.028 & 0.021 & -1.37 & 66 & ns \\
\hline
\end{tabular}




\section{DISCUSSION}

The goal of the current study was to show that algebra knowledge in $1^{\text {st }}$ and $2^{\text {nd }}$ grade is an important predictor of mathematics knowledge and trajectories in upper elementary grades. The study was able to work with longitudinal archival data from one large, urban district. The archival design took advantage of existing district and state assessment data to study the impact of early algebra knowledge using more than a thousand students across 68 schools. Results from the study point out that students' algebra knowledge in $1^{\text {st }}$ and $2^{\text {nd }}$ grade may be an important predictor of students' $5^{\text {th }}$ grade state standardized mathematics test scores and students' $5^{\text {th }}$ grade knowledge of algebraic thinking and general mathematics concepts measured by district assessments. Results also point out that algebra knowledge in $1^{\text {st }}$ and $2^{\text {nd }}$ grade may be an important predictor of student's rate of growth on state standardized mathematics test scores from $3^{\text {rd }}$ through $5^{\text {th }}$ grade.

\section{Contributions}

The current study contributes to the research on teaching and learning algebra in elementary education. Most prior work on algebra education has focused on teaching algebra in middle school or the longitudinal impact of passing algebra in high school. The current study demonstrates that knowledge of algebra as early as $1^{\text {st }}$ and $2^{\text {nd }}$ grade can have a longitudinal impact on mathematics performance.

The findings of the current study support the theories and research of Kaput 
$(2000 ; 1999 ; 1995 ;$ Kaput \& Blanton, 2001) who believed that algebra is a language of mathematics. As discussed above, he felt that knowledge of fundamental algebra concepts connects to and support students' understanding other mathematics content areas. This parallels researchers who feel that algebra may help students cognitively structure their mathematics knowledge (Fosnot \& Jacob, 2010; Seo \& Ginsburg, 2003). Cognitive structures using algebra can help students integrate more advanced mathematics concepts.

This may be why algebraic thinking knowledge was the only content area that significantly predicted a positive trajectory on students' state standardized mathematics assessments from $3^{\text {rd }}$ through $5^{\text {th }}$ grade. Students who understood early algebraic thinking concepts may have had the tools to better structure their knowledge and learn more advanced concepts in all areas of mathematics as they progressed through elementary school. Students' knowledge scores in the other mathematics content areas in $1^{\text {st }}$ and $2^{\text {nd }}$ grade (number properties and operations, measurement, geometry, analysis and probability, and algebraic thinking) were predictors of $5^{\text {th }}$ grade state standardized test scores, but not growth across $3^{\text {rd }}, 4^{\text {th }}$, and $5^{\text {th }}$ grade. Algebraic thinking knowledge could be a key to stronger gains than predicted by general mathematics knowledge.

In researching the impact that algebra has on later education, educators have agreed that algebra is a gateway to learning higher mathematics (National Mathematics Advisory Panel, 2008a; 2008b; Spielhagen, 2006, Evan, Gray, \& Olchefske, 2006; Achieve, Inc., 2006; Horn \& Nunez, 2000; Horowitz, 2005; Adelman, 1999). This research has made known that students who do well in algebra have better lifelong trajectories in mathematics. This is why researchers have posited that algebra should be 
taught earlier in education (Kaput, 2000; 1999; Schifter, \& Fosnot, 1993; Fosnot \& Jacob, 2010; Kieran, 1992).

Research in middle school has shown that when algebra learning programs are implemented there is evidence that it helps students have more long term success (e.g. Corbett et al., 2001; Fernandez \& Anhalt, 2001). Programs have been designed to help students learn the fundamental concepts of algebra before entering formal algebra in later grades. Students in these programs were able to learn the novel algebraic concepts and how they relate to other areas of mathematics. The programs also demonstrated that learning algebra in middle school could lead to gains in long term mathematics outcomes (e.g. Smith, 1996; Carpenter and Levi, 2000; Fernandez \& Anhalt, 2001). Similar programs could be formed to teach the fundamental concepts of algebra in early elementary education. Researchers and educators could take these existing programs and adapt them for younger students or they could create new programs to help students learn algebra as early as $1^{\text {st }}$ and $2^{\text {nd }}$ grade. Students in programs that target algebra this early may have increased mathematics gains by $5^{\text {th }}$ grade that could positively impact their lifelong mathematics outcomes.

Kaput and Blanton (2001) did test one elementary school program that had $3^{\text {rd }}$ grade teachers create an environment that supported algebraic learning. Students who learned in this environment outperformed their piers on standardized mathematics items. Unfortunately, Kaput and Blanton's (2001) study could only use a small number of students because the corresponding professional development required an entire year of effort. The participating district in their study had also just begun to think about algebra early in these early grades. Thus there was a required shift in pedagogical approaches for 
the participating teachers. Even with these constraints, the authors revealed positive findings of learning algebra an elementary grade. The current study supported these findings and was done on a larger scale. The current study was able to test the effect of students' early algebra knowledge across numerous schools in a district that was already supporting early algebraic learning. The archival nature of the study was able to support Kaput and Blanton's assumptions using a larger sample of students over a longer duration of time.

This study also demonstrated the importance of early knowledge of patterns, relations, and functions. The majority of Core Content Assessment items in $1^{\text {st }}$ and $2^{\text {nd }}$ grade fell within this domain of algebra. Researchers have previously posited that these algebraic areas in particular can help students structure their knowledge. For example, Carraher et al. (2008) used activities based around functions to help students learn number operations from $2^{\text {nd }}$ through $4^{\text {th }}$ grade. The students in this research project used functions to help understand operations from basic addition to fractions. Students were able to use algebraic knowledge of functions to represent and discuss the relationships among quantities. They were able to use these strategies to help solve problems. Schifter et al. (1996) found that students in elementary grades could use knowledge of patterns to discover properties of operations, such as the commutative property. Students in her studies were able to use algebra to discover and understand properties of addition and subtraction (2008) as well as multiplication and division (1996). The current study added to these findings by demonstrating that early algebraic knowledge, mostly of patterns and functions, predicts how well students perform on mathematics problems in $3^{\text {rd }}, 4^{\text {th }}$, and $5^{\text {th }}$ grades. This may have been a result of students using knowledge of patterns, relations, 
and functions to build their knowledge using algebra, as seen in these studies.

Research has also demonstrated that knowledge of patterns, relations, and functions can support learning in other mathematics content areas, such as measurement, data analysis, and geometry (e.g. Dougherty, 2008; Smith, 2008; Lehrer et al.,1999; 2002; Goldenberg et al., 1998; Boester and Lehrer, 2008). For example, Lehrer et al. (2002) looked at $3^{\text {rd }}$ grade students' use of patterns and functions to make sense of geometric principles. The authors showed that $3^{\text {rd }}$ grade students could generate algebraic expressions to represent patterns and relationships of shapes. The students were able to apply data techniques and geometry, such as graph and charts including Cartesian coordinates, to represent and discuss these relationships. The current study expanded upon these findings by demonstrating that algebra knowledge may help students' longitudinal general mathematics knowledge, which includes these content areas. Additionally, these prior studies did not follow students for more than a calendar year or use standardized or local assessments, which the current study was able to accomplish.

The size of the coefficients for general mathematics knowledge in each model is also of interest. Students' general mathematics knowledge in $1^{\text {st }}$ and $2^{\text {nd }}$ grade was the largest predictor of their $5^{\text {th }}$ grade score in all three HLM models. This underlines the importance of fostering students' knowledge of other areas of mathematics as well as algebra. Although general mathematics did not predict students growth of knowledge from $3^{\text {rd }}$ through $5^{\text {th }}$ grade, such large coefficients for predicting $5^{\text {th }}$ grade outcomes cannot be ignored. The coefficients indicate that building students' knowledge of each area of mathematics should not be diminished while bringing algebra into early education. Instead, algebra should be used to enhance the way students learn these areas 
of mathematics as outlined in the Introduction. This will allow students to gain in knowledge of general mathematics while learning and applying algebraic principles. These findings also indicate that students should be assessed on each area of mathematics early in education since general mathematics knowledge is such a large predictor of later outcomes. Students who are struggling in any mathematics content area should be supported in that area as early as possible so they can have the highest possible trajectories from the beginning of education.

A secondary but important goal of the current study was to contribute to the knowledge about the effects of demographic variables on students' mathematics performance and trajectories. The findings of this study reveal the importance of considering variables such as race, free and reduced lunch, and reading ability when analyzing longitudinal mathematics ability. For example, students' race contributed significantly to the models in the study. Students who were races other than Caucasian or Asian-American were predicted to perform lower on mathematics assessments. This result supports previous research that showed these minority students may have lower achievement levels (e.g. Thernstrom \& Thernstrom, 2004). For example, Thernstrom and Thernstrom (2004) provided evidence that the racial gap between Caucasian or AsianAmerican students and African-American or Hispanic students is seen in standardized test as early as $4^{\text {th }}$ grade and persists through $12^{\text {th }}$ grade. In the current study, race did not significantly predict students' growth in ability. This indicates that the racial gap did not change significantly from $3^{\text {rd }}$ through $5^{\text {th }}$ grade. This finding supports previous research that showed the gap that minority students face begins early and is persistent (Lee, 2002; Stiefel et al., 2006; Thernstrom \& Thernstrom, 2004). Closing the gap across races is an 
on-going issue of high importance. Educators and policy makers have repeatedly noted the racial gap in academic performance, including mathematics, and discussed factors that may attribute to or alleviate the gap (e.g. Lee, 2002; Stiefel, et al., 2006). The current study builds support for increasing efforts to support lower performing populations of students. The current study did not find a significant difference between gender. This indicates that males and females in this district did not have a significant gap in elementary mathematics performance as seen in other studies (e.g. Fryer \& Levitt, 2010). This finding does not negate that other differences in gender (such as differences in variance) could exist and should be considered by future studies.

The current study found that schools' percentage of students receiving free and reduced lunch was shown to be a significant negative predictor of both student mathematics achievement in $5^{\text {th }}$ grade and trajectory from $3^{\text {rd }}$ through $5^{\text {th }}$ grade. This supports previous research which indicated that students from poverty at are risk for lower achievement (e.g. Lee \& Burkam, 2002; Burnett \& Farkas, 2009; Greenwald \& Hedges; 1996; Sameroff et al., 1998). These authors thoroughly discuss the risk factors associated with poverty, such as lack of resources, which can hinder children's learning. For example, Lee and Burkam (2002) provide evidence that students from impoverished backgrounds are behind their peers in mathematics skills before formal education even begins. Studies such as Burnett and Farkas (2009) have demonstrated that poverty also effects achievement in elementary grades.

The poverty variable in the current study was at the school level. This supports previous research that showed that poverty can have an adverse effect on mathematics achievement when is clustered at the classroom, school, or even neighborhood level (e.g. 
Palardy, 2008; Hallinan \& Kubitschek, 2010; Georges, 2009); Whipple, Evans, Barry, \& Maxwell, 2010). For example, Hallican \& Kubitschek (2010) performed a longitudinal study on students from $6^{\text {th }}$ through $8^{\text {th }}$ grade and found that school poverty had a negative effect on student outcomes. The authors found that schools with a higher percentage of free and reduced lunch students had lower gains in achievement on the Iowa Test of Basic Skills. Palardy (2008) also found that school level poverty predicted slower learning rates even when controlling for extensive individual and other school level factors. Georges (2009) demonstrated that classroom level poverty can have adverse effects that are stronger than the positive effects of beneficial instructional practices. The current study further emphasizes the importance of promoting this research around the effects of poverty on students' mathematics learning, even if information is only available at the school level. It also builds support for increasing efforts to support schools and students in lower socioeconomic contexts.

The district could benefit from these demographic analyses. These analyses demonstrate a gap in mathematics knowledge and performance for African American and Hispanic students. The findings also reveal schools with a higher percentage of free and reduced lunch students are at risk for lower performance on mathematics assessments. The district may use this information to support initiatives that target schools with higher levels of free and reduced lunch students or minority students. The district may also want to use similar methodologies to explore the effect of additional school or student level variables, such as individualized learning plans or the percentage of English language learners in a school.

This study did not have available an external measure of students' intelligence or 
overall academic ability. Instead, reading knowledge was used as an indicator. Students' mathematics ability in four content areas (number properties and operations, measurement, geometry, analysis and probability) was also included. These variables aimed to account for overall cognitive ability so the effect of early algebra knowledge could be isolated when predicting later mathematics performance. Byrnes and Wasik (2009) found propensity factors such as these in kindergarten and $1^{\text {st }}$ grade to be the strongest predictors of later student achievement in third grade. In the current study, early mathematics ability and reading ability significantly predicted later mathematics ability in each model. This indicates that these measures were able to account for a significant amount of students' academic ability. The results also indicate that reading ability and potential other propensity scores should be considered in long term studies involving growth in mathematics ability.

Lastly, the findings also support methodology that uses hierarchical linear modeling in education settings involving schools or classrooms. Prior research has shown that school level factors can influence student outcomes (e.g. Palardy, 2008). Research that does not take into consideration how students are clustered in schools or classrooms will not account for the variation in student outcomes that is attributable to this clustering. Accounting for more variance by using the different levels of data creates more powerful models by helping to isolate the variation attributable to the variables of interest (O'Connell \& McCoach, 2008). Hierarchical linear modeling also allows the inclusion of variables at each level. This can be particularly beneficial when student level data is unavailable. In the current study, data for student level socioeconomic status could not be obtained. School level socioeconomic status data, however, was publicly available. 
Using this school level data was critical to account for poverty and strengthened the overall models since it predicted student final outcomes and trajectories.

\section{Implications}

A key implication of this study is that the policies around algebra are headed in the right direction. The findings support the implementation and execution of these policies. For example, the states that have adopted the Common Core State Standards for mathematics in 2011 know there is an emphasis on teaching algebraic concepts in elementary grades. Focusing on early algebra knowledge may be a strong shift in thinking for states, regions, or districts that have not been addressing algebra this early in education.

Teachers' may need to strengthen their pedagogical content knowledge and instructional approaches to create a more algebraic environment. Teachers' content knowledge and pedagogical strategies have been shown to impact student outcomes (e.g. Hill, Rowan, and Ball, 2005; Garet, Porter, Desimone, Birman, \& Yoon, 2010; Gersten, Dimino, Jayanthi, Kim, \& Santoro, 2010). Teachers and their students can benefit from professional development that supports teacher knowledge of early algebra concepts. Since teaching algebraic thinking earlier may be required of teachers with the new Standards, they will need support in raising their own algebraic content knowledge and related pedagogical approaches. Teachers will need to have a depth of understanding how

early algebraic concepts are embedded in the Standards and curriculum and how they can be assessed using formative and summative methods in order to adjust teaching strategies to ensure all students understand and apply algebraic reasoning.

There will be a need for supporting professional development involving algebra 
from policy makers and education leaders. The participating district is in a state that began using the Common Core State Standards in 2011. This study will lend support for heeding the Standards' emphasis on algebra in the early grades. Having evidence that early algebra knowledge can predict later mathematics achievement can demonstrate to administrators and teachers the importance of early algebra knowledge and emphasizing how it connects to other mathematics content areas.

Professional development should be geared towards helping teachers integrate algebraic concepts from the new Common Core State Standards into their classrooms. Teachers may need to learn how to apply the earliest algebraic concepts to help structure students' knowledge, as discussed in the Introduction. For example, the Standards include the content area of Operations \& Algebraic Thinking. When addressing this combined content area, teachers will need to help students learn to represent problems, not just solve them. Teachers can help students learn to represent quantities and relationships between quantities in problem situations. For example, teachers can discuss with students how the equals sign does not indicate an operation, but instead shows a relationship of two quantities. Students can then reason about quantities such as 8 to see that it can be broken up into 6 and 2 or 4 and 4 or $6+2$ or $4+4$. Students can then see that $4+4=$ is not just an operation that needs to be memorized, but two ways to represent an equal quantity.

For teachers to promote this type of thinking among students, teachers needs to provide the opportunity for students to work with the underlying concepts within problems. Fostering discussions around the way students are reasoning about concepts in problems will help student to think algebraically. During algebra based activities or 
discussions, students should be aware that they are not just looking for answers, but exploring quantities to look for patterns and relationships. They should look for ways to represent these relationships that make sense to them. Teachers can then use different student ideas and perspectives to discuss the algebra within problems and across problems in each mathematics content area. Teachers can also use students' knowledge and reasoning when introducing a new or more difficult topic. Students can apply the algebraic concepts they know to discover properties and problem solving strategies of a new area, such as applying knowledge of addition to reason about multiplication. For example, student can use knowledge of addition to explore the distributive property of multiplication. They can reason that $12 \times 6$ is similar to adding 12 sets of 6 , or 6 sets of 6 6 plus 6 sets of 6 , or 3 sets of 12 plus 3 set of 12 , and so on. By connecting addition to multiplication, students can see how multiplication is more than just memorizing answers, but uses similar algebraic structures as addition. This process will allow students to structure their knowledge of a new area using the same algebraic principles they used to structure previous knowledge. Students will not always perform this type of reasoning naturally. By setting up a classroom where students are encouraged to reason about problems using representations and relationships, teachers can create activities and discussions to truly help students learn algebra and learn other mathematics content areas by using algebra.

Once the Standards are established in the district used for the current study, the district may want to perform parallel research. They could examine if trends in this study persist with the cohort of students entering into $1^{\text {st }}$ grade in 2011 or 2012 with the new Standards. They may also need to research how the CCA can be adjusted and used to 
measure student performance with the new Standards. Lastly, the district may want to perform in depth studies on the role that teacher instructional practices may have on the current findings.

Analysis of the Core Content Assessments revealed some trends that were not the focus of this study, but indicate content areas on which teachers may need to emphasize. These trends may be of interest for the district to explore further. For example, in $1^{\text {st }}$ and $2^{\text {nd }}$ grade, students were performing strongly in geometry compared to the other areas. Data analysis seemed to be a challenge in $3^{\text {rd }}$ grade. Students were high in measurement knowledge in $3^{\text {rd }}$ grade, but then showed a steep drop in $4^{\text {th }}$ grade $(-20 \%)$. These patterns may indicate areas where students are struggling or where they could be challenged further. These patterns could be analyzed against trends the district has noticed at the school or teacher level as well. The patterns may also have implications for teaching content or practices. For example, students' CCA algebra performance was lower in $5^{\text {th }}$ grade than other grades. The algebra content or standards in this grade may be especially challenging for students. The district may want to consider ways to strengthen students' knowledge of those algebra concepts. For example, the district could place more emphasis on teaching connections between basic algebra concepts and the algebraic concepts within the $5^{\text {th }}$ grade standards.

\section{Limitations}

One major limitation of the study was the lack of information at the classroom level. The models in the study assumed that early algebraic thinking knowledge can have an impact on students' knowledge across a variety of classrooms. The study was not able to delve into the moderating role that teachers' content knowledge or pedagogical 
practices might have in student trajectories. The influence of an effective teacher and teaching has long been documented (e.g. Hill, et al., 2005; Garet, et al., 2010), even in the context of teaching algebra (see Rakes, Valentine, McGatha, \& Ronau; Kaput \& Blanton, 2001; Carpenter \& Levi, 2000). For example, Kaput and Blanton (2001) showed that teachers enhance student learning if they learn where and when to help students' cognitive connections between algebra and general mathematics.

In the current study, how teachers supported student algebraic thinking knowledge was not possible to gather with the limitations of the archival design. The district had not systematically collected this data. The assumption that students most likely had five different teachers during the course of the study would further complicate the design as well. However, if this information would have been available, the role of the teachers' pedagogy in students' trajectories would have added interesting findings to the study.

Relatedly, there was no measure of the fidelity of teachers' implementation of the curriculum or standards. The effect of having the curriculum 'Investigations in Number, Data, and Space' was not significant. The more important aspect of the curricula may have been the fidelity of teachers' use. Other curricula may have been used to emphasize algebra concepts as well. Unfortunately this study had no measure of the degree to which teachers emphasized the early algebra components in the classroom. So even with information on which mathematics curriculum was used in each school, there were no data on classroom implementation. This may have contributed to why schools' curriculum did not improve the fit of any models and was not included in final analyses.

There were also limitations using the district benchmark Core Content 
Assessments. These assessments were not mandated and were not given to all students throughout each year of the study. Teachers and schools that did not implement the CCAs were therefore not included in the study. This may have biased the sample of students. Another limitation became apparent when using the CCA as the longitudinal outcome variable when analyzing students' growth in CCA performance in $3^{\text {rd }}$ through $5^{\text {th }}$ grade (HLM Models 2 and 3). While CCA provided a good measure for early algebraic thinking knowledge, looking at growth across time became limiting when students scored higher in $3^{\text {rd }}$ grade and performed lower in $4^{\text {th }}$ and $5^{\text {th }}$ grade. This may partially be due to the model of the state standards (see Table 1 and Kentucky Department of Education, $2008 \mathrm{a} ; 2009$ for the full tables). The district labeled $1^{\text {st }}, 2^{\text {nd }}$, and $3^{\text {rd }}$ grade as primary grades and created one set of standards that students should master while in those grades. For $4^{\text {th }}$ and $5^{\text {th }}$ grade, the district had created unique standards that target specific content within that grade. Students who mastered the fundamental concepts in $1^{\text {st }}$ and $2^{\text {nd }}$ grade may have hit the ceiling on CCA performance before and/or across $3^{\text {rd }}$ grade. This may partially explain why CCA results dipped in $4^{\text {th }}$ and $5^{\text {th }}$ grade, when students were tested on more novel standards.

The formative nature of these assessments was also a limitation. Teachers administration of the CCA was not uniform, so the number of assessments given varied from school to school and year to year. The number of items across each mathematics content area also varied accordingly and percentage of items in each content area did not match the KCCT (see Tables 4 and 6). This indicates that the assessment did not reflect the same trajectory of knowledge as the Kentucky Core Content Test. The assessments and items were also not as rigorously tested for validity and reliability as the items on the 
Kentucky Core Content Test, which was a limitation of using the district created Core Content Assessments.

The primary weakness for CCA algebraic thinking knowledge in $1^{\text {st }}$ and $2^{\text {nd }}$ grade was the emphasis on patterns, relations, and functions (seen in Table 7). Patterns, relations, and functions constituted $97.1 \%$ of the algebraic thinking items in $1^{\text {st }}$ grade and $79.1 \%$ in $2^{\text {nd }}$ grade. The rest of the items were on equations and inequalities. As discussed above, patterns, relations, and functions could be an important early predictor of mathematics, but without including more items from other algebra topics, the findings may not reveal the complete picture of how early algebra can help students. There were no standards and thus no items around variables, expressions, and operations. In fact, knowledge within this area was barely assessed before $5^{\text {th }}$ grade. Students' early knowledge of these concepts may help to better predict student achievement.

The standards also do not perfectly match the core algebra components that may underlie algebraic knowledge structures: early structuring of the number system; equivalence; comparing quantities and relations, and variance and variables (Fosnot \& Jacob, 2010). It is also unclear how much the problems tested students' mastery of creating generalizations and representations, which Kaput and Blanton (2010) argued is the key to algebra. If the CCA measured these components more explicitly, they may have been a more accurate predictor of mathematics knowledge and growth. Future research could include assessments that match these components, especially in the framework of the newly adopted Common Core State Standards. The Common Core State Standards are a step in the right direction by including unique standards for $1^{\text {st }}, 2^{\text {nd }}$, and $3^{\text {rd }}$ grade. They also emphasize variables, expressions, and operations in these grades 
by combining operational knowledge with algebraic thinking (see CCSSI, 2010).

It is also of interest that algebraic thinking knowledge in $5^{\text {th }}$ grade was the only outcome measure that did not correlate with reading or schools' percentage of students receiving free or reduced lunch. There was also no difference across race. In other words, CCA measurement of algebraic thinking knowledge in $5^{\text {th }}$ grade did not match the patterns of the other mathematics measures. This may be due the fact that variables, expressions and operations were barely assessed until $5^{\text {th }}$ grade (see Table 7). These concepts may have been much more difficult for students. Students may not have had the proper foundation for these concepts since there were no standards addressing them in $1^{\text {st }}$, $2^{\text {nd }}$, or $3^{\text {rd }}$ grade. These concepts could have been challenging for everyone, so all students would have had equivalently weakened performance. This may also explain the dip in averages seen in CCA algebraic thinking knowledge in $5^{\text {th }}$ grade (see Table 9).

Another limitation of this archival design was the amount of missing data and how it was treated. As mentioned earlier entire schools were missing from the dataset since completing CCA was not mandated. In other cases, students in schools that used the CCA each year may not have taken every assessment. This was especially true in the early elementary grades, which resulted in many students having missing data. Students who were missing necessary data were excluded from some analyses, as discussed above. Another approach that could have been used is data imputation. Data imputation is a method where available data is used to calculate missing data points through advanced estimation procedures. Thus all subjects can have complete sets of data. Enders (2010) argues that estimating missing data in this manner will result in datasets with better estimations of population parameters. Thus he argues these datasets will yield more 
accurate results. He suggests a procedure that includes the imputation of numerous full data sets. He then suggests analyses be run with each dataset and final results be computed by pooling results. His recommended multiple data imputation procedure requires advanced statistical packages that were not available to the researcher for this study. Instead, the current study was designed to only look at students who were in the district for five years in schools that consistently gave the Core Content Assessments. This was done to help control for external variability of students switching schools or districts. It was also done because the patterns of missing data were erratic with many students missing over $50 \%$ of their assessments. Thus focusing the sample to students with complete level 2 data made for more concise interpretation of the results.

A final limitation was having only three time points for knowledge growth. A longer study across more grades or time points would provide additional information on student trajectories. A study continuing into later grades could be especially helpful as algebra becomes more and more overtly emphasized. If the CCA were given more consistently during each year, growth within each grade could also have been tracked. This would have added valuable information for how and when students' trajectories in mathematics were shifting.

\section{Future Research}

Despite the identified limitations, the findings demonstrate the importance of early algebra knowledge and have strong implications for future research. Future research should aim to replicate and expand upon these findings while addressing the limitations of this study. The opportunity for effective research will be presented in the upcoming years while states implement the newly adopted Common Core State Standards. Research 
using assessments that target these Standards will address the limitations within the current study by using more specific grade band standards. The Common Core State Standards do spell out clearer concepts for early algebraic knowledge, especially around variables, expressions, and operations. These Standards could lead to more or other areas of algebra being emphasized in $1^{\text {st }}$ and $2^{\text {nd }}$ grade. Research will be needed around the impact of teaching this new range of algebraic concepts in early grades. Future research could target which major concepts of algebra are being learned in the new Standards and how knowledge of these early concepts is supporting student learning.

As mentioned above, future research is needed around the impact of professional development, teacher pedagogical content knowledge, classroom practices, and assessments within the context teaching early algebra using the Common Core State Standards. More research is needed to determine the processes of classroom interactions that help students apply algebra to build their mathematics knowledge structures. With many states adopting the Standards, opportunities for this type of research will be abundant and should be pursued immediately. Learning how to fully support students' overall cognitive structures will make the best use of students' algebraic knowledge and thinking.

Since future studies around the new Common Core State Standards will not be archival, researchers can also plan to analyze moderating classroom variables, such as teaching practices. Researchers can investigate how teachers' algebraic content knowledge, pedagogical strategies, and professional development experiences moderate students' learning trajectories. Future studies in the context of the Standards will have wider validity of results as well. The findings will help shape how algebra is viewed and 
taught throughout the country.

Learning more about the process of how students use algebra to form their cognitive structures can also inform cognitive research around mathematics. Students' cognitive structures for mathematics are intricate and constantly evolving as they learn. Researchers need to discover algebra's role as students' structures grow vertically (higher in difficulty) and horizontally (learning new content areas). Future cognitive research in this area can help unfold this process from the beginning of education. This research can build upon the previous studies that show how students use algebra in each grade to connect their thinking to other areas of mathematics. Researchers could focus on connections and relationships to other specific content areas. Researchers could try to undercover how algebraic principles in each grade are scaffolding students' knowledge of each standard within the content areas. This would require significant classroom research around students' perceptions and knowledge of algebra and how it affects their conceptual reasoning. Such educational and psychological research could be done in parallel to discover the theoretical and practical implications of how students are developing their cognitive structures of mathematics within the school system.

Future research could model and expand upon earlier studies, such as Kaput and Blanton's (2001), on a larger scale. The effective elements from algebraic programs that have shown success could be used on entire districts or regions. The students could also be tracked along the new Standards for longer than five years to see if early algebra mastery can lead to better mathematics outcomes in middle school and potentially beyond.

The current study also has implications for algebra knowledge before $1^{\text {st }}$ grade. 
When parents and teachers first begin to teach mathematics to children, the fundamental concepts of algebra can be emphasized. If children learn the skills of creating representations and generalizations early in life, they may gain an even larger advantage when entering formal education. Getting children thinking algebraically, such as considering equivalence and comparing quantities and relations, while learning the early number systems, could help lead them into elementary school with algebraic knowledge structures. Studies such as Moyer et al. (2005) have shown that students in kindergarten can creatively think about and apply algebraic concepts such as patterns. This fundamental knowledge could help them build more complex cognitive structures during formal learning. Future research could target students' school readiness in mathematics in light of algebraic thinking. Researchers could demonstrate the longitudinal impact of thinking algebraically before formal education.

\section{Conclusions}

The current study demonstrated that algebra knowledge in $1^{\text {st }}$ and $2^{\text {nd }}$ grade can predict mathematics ability in $5^{\text {th }}$ grade. Early algebra knowledge was also shown to predict growth in standardized test scores in $3^{\text {rd }}$ through $5^{\text {th }}$ grade. The results considered students' early ability in other areas of mathematics, reading ability, race, gender, and schools' curriculum use and percentage of students receiving free and reduced lunch. The findings support prior research that demonstrated students can learn and apply fundamental algebra concepts in early elementary school. The findings also support theories that early algebraic conceptual knowledge can support the way students structure their on-going mathematics knowledge. Focusing on learning and applying fundamental algebra concepts can help students structure their mathematics knowledge from the 
beginning of education. The results underline the importance of including algebra in early elementary teaching, standards, and assessments. The current study also suggests that further research is needed that looks at how algebra is being taught and how students are using algebra to build their cognitive knowledge structures across elementary grades. 


\section{REFERENCES}

Achieve, Inc. (2010). Comparing the Common Core State Standards and Singapore's mathematics syllabus. Washington, DC: Author.

Achieve, Inc. (2006). Closing the expectations gap: An annual 50-state progress report on the alignment of high school policies with the demands of college and work. Washington, DC: Author.

Adelman, C. (1999). Answers in the toolbox: Academic intensity, attendance patterns and bachelor's degree attainment. Washington, DC: U.S. Department of Education. Anderson, J. R., Corbett, A. T., Koedinger, K. R., \& Pelletier, R. (1995). Cognitive tutors: Lessons learned. The Journal of the Learning Sciences, 4(2), 167-207.

Baroudi, Z. (2006). Easing students transition to algebra. Australian Mathematics Teacher, 62, 28-33.

Bastable, V., \& Schifter, D. (2008). Classroom stories: Examples of elementary students engaged in early algebra. In J. Kaput, D. Carraher, \& M. Blanton (Eds.), Algebra in the early grades (pp. 165-184). Mahwah, NJ: Lawrence Erlbaum Associates.

Behr, M. (1980). How children view the equal sign. Mathematics Teaching, 92, 13-15.

Behr, M., Lesh, R., Post, T., \& Silver E. (1983). Rational number concepts. In R. Lesh, \& M. Landau (Eds.), Acquisition of mathematics concepts and processes (pp. 91125). New York: Academic Press.

Behr, M., Wachsmuth, I., \& Post, T. (1985). Construct a sum: A measure of children's 
understanding of fraction size. Journal for Research in Mathematics Education, $16(2), 120-131$.

Blanton, M., \& Kaput, J. J. (2003). Developing elementary teachers' "algebra eyes and ears". Teaching Children Mathematics, 10(2), 70-77.

Boester, T., \& Lehrer, R. (2008). Visualizing algebraic reasoning. In J. J. Kaput, D. W. Carraher, \& M. L. Blanton (Eds.), Algebra in the early grades (pp. 211-234). New York: Routledge.

Brenner, M. E., Mayer, R. E., Moseley, B., Brar, T., Duran, R., Reed, B. S., \& Webb, D. (1997). Learning by understanding: The role of multiple representations in learning algebra. American Educational Research Journal, 34(4), 663-689.

Briggs, J., Demana, F., \& Osborne, A. (1986). Moving into algebra: Developing the concepts of variable and function. The Australian Mathematics Teacher, 42, 5-8.

Brizuela, B. M., \& Earnest, E. (2008). Multiple notational systems and algebraic understandings: The case of the "Best Deal" problem. In J. J. Kaput, D. W. Carraher, \& M. L. Blanton (Eds.), Algebra in the early grades (pp. 273-302). New York: Routledge.

Brizuela, B., Carraher, D. W., \& Schliemann, A. D. (2000, April). Mathematical notation to support and further reasoning ("to help me think of something"). Paper presented at the Annual Research Presession of the National Council of Teachers of Mathematics, Chicago, IL.

Brown, V. (1996). Third graders explore multiplication. In D. Schifter (Ed.), What's happening in math class? Vol. 1. Envisioning new practices through teacher narratives (pp. 18-23). New York: Teachers College Press. 
Byrnes, J. P., \& Wasik, B. A. (2009). Factors predictive of mathematics achievement in kindergarten, first and third grades: An opportunity-propensity analysis. Contemporary Educational Psychology, 34(2),167-183.

Burnett, K., \& Farkas, G. (2009). Poverty and family structure effects on children's mathematics achievement: Estimates from random and fixed effects models. The Social Science Journal, 46(2), 297-318.

Caldas, S. J., \& Bankston, C. (1997). Effect of school population socioeconomic status on individual academic achievement. The Journal of Educational Research, 90(5), 269-277.

Carpenter, T. P., Fennema, E., Franke, M. L., Levi, L., \& Empson, S. B. (2000). Cognitively Guided Instruction: A research-based teacher development program for elementary school mathematics. Madison, WI: National Center for Improving Student Learning and Achievement in Mathematics and Science.

Carpenter, T. P., Fennema, E., Franke, M. L., Levi, L., \& Empson, S. B. (1999). Children's mathematics: Cognitively Guided Instruction. Portsmouth, N.H.: National Council of Teachers of Mathematics.

Carpenter, T. P., \& Levi, L. B. (2000). Developing concentrations of algebraic reasoning in the primary grades. Madison, WI: National Center for Improving Student Learning and Achievement in Mathematics and Science.

Carraher, D., Schliemann, A. D., \& Brizuela, B. M. (2000, October). Early algebra, early arithmetic: Treating operations as function. Presented at the Twenty-second Annual Meeting of the North American Chapter of the International Group for the Psychology of Mathematics Education, Tucson, AZ. 
Carraher, D., Schliemann, A. D., \& Brizuela, B. M. (2001). Can young students operate on unknowns? In M. van den Hueuvel-Panhuizen (Ed.), Proceedings of the 25th Conference of the International Group for the Psychology of Mathematics Education: Vol. 1 (pp. 130-140). The Netherlands: Freudental Institute, Utrecht University.

Carraher, D., Schliemann, A. D., \& Schwartz, J. L. (2008). Early algebra is not the same as algebra early. In J. J. Kaput, D. W. Carraher, \& M. L. Blanton (Eds.), Algebra in the early grades (pp. 235-272). New York: Routledge.

Clement, L. L. (2001). What do students really know about functions? Mathematics Teacher, 94, 745-748.

Cobb, P., Gravemeijer, K., Yackel, E., McClain, K., \& Whitenack, J. (1997). Mathematizing and symbolizing: The emergence of chains of signification in one first-grade classroom. In D. Kirshner \& J. A. Whiston (Eds.), Situated cognition theory: Social, semiotic, and neurological perspectives (pp. 151-233). Hillsdale, NJ: Lawrence Erlbaum Associates.

Cohen, J. (1988). Statistical power analysis for the behavioral sciences (2nd ed.). Hillsdale, NJ: Lawrence Erlbaum Associates.

Common Core State Standards Initiative. (2010). Common Core State Standards for mathematics. Retrieved December 20, 2010, from corestandards.org: http://www.corestandards.org/assets/CCSSI_Math\%20Standards.pdf

Corbett, A. T., Koedinger, K., \& Hadley, W. S. (2001). Cognitive tutors: From the research classroom to all classrooms. In P. S. Goodman (Ed.), Technology enhanced learning: Opportunities for change (pp. 235-263). Mahwah, N.J.: 
Lawrence Erlbaum Associates.

Cramer, K. (2001). Using models to build an understanding of functions. Mathematics Teaching in the Middle School, 6(5), 310-318.

Cramer, K., Behr, M., Post T., \& Lesh, R. (1997). Rational Number Project: Fraction lessons for the middle grades - Level 1. Dubuque, IA: Kendall/Hunt Publishing.

Cramer, K. A., Post, T. R., \& delMas, R. C. (2002). Initial fraction learning by fourthand fifth-grade students: A comparison of the effects of using commercial curricula with the effects of using the Rational Number Project curriculum. Journal for Research in Mathematics Education, 33(2) 111-144.

Cuevas, G. J., \& Yeatts, K. Y. (2001). Navigating through algebra in grades 3-5. Reston, VA: National Council of Teachers of Mathematics.

Cuoco, A., Goldenberg, E. P., \& Mark, J. (1996). Habits of mind: An organizing principle for mathematics curriculum. Journal Mathematics Behavior, 15(4), 375402.

Davydov, V. V. (1975). The psychological characteristics of the "prenumerical" period of mathematics instruction. In L. P. Steffe (Ed.), Children's capacity for learning mathematics: Vol. 7. Soviet studies in the psychology of learning and teaching mathematics (pp. 109-205). Chicago: University of Chicago.

Dietiker, L., Kysh, J., Hoey, B. \& Salley, T. (2006). Algebra connections (Version 3.0). Sacramento, CA: College Preparatory Mathematics.

DiSessa, A. (2004). Metarepresentation: Native competence and targets for instruction. Cognition \& Instruction, 22(3), 293-331.

Dossey, J. A. (1998). Making algebra dynamic and motivating: A national challenge. In 
The nature and role of algebra in the K-14 curriculum: Proceedings of a national symposium (pp. 17-22). Washington, D.C.: National Academy Press.

Dougherty, B. (2008). Measure up: A quantitative view of early algebra. In J. J. Kaput, D. W. Carraher, \& M. L. Blanton (Eds.), Algebra in the early grades (pp. 389412). New York: Routledge.

Dreyfus, T., \& Eisenberg, T. (1984). Intuitions of functions. Journal of Experimental Education, 52, 77-85.

Driscoll, M. (1999). Fostering algebraic thinking: A guide for teachers grades 6-10. Portsmouth, NH: Heineman.

Driscoll, M., Zawojeski, J., Humez, A., Nikula, J, Goldsmith, L., \& Hammerman, J. (2001). The fostering of algebraic thinking toolkit: A guide of staff development. Portsmouth, NH: Heinemann.

EDinformatics. (2010). NCTM Focal Points and Singapore Math Syllabus: New Curriculum is more in line with International Standards. Retrieved December 20, 2010, from edinformatics.com:

http://www.edinformatics.com/math_science/nctm_singapore_math.htm

Enders, C. K. (2010). Applied missing data analysis: Methodology in the social sciences. New York: Guilford Press.

Evan, A., Gray, T., \& Olchefske, J. (2006). The gateway to student success in mathematics and science. Washington, DC: American Institutes for Research.

Fernandez, M. L., \& Anhalt, C. O. (2001). Transition Toward Algebra. Mathematics Teaching in the Middle School, 7(4), 236-241.

Fey, J. T. (1989). School algebra for the year 2000. In S. Wanger \& C. Kieran (Eds.), 
Research in the learning and teaching of algebra (pp. 199-213). Reston, VA: National Council of the Teachers of Mathematics.

Fosnot, C. T., \& Jacob, B. (2010). Young mathematicians at work: Constructing algebra. Portsmouth, NH: Heinemann.

Fryer, R. G., \& Levitt, S. D. (2010). An empirical analysis of the gender gap in mathematics. American Economic Journal: Applied Economics, 2(2), 210-140.

Fujii, T. (2003). Probing students' understanding of variables through cognitive conflict problems: Is the concept of a variable so difficult for students to understand? In N. Pateman, B. Dougherty, \& J. Zilliox (Eds.), Proceedings of the $27^{\text {th }}$ Conference of the International Group for the Psychology of Mathematics Education: Vol. 1 (pp. 49-66). Honolulu, HI: University of Hawaii.

Garet, M. S., Porter, A. C., Desimone, L., Birman, B. F., \& Yoon, K. S. (2001). What makes professional development effective? Results from a national sample of teachers. American Educational Research Journal, 38(4), 915-945.

Georges, A. (2009). Relation of instruction and poverty to mathematics achievement gains during kindergarten. Teachers College Record, 111(9), 2148-2178.

Gersten, R., Dimino, J., Jayanthi, M., Kim, J. S., \& Santoro, L. E. (2010). Teacher study group: Impact of the professional development model on reading instruction and student outcomes in first grade classrooms. American Educational Research Journal 47(3), 694-739.

Ginsburg, H. P., Leinwand, S., Anstrom, T., \& Pollock, E. (2005). What the United States can learn from Singapore's world-class mathematics system (and what Singapore can learn from the United States): An exploratory study. Washington, DC: 
American Institutes for Research.

Goldenberg, E. P., Cuoco, A. A., \& Mark, J. (1998). A role for geometry in general education. In R. Lehrer \& C. Chazan (Eds.), Designing learning environments for developing understanding of geometry and space (pp. 3-44). Mahwah, NJ: Lawrence Erlbaum Associates.

Goldenberg, E. P. \& Shteingold, N. (2008). Early algebra: The math workshop perspective. In J. Kaput, D. Carraher, \& M. Blanton (Eds.), Algebra in the early grades (pp. 449-477). Mahwah, NJ: Lawrence Erlbaum Associates.

Goldenberg, E. P. \& Shteingold, N. (2003). Mathematical habits of mind. In F. Lester \& R. I. Charles (Eds.), Teaching mathematics through problem solving:

Prekindergarten-grade 6 (pp. 15-29). Reston, VA: National Council of Teachers of Mathematics.

Gonzales, P., Guzmán, J. C., Partelow, L., Pahlke, E., Jocelyn, L., Kastberg, D., \& Williams, T. (2004). Highlights from the Trends in International Mathematics and Science Study (TIMSS) 2003 (NCES 2005-005). U.S. Department of Education, National Center for Education Statistics. Washington, DC: U.S. Government Printing Office.

Gravemeijer, K., Cobb, P., Bowers, J., \& Whitenack, J. (2000). Symbolizing, modeling, and instructional design. In P. Cobb, E. Yackel, \& K. McClain (Eds.), Symbolizing and communicating in mathematics classrooms (pp. 225-274). Mahwah, NJ: Lawrence Erlbaum Associates.

Greenes, C., Cavanagh, M., Dacey, L., Findell, C., \& Small, M. (2001). Navigating through algebra in prekindergarten-grade 2. Reston, VA: National Council of 
Teachers of Mathematics.

Greenwald, R., \& Hedges, L. V. (1996). The effect of school resources on student achievement. Review of Educational Research, 66(3), 361-396.

Hallinan, M. T., \& Kubitschek, W. N. (2010). School sector, school poverty, and the catholic school advantage. Catholic Education: A Journal of Inquiry and Practice, 14(2), 143-172.

Hill, H. C., Rowan, B., \& Ball, D. L. (2005). Effects of teachers' mathematical knowledge for teaching on student achievement. American Educational Research Journal, 42(2), 371-406.

Horn, L., \& Nunez, A. (2000). Mapping the road to college: First-generation students' math track, planning strategies, and context of support (NCES 2000-153). Washington DC: U.S. Department of Education.

Horowitz, J. E. (2005). Inside high school reform: Making the changes that matter. San Fransisco: WestEd.

Kalchman, M. S., \& Koedinger, K. R. (2005). Teaching and learning functions. In M. S. Donovan \& J. D. Bransford (Eds.), How students learn: History, mathematics, and science in the classroom (pp. 351-396). Washington, D.C.: National Academic Press.

Kaput, J. J. (2000). Transforming algebra from an engine of inequity to an engine of mathematical power by "algebrafying" the K-12 curriculum. Dartmouth, MA: National Center for Improving Student Learning and Achievement in Mathematics and Science.

Kaput, J. J. (1999). Teaching and learning a new algebra with understanding. In E. 
Fennema, \& T. A. Romberg (Eds.), Mathematics classrooms that promote understanding (pp. 133-155). Mahwah, NJ: Lawrence Erlbaum Associates.

Kaput, J. J. (1995, October). A research base supporting long term algebra reform?

Paper presented at the 17th Annual Meeting of the North American Chapter of the International Group for the Psychology of Mathematics Education, Columbus, $\mathrm{OH}$.

Kaput, J. J., \& Blanton, M. L. (2001). Student achievement in algebraic thinking: A comparison of $3^{\text {rd }}$ graders' performance on a state $4^{\text {th }}$ grade assessment. In R. Speiser, C. Maher, \& C. Walter (Eds.), The proceedings of the $23^{\text {rd }}$ annual meeting of the North American Chapter of the International Group for the Psychology of Mathematics Education: Vol. 1 (pp. 99-107). Columbus, OH: The ERIC Clearinghouse for Science, Mathematics, and Environmental Education.

Kaput, J. J., \& Blanton, M. L. (2000). Algebraic reasoning in the context of elementary mathematics: Making it implementable on a massive scale. Dartmouth, MA: National Center for Improving Student Learning and Achievement in Mathematics and Science.

Kaput, J. J., Blanton, M. L., \& Moreno, L. (2008). Algebra from a symbolization point of view. In J. Kaput, D. Carraher, \& M. Blanton (Eds.), Algebra in the early grades (pp. 19-55). Mahwah, NJ: Lawrence Erlbaum Associates.

Kaput, J. J., Carraher, D. W., \& Blanton, M. L. (Eds.). (2008). Algebra in the early grades. New York: Routledge.

Kentucky Department of Education. (2010, January 13). Kentucky school testing system. Retrieved January 31, 2010, from google.com: 
http://www.education.ky.gov/KDE/Administrative+Resources/Testing+and+Repo rting+/Kentucky+School+Testing+System/

Kentucky Department of Education. (2009). Core Content Guide. Retrieved October 1, 2009, from google.com:

http://www.education.ky.gov/KDE/Instructional+Resources/Curriculum+Docume nts+and+Resources/Core+Content + for+Assessment/

Kentucky Department of Education. (2008a, June 7). Social studies curriculum maps. Retrieved October 1, 2009, from google.com:

http://www.education.ky.gov/KDE/Instructional+Resources/Curriculum+Docume nts+and+Resources/Teaching + Tools/Curriculum+Maps

Kentucky Department of Education. (2008b, June 2). Core Content for Assessment version 4.1. Retrieved October 1, 2009, from google.com: http://www.education.ky.gov/KDE/Instructional+REsources/Curriculum+Docum ents+and + Resources $/$ Core + Content + for + Assessment $/$ Core + Content + for + Assess ment+4.1/

Kentucky Department of Education. (2006, August). Core Content for Reading Assessment: Elementary version 4.1. Retrieved October 1, 2009, from google.com:

http://www.education.ky.gov/KDE/Instructional+Resources/Curriculum+Docume nts + and + Resources $/$ Core + Content + for + Assessment $/$ Core + Content + for + Assessm ent $+4.1 /$

Kentucky Department of Education. (2004). 2004 CATS interpretive guide detailed information on using your score reports. Frankfort, KY: Author. Retrieved 
October 1, 2009, from google.com:

http://www.education.ky.gov/NR/rdonlyres/B8D0B770-7D3F-4C8E-B7CD-

77D31DC092EA/0/InterpretiveGuide2004.pdf

Kieran, C. (1981). Concepts associated with the equality symbol. Educational Studies in Mathematics, 12(3), 317-326.

Kieran, C. (1992). The learning and teaching of school algebra. In D. A. Grouws (Ed.), Handbook of research on mathematics teaching and learning: A project of the National Council of Teachers of Mathematics (pp. 390-419). New York: Macmillan.

Kieran, C. (2008). What do students struggle with when first introduced to algebra symbols? Reston, VA: National Council for Teachers of Mathematics. Retrieved February 11, 2011, from google.com: http://www.nctm.org/news/content.aspx?id=12332

Koedinger, K. R., \& Anderson, J. R. (1998). Illustrating principled design: The early evolution of a cognitive tutor for algebra symbolization. Interactive Learning Environments, 5, 161-179.

Koedinger, K. R., Anderson, J. R., Hadley, W. H., \& Mark, M. A. (1997). Intelligent tutoring goes to school in the big city. International Journal of Artificial Intelligence in Education, 8, 30-43.

Koedinger, K. R., \& MacLaren, B. A. (2002). Developing a pedagogical domain theory of early algebra problem solving. CMU-HCII Tech Report 02-100. Pittsburgh, PA: Carnegie Mellon University, School of Computer Science.

Lee, J. (2002). Racial and ethnic achievement gap trends: Reversing the progress toward 
equity? Educational Researcher January, 31, 3-12.

Lee, V. E., \& Burkam, D. T. (2002). Inequality at the starting gate: Social background differences in achievement as children begin school. Washington, D.C.: Economic Policy Institute.

Lehrer, R., Jacobson, C., Kemeny, V., \& Strom, D. (1999). Building on children's intuitions to build mathematical understanding in space. In E. Fennema \& T. A. Romberg (Eds.), Mathematics classrooms that promote understanding (pp. 6387). Mahwah, NJ: Lawrence Erlbaum Associates.

Lehrer, R., Strom, D., \& Confrey, J. (2002). Grounding metaphors and inscriptional resonance: Children's emerging understanding of mathematical similarity. Cognition and Instruction, 20, 359-398.

Lester, J. B. (1996). Is the algorithm all there is? In C. T. Fosnot (Ed.), Constructivism: Foundations, perspectives, and practice (pp. 145-152). New York: Teachers College Press.

Little, R. J. A., \& Rubin, D. B. (2002). Statistical analysis with missing data (2nd ed.). New York: Wiley.

Marzano, R. J. (2006). Classroom assessment \& grading that work. Alexandria, VA: Association for Supervision and Curriculum Development.

Mason, J. (2008). Making use of children's powers to produce algebraic thinking. In J. Kaput, D. Carraher, \& M. Blanton (Eds.), Algebra in the early grades (pp. 57-94). Mahwah, NJ: Lawrence Erlbaum Associates.

McCoach, D. B., \& Black, A. C. (2008). Evaluation of model fit and adequacy. In A. A. O'Connell \& D. B. McCoach (Eds.), Multilevel modeling of educational data (pp. 
245-272). Charlotte, NC: Information Age Publishing.

Moses, R. P., \& Cobb, C. Jr. (2001). Organizing algebra: The need to voice a demand. Social Policy, 3, 4-12.

Moss, J., \& Case, R. (1999). Developing children's understanding of the rational numbers: A new model and experimental curriculum. Journal for Research in Mathematics Education, 30, 122-147.

Moyer, P. S., Niezgoda, D., \& Stanley, J. (2005). Young children's use of virtual manipulatives and other forms of mathematical representation. In W. J. Masalski \& P. C. Elliott (Eds.), Technology-supported mathematics learning environments $67^{\text {th }}$ yearbook (pp. 17-34). Reston, VA: National Council of Teachers of Mathematics.

Moynahan, J. (1996). Of-ing fractions. In D. Schifter (Ed.), What's happening in math class? Vol. 1. Envisioning new practices through teacher narratives (pp. 24-36). New York: Teachers College Press.

National Council of Teachers of Mathematics. (2000). Principles and standards for school mathematics. Reston, Va.: Author.

National Council of Teachers of Mathematics. (1998). The nature and role of algebra in the K-14 curriculum. Reston, VA: Author.

National Council of Teachers of Mathematics. (1989). Curriculum and evaluation standards for school mathematics. Reston, VA: Author.

National Mathematics Advisory Panel. (2008a). Foundations for success: The final report of the National Mathematics Advisory Panel. Washington, DC: U.S. Department of Education. 
National Mathematics Advisory Panel. (2008b). Reports of the task groups and subcommittees. Washington DC: Author.

O'Connell A. A., \& McCoach, D. B. (2008). Multilevel modeling of educational data. Charlotte, NC: Information Age Publishing.

Palardy, G. J. (2008). Differential school effects among low, middle, and high social class composition schools: A multiple group, multilevel latent growth curve analysis. School Effectiveness and School Improvement, 19(1), 21-49.

Phillips, E., \& Lappan, G. (1998). Algebra: The first gate. In L. Leutzinger (Ed.), Mathematics in the middle (pp. 10-19). Reston, VA: National Council of Teachers of Mathematics.

Post, T. (1979). Making time for the basics: Some thoughts on viable alternatives within a balanced mathematics program. In S. Sharron, \& R. Reys (Eds.), Applications in school mathematics: 1979 yearbook (pp. 352-356). Reston, VA: National Council of Teachers of Mathematics.

Rakes, C. R., Valentine, J. C., McGatha, M. B., \& Ronau, R. N. (2010). Methods of instructional improvement in algebra: A systematic review and meta-analysis. Review of Educational Research, 80(3), 372-400.

RAND Mathematics Study Panel (2003). Mathematical proficiency for all students. Pittsburgh: RAND.

Raudenbush, S. W., \& Bryk, A. S. (2002). Hierarchical linear models: Applications and data analysis methods. Thousand Oaks, CA: Sage.

Sameroff, A. J., Bartko, W. T., Baldwin, A., \& Seifer, R. (1998). Family and social influences on the development of child competence. In M. Lewis \& C. Feiring 
(Eds.), Families, risk, and competence (pp. 161-185). Mahwah, NJ: Erlbaum.

Schifter, D. (Ed.). (1996). What's happening in math class? Vol. 1. Envisioning new practices through teacher narratives. New York: Teachers College Press.

Schifter, D. (Ed.). (1996). What's happening in math class? Vol. 2. Reconstructing professional identities. New York: Teachers College Press.

Schifter, D. (1996). A constructivist perspective on teaching and learning mathematics. Phi Delta Kappan, 77(7), 492-499.

Schifter, D., Bastable, V., \& Russell, S. J. (1997). Attention to mathematical thinking: Teaching to the Big Ideas. In S. Friel, \& G. Bright (Eds.), Reflecting on our work: NSF teacher enhancement in mathematics $K-6$ (pp. 255-262). Washington, DC: University Press of America.

Schifter, D., \& Fosnot, C. T. (1993). Reconstructing mathematics education: Stories of teachers meeting the challenge of reform. New York: Teachers College Press.

Schifter, D., Monk, S., Russell, S. J., \& Bastable, V. (2008). Early algebra: What does understanding the laws of arithmetic mean in the elementary grades? In J. Kaput, D. Carraher, \& M. Blanton (Eds.), Algebra in the early grades (pp. 413-447). Mahwah, NJ: Lawrence Erlbaum Associates.

Schliemann, A. D., Carraher, D. W., \& Brizuela, B. M. (2000, April). From quantities to ratio, function, and algebraic relations. Paper presented at the 2000 Annual Meeting of the American Educational Research Association, New Orleans, LA.

Scientific Software International, Inc. (2010a). Proportion variance explained: Two-level models. Retrieved February 10, 2011, from google.com: http://www.ssicentral.com/hlm/help6/faq/Proportion_Variance_Explained_Two- 
level_models.pdf

Scientific Software International, Inc. (2010b). Use of deviance statistics for comparing models. Retrieved February 10, 2011, from google.com:

$\mathrm{http} / / \mathrm{www} . s s i c e n t r a l . c o m / \mathrm{hlm} / \mathrm{help} 6 /$ faq/Use_of_deviance_statistics_for_compar ing models.pdf

Seo, K., \& Ginsburg, H. P. (2003). "You've got to carefully read the math sentence ...":

Classroom context and children's interpretations of the equals sign. In A. J.

Baroody, \& A. Dowker (Eds.), The development of arithmetic concepts and skills:

Constructing adaptive expertise (pp. 161-187). Mahwah, NJ: Lawrence Erlbaum Associates.

Sfard, A. (2000). Symbolizing mathematical reality into being-Or how mathematical discourse and mathematical objects create each other. In P. Cobb, E. Yackel, \& K. McCain (Eds.), Symbolizing and communicating in mathematics classroom (pp. 37-97). London: LEA.

Silva, C., \& Moses, R. P. (1990). The Algebra Project: Making middle school mathematics count. Journal of Negro Education, 59(3), 375-91

Sinclair, A. L., Bynum, B. H., Thacker, A. A., \& Hoffman, R. G. (2008). Third-party checking of calibration, scaling and equating of the 2008 Kentucky Core Content Test. Human Resources Research Organization. Report prepared for the Kentucky Department of Education.

Smith, J. B. (1996). Does an extra year make any difference? The impact of early access to algebra on long-term gains in mathematics achievement. Educational Evaluation and Policy Analysis, 18(2), 141-153. 
Smith, J. P., \& Thompson, P. W. (2008). Quantitative reasoning and the development of algebraic reasoning. In J. Kaput, D. Carraher, \& M. Blanton (Eds.), Algebra in the early grades (pp. 95-132). Mahwah, NJ: Lawrence Erlbaum Associates.

Snijders, T. (1996). Analysis of longitudinal data using the hierarchical linear model. Quality \& Quantity, 30(4), 405-426.

Sowder, L. (1988). Children's solutions of story problems. Journal of Mathematical Behavior, 7, 227-238.

Spielhagen, F. R. (2006). Closing the achievement gap in math: The long-term effects of eighth-grade algebra. Journal of Advanced Academics, 18(1), 34-59.

Stiefel, S., Schwartz, A. E., \& Ellen, I. G. (2006). Disentangling the racial test score gap: Probing the evidence in a large urban school district. Journal of Policy Analysis and Management, 26(1), 7-30.

Stiggins, R. J., Arter, J. A., Chappuis, J., \& Chappuis, S. (2009). Classroom assessment for student learning: Doing it right, using it well. Boston, MA: Allyn \& Bacon.

Stiggins, R. J. (2005). The unfulfilled promise of classroom assessment. Educational Measurement: Issues and Practice, 20(3), 5-15.

Suh, J., \& Moyer, P. S. (2007). Developing students' representational fluency using virtual and physical algebra balances. Journal of Computers in Mathematics and Science Teaching, 26, 155-173.

TERC. (2007). Investigations in Number, Data, and Space. Retrieved October 1, 2009, from google.com: http://investigations.terc.edu/

Thernstrom, A. \& Thernstrom, S. (2004). No excuses: Closing the racial gap in learning. New York: Simon \& Schuster. 
United States Department of Agriculture. (2011, May 18). Nutrition and Health Services.

Retrieved May 23, 2011, from google.com:

http://scn.ky.gov/octdataout/rptlist.htm

United States Department of Agriculture. (2009, October 29). National School Lunch

Program. Retrieved October 1, 2009, from google.com:

http://www.fns.usda.gov/cnd/Lunch/

Van de Walle, J. A. (1990). Elementary school mathematics: Teaching developmentally. New York: Longman.

Whipple, S. S., Evans, G. W., Barry, R. L., \& Maxwell, L. E. (2010). An ecological perspective on cumulative school and neighborhood risk factors related to achievement. Journal of Applied Developmental Psychology, 31(6), 422-427.

Williams, S. R. (1993). Mathematics and being in the world: Toward an interpretive framework. For the Learning of Mathematics, 13(2), 2-7.

Yerushalmy, M. (1997). Designing representations: Reasoning about functions of two variables. Journal for Research in Mathematics Education, 28, 431-466. 


\section{APPENDIX A}

The percentages of total items given to students that target standards in each mathematics content area are shown in Table 7.

Table 22

Percentage of CCA Number Properties and Operations Items Targeting Each of Its Components

\begin{tabular}{lccccc}
\hline Grade & $\begin{array}{c}\text { Number } \\
\text { Sense }\end{array}$ & Estimation & $\begin{array}{c}\text { Number } \\
\text { Operations }\end{array}$ & $\begin{array}{c}\text { Ratios and } \\
\text { Proportional } \\
\text { Reading }\end{array}$ & $\begin{array}{c}\text { Properties of } \\
\text { Numbers and } \\
\text { Operations }\end{array}$ \\
\hline $1^{\text {st }}$ & $27.0 \%$ & $0.4 \%$ & $71.7 \%$ & $0.0 \%$ & $0.9 \%$ \\
$2^{\text {nd }}$ & $42.3 \%$ & $15.7 \%$ & $33.9 \%$ & $0.0 \%$ & $8.0 \%$ \\
$3^{\text {rd }}$ & $44.3 \%$ & $7.6 \%$ & $41.8 \%$ & $0.0 \%$ & $6.3 \%$ \\
$4^{\text {th }}$ & $45.8 \%$ & $5.3 \%$ & $34.6 \%$ & $0.0 \%$ & $14.3 \%$ \\
$5^{\text {th }}$ & $40.8 \%$ & $7.0 \%$ & $34.1 \%$ & $1.1 \%$ & $17.1 \%$ \\
\hline
\end{tabular}

Table 23

Percentage of CCA Data Analysis and Probability Items Targeting Each of Its

Components

\begin{tabular}{lcccc}
\hline Grade & $\begin{array}{c}\text { Data } \\
\text { Representations }\end{array}$ & $\begin{array}{c}\text { Characteristics } \\
\text { of Datasets }\end{array}$ & $\begin{array}{c}\text { Experiments } \\
\text { and Samples }\end{array}$ & Probability \\
\hline $1^{\text {st }}$ & N/A* & N/A* & N/A* & N/A* \\
$2^{\text {nd }}$ & $99.8 \%$ & $0.0 \%$ & $0.0 \%$ & $0.2 \%$ \\
$3^{\text {rd }}$ & $97.1 \%$ & $0.0 \%$ & $0.0 \%$ & $2.9 \%$ \\
$4^{\text {th }}$ & $45.0 \%$ & $27.5 \%$ & $0.5 \%$ & $27.0 \%$ \\
$5^{\text {th }}$ & $34.3 \%$ & $24.9 \%$ & $1.8 \%$ & $39.0 \%$ \\
\hline
\end{tabular}

${ }^{*}$ No items were given on Data Analysis and Probability in the $1^{\text {st }}$ grade. 
Table 24

Percentage of CCA Measurement Items Targeting Each of Its Components

\begin{tabular}{lcc}
\hline Grade & Measuring Physical Attributes & Systems of Measurement \\
\hline $1^{\text {st }}$ & $98.8 \%$ & $1.2 \%$ \\
$2^{\text {nd }}$ & $95.7 \%$ & $4.3 \%$ \\
$3^{\text {rd }}$ & $93.1 \%$ & $6.9 \%$ \\
$4^{\text {th }}$ & $63.7 \%$ & $36.3 \%$ \\
$5^{\text {th }}$ & $81.2 \%$ & $18.8 \%$ \\
\hline
\end{tabular}

Table 25

Percentage of CCA Geometry Items Targeting Each of Its Components

\begin{tabular}{lccc}
\hline Grade & Shapes and Relationships & Transformations of Shapes & Coordinate Geometry \\
\hline $1^{\text {st }}$ & $99.6 \%$ & $0.4 \%$ & $0.0 \%$ \\
$2^{\text {nd }}$ & $62.0 \%$ & $38.0 \%$ & $0.0 \%$ \\
$3^{\text {rd }}$ & $78.0 \%$ & $21.6 \%$ & $0.4 \%$ \\
$4^{\text {th }}$ & $78.2 \%$ & $12.3 \%$ & $9.4 \%$ \\
$5^{\text {th }}$ & $81.6 \%$ & $13.1 \%$ & $5.3 \%$ \\
\hline
\end{tabular}




\section{APPENDIX B}

Table 26

Student Mathematics Comparison by Gender

\begin{tabular}{lccccccc}
\hline & Gender & $\mathrm{N}$ & Mean & S.D. & t & df & p \\
\hline KCCT Mathematics3 & Female & 683 & 54.24 & 22.21 & \multirow{2}{*}{0.49} & 1383 & ns \\
& Male & 702 & 55.05 & 21.50 & & & \\
KCCT Mathematics4 & Female & 655 & 51.42 & 22.42 & 0.19 & 1319 & ns \\
& Male & 666 & 53.00 & 21.79 & & & \\
KCCT Mathematics5 & Female & 634 & 48.04 & 22.89 & 0.70 & 1284 & ns \\
& Male & 652 & 48.53 & 22.44 & & & \\
General Mathematics CCA12 & Female & 683 & $76.39 \%$ & 16.71 & \multirow{2}{*}{0.90} & 1383 & ns \\
& Male & 702 & $76.51 \%$ & 15.96 & & & \\
CCA3 General Mathematics & Female & 666 & $73.90 \%$ & 17.72 & \multirow{2}{*}{0.94} & 1344 & ns \\
& Male & 680 & $73.97 \%$ & 17.29 & & & \\
CCA4 General Mathematics & Female & 585 & $63.99 \%$ & 20.45 & 0.98 & 1187 & ns \\
& Male & 604 & $64.03 \%$ & 21.47 & & & \\
CCA5 General Mathematics & Female & 579 & $67.46 \%$ & 20.10 & \multirow{2}{*}{0.08} & 1173 & ns \\
& Male & 596 & $69.43 \%$ & 18.92 & & & \\
CCA12 Algebra & Female & 683 & $77.03 \%$ & 25.48 & 0.20 & 1383 & ns \\
& Male & 702 & $78.81 \%$ & 25.94 & & & \\
CCA3 Algebra & Female & 595 & $71.00 \%$ & 24.37 & 0.24 & 1196 & ns \\
& Male & 603 & $72.64 \%$ & 23.84 & & & \\
CCA4 Algebra & Female & 330 & $75.72 \%$ & 28.31 & 0.41 & 637 & ns \\
& Male & 309 & $73.87 \%$ & 28.03 & & & \\
CCA5 Algebra & Male & 179 & $69.35 \%$ & 37.03 & 0.22 & 352 & ns \\
& & & & & & &
\end{tabular}


Table 27

Student Mathematics Comparison by Race

\begin{tabular}{|c|c|c|c|c|c|c|c|c|}
\hline & Grade & Race & $\mathrm{N}$ & Mean & S.D. & $F$ & $\mathrm{df}$ & $p$ \\
\hline $\begin{array}{l}\text { KCCT } \\
\text { Mathematics }\end{array}$ & 3 & $\begin{array}{c}\text { Asian-American } \\
\text { African-American } \\
\text { Hispanic } \\
\text { Caucasian }\end{array}$ & $\begin{array}{c}29 \\
466 \\
75 \\
701\end{array}$ & $\begin{array}{l}64.41 \\
45.41 \\
54.09 \\
58.92\end{array}$ & $\begin{array}{l}16.68 \\
22.81 \\
19.88 \\
20.09\end{array}$ & 40.90 & $\begin{array}{c}3 \\
1267\end{array}$ & $<.001$ \\
\hline $\begin{array}{l}\text { KCCT } \\
\text { Mathematics }\end{array}$ & 4 & $\begin{array}{c}\text { Asian-American } \\
\text { African-American } \\
\text { Hispanic } \\
\text { Caucasian }\end{array}$ & $\begin{array}{c}29 \\
454 \\
70 \\
659\end{array}$ & $\begin{array}{l}60.28 \\
42.72 \\
49.34 \\
56.78\end{array}$ & $\begin{array}{l}20.06 \\
22.05 \\
19.43 \\
20.85\end{array}$ & 41.34 & $\begin{array}{c}3 \\
1208\end{array}$ & $<.001$ \\
\hline $\begin{array}{l}\text { KCCT } \\
\text { Mathematics }\end{array}$ & 5 & $\begin{array}{c}\text { Asian-American } \\
\text { African-American } \\
\text { Hispanic } \\
\text { Caucasian }\end{array}$ & $\begin{array}{c}27 \\
442 \\
72 \\
638\end{array}$ & $\begin{array}{l}62.56 \\
38.05 \\
44.72 \\
53.37\end{array}$ & $\begin{array}{l}18.52 \\
23.06 \\
19.39 \\
20.40\end{array}$ & 49.86 & $\begin{array}{c}3, \\
1175\end{array}$ & $<.001$ \\
\hline
\end{tabular}

*Continued on next page 
Table 27 continued

Student Mathematics Comparison by Race

\begin{tabular}{|c|c|c|c|c|c|c|c|c|}
\hline & Grade & Race & $\mathrm{N}$ & Mean & S.D. & $\mathrm{F}$ & $\mathrm{df}$ & $\mathrm{p}$ \\
\hline $\begin{array}{l}\text { CCA } \\
\text { General } \\
\text { Mathematics }\end{array}$ & $1-2$ & $\begin{array}{c}\text { Asian-American } \\
\text { African-American } \\
\text { Hispanic } \\
\text { Caucasian }\end{array}$ & $\begin{array}{c}29 \\
466 \\
75 \\
701\end{array}$ & $\begin{array}{l}84.51 \\
70.24 \\
70.63 \\
80.47\end{array}$ & $\begin{array}{l}10.33 \\
16.54 \\
18.57 \\
14.73\end{array}$ & 46.21 & $\begin{array}{c}3, \\
1267\end{array}$ & $<.001$ \\
\hline $\begin{array}{l}\text { CCA } \\
\text { General } \\
\text { Mathematics }\end{array}$ & 3 & $\begin{array}{c}\text { Asian-American } \\
\text { African-American } \\
\text { Hispanic } \\
\text { Caucasian }\end{array}$ & $\begin{array}{c}28 \\
455 \\
72 \\
678\end{array}$ & $\begin{array}{l}83.46 \\
66.76 \\
72.01 \\
77.49\end{array}$ & $\begin{array}{l}14.61 \\
18.60 \\
17.76 \\
15.53\end{array}$ & 40.40 & $\begin{array}{c}3, \\
1229\end{array}$ & $<.001$ \\
\hline $\begin{array}{l}\text { CCA } \\
\text { General } \\
\text { Mathematics }\end{array}$ & 4 & $\begin{array}{c}\text { Asian-American } \\
\text { African-American } \\
\text { Hispanic } \\
\text { Caucasian }\end{array}$ & $\begin{array}{c}24 \\
404 \\
64 \\
596\end{array}$ & $\begin{array}{l}71.90 \\
55.27 \\
56.64 \\
68.12\end{array}$ & $\begin{array}{l}21.75 \\
20.30 \\
22.18 \\
18.89\end{array}$ & 37.98 & $\begin{array}{c}3 \\
1084\end{array}$ & $<.001$ \\
\hline $\begin{array}{l}\mathrm{CCA} \\
\text { General } \\
\text { Mathematics }\end{array}$ & 5 & $\begin{array}{c}\text { Asian-American } \\
\text { African-American } \\
\text { Hispanic } \\
\text { Caucasian }\end{array}$ & $\begin{array}{c}25 \\
395 \\
71 \\
585\end{array}$ & $\begin{array}{l}75.21 \\
61.03 \\
67.85 \\
71.63\end{array}$ & $\begin{array}{l}19.88 \\
19.62 \\
17.80 \\
18.42\end{array}$ & 26.24 & $\begin{array}{c}3, \\
1072\end{array}$ & $<.001$ \\
\hline $\begin{array}{l}\text { CCA } \\
\text { Algebra }\end{array}$ & $1-2$ & $\begin{array}{c}\text { Asian-American } \\
\text { African-American } \\
\text { Hispanic } \\
\text { Caucasian }\end{array}$ & $\begin{array}{c}29 \\
466 \\
75 \\
701\end{array}$ & $\begin{array}{l}82.11 \\
71.73 \\
71.17 \\
81.73\end{array}$ & $\begin{array}{l}27.91 \\
28.26 \\
30.43 \\
23.00\end{array}$ & 16.06 & $\begin{array}{c}3, \\
1267\end{array}$ & $<.001$ \\
\hline $\begin{array}{l}\text { CCA } \\
\text { Algebra }\end{array}$ & 3 & $\begin{array}{c}\text { Asian-American } \\
\text { African-American } \\
\text { Hispanic } \\
\text { Caucasian }\end{array}$ & $\begin{array}{c}24 \\
396 \\
62 \\
610\end{array}$ & $\begin{array}{l}80.63 \\
64.51 \\
69.01 \\
75.80\end{array}$ & $\begin{array}{l}19.54 \\
25.40 \\
26.48 \\
22.60\end{array}$ & 19.39 & $\begin{array}{c}3, \\
1088\end{array}$ & $<.001$ \\
\hline $\begin{array}{l}\text { CCA } \\
\text { Algebra }\end{array}$ & 4 & $\begin{array}{c}\text { Asian-American } \\
\text { African-American } \\
\text { Hispanic } \\
\text { Caucasian }\end{array}$ & $\begin{array}{c}15 \\
207 \\
21 \\
314\end{array}$ & $\begin{array}{l}87.48 \\
66.59 \\
78.91 \\
77.22\end{array}$ & $\begin{array}{l}18.73 \\
31.86 \\
27.05 \\
26.18\end{array}$ & 7.39 & $\begin{array}{c}3, \\
553\end{array}$ & $<.001$ \\
\hline $\begin{array}{l}\text { CCA } \\
\text { Algebra }\end{array}$ & 5 & $\begin{array}{c}\text { Asian-American } \\
\text { African-American } \\
\text { Hispanic } \\
\text { Caucasian }\end{array}$ & $\begin{array}{c}6 \\
107 \\
16 \\
218\end{array}$ & $\begin{array}{l}81.94 \\
64.82 \\
68.72 \\
66.72 \\
\end{array}$ & $\begin{array}{l}40.28 \\
34.14 \\
35.34 \\
40.35 \\
\end{array}$ & 0.41 & $\begin{array}{c}3, \\
343\end{array}$ & ns \\
\hline
\end{tabular}


Table 28

Testing for the Achievement Gap in Student Mathematics: Caucasian and Asian-

American students (CA) compared to African-American and Hispanic students (AH)

\begin{tabular}{lcccccccc}
\hline & Grade & Race & $\mathrm{N}$ & Mean & S.D. & t & df & p \\
\hline \multirow{2}{*}{ KCCT Mathematics } & 3 & AH & 541 & 46.62 & 22.61 & -10.44 & 1269 & $<.001$ \\
& & CA & 730 & 59.14 & 19.99 & & & \\
KCCT Mathematics & 4 & AH & 524 & 43.60 & 21.82 & -10.81 & 1210 & $<.001$ \\
& & CA & 688 & 56.93 & 20.81 & & & \\
KCCT Mathematics & 5 & AH & 514 & 38.98 & 22.68 & -11.73 & 1177 & $<.001$ \\
& & CA & 665 & 53.74 & 20.39 & & & \\
CCA General Mathematics & $1-2$ & AH & 541 & 7029 & 16.82 & -11.69 & 1269 & $<.001$ \\
& & CA & 730 & 80.63 & 14.60 & & & \\
CCA General Mathematics & \multirow{2}{*}{ 3 } & AH & 527 & 67.47 & 18.56 & -10.54 & 1231 & $<.001$ \\
& & CA & 706 & 77.72 & 15.53 & & & \\
CCA General Mathematics & 4 & AH & 468 & 55.46 & 20.55 & -10.63 & 1086 & $<.001$ \\
& & CA & 620 & 68.26 & 19.01 & & & \\
CCA General Mathematics & 5 & AH & 466 & 62.07 & 19.49 & -8.34 & 1074 & $<.001$ \\
& & CA & 610 & 71.78 & 18.47 & & & \\
CCA Algebra & $1-2$ & AH & 541 & 71.66 & 28.55 & -6.95 & 1269 & $<.001$ \\
& CA & 730 & 81.74 & 23.19 & & & \\
CCA Algebra & & AH & 458 & 65.12 & 25.56 & -7.44 & 1090 & $<.001$ \\
& 3 & CA & 634 & 75.98 & 22.49 & & & \\
CCA Algebra & & AH & 228 & 67.72 & 31.59 & -4.07 & 555 & $<.001$ \\
& 4 & CA & 329 & 77.69 & 25.95 & & & \\
CCA Algebra & & AH & 123 & 65.32 & 34.18 & -0.42 & 345 & ns \\
\hline
\end{tabular}


Table 29

Correlations of Students ' Mathematics Scores to Their Reading Scores and Schools'

Percentage of Students Receiving Free and Reduced Lunch (FRL)

\begin{tabular}{lcllll}
\hline & \multicolumn{5}{c}{ KCCT Reading } \\
& Grade & 3 & 4 & 5 & FRL \\
\hline KCCT Mathematics & 3 & $.74^{*}$ & $.67^{*}$ & $.63^{*}$ & $-.31^{*}$ \\
KCCT Mathematics & 4 & $.70^{*}$ & $.78^{*}$ & $.68^{*}$ & $-.37^{*}$ \\
KCCT Mathematics & 5 & $.66^{*}$ & $.71^{*}$ & $.72^{*}$ & $-.36^{*}$ \\
CCA General Mathematics & $1-2$ & $.55^{*}$ & $.54^{*}$ & $.51^{*}$ & $-.33^{*}$ \\
CCA General Mathematics & 3 & $.58^{*}$ & $.54^{*}$ & $.46^{*}$ & $-.29^{*}$ \\
CCA General Mathematics & 4 & $.55^{*}$ & $.56^{*}$ & $.52^{*}$ & $-.33^{*}$ \\
CCA General Mathematics & 5 & $.50^{*}$ & $.55^{*}$ & $.53^{*}$ & $-.26^{*}$ \\
CCA Algebra & $1-2$ & $.29^{*}$ & $.31^{*}$ & $.30^{*}$ & $-.17^{*}$ \\
CCA Algebra & 3 & $.46^{*}$ & $.42^{*}$ & $.39^{*}$ & $-.25^{*}$ \\
CCA Algebra & 4 & $.39^{*}$ & $.45^{*}$ & $.41^{*}$ & $-.19^{*}$ \\
CCA Algebra & 5 & .01 & .04 & .05 & -.02 \\
\hline
\end{tabular}

${ }^{*} \mathrm{p}<.001$ 


\section{CURRICULUM VITAE}

NAME:

ADDRESS:

DOB:

EDUCATION:
Scott Strother

317 Life Sciences Bldg

Dept. of Psychological and Brain Sciences

University of Louisville

Louisville, KY 40292

Covington, Kentucky - November 4, 1979

B. A., Pre-professional Studies (Psychology)

University of Notre Dame

1998-2002

M. A., Experimental Psychology

University of Louisville

2002-2004

Ph. D., Experimental Psychology

University of Louisville

2004-2011 